EVALUATION OF A MECHANICAL ANCHORING SYSTEM TO IMPROVE PERFORMANCE OF CARBON FIBER REINFORCED POLYMER MITIGATED CONCRETE SLABS UNDER CLOSE IN BLASTS

A Thesis
presented to
the Faculty of the Graduate School
at the University of Missouri-Columbia

In Partial Fulfillment

of the Requirements for the Degree

Master of Science

by

MATTHEW CEDAR WHEELER

Dr. Sarah Orton, Thesis Supervisor

DECEMBER 2013 
The undersigned, appointed by the dean of the Graduate School, have examined the thesis entitled

\section{EVALUATION OF A MECHANICAL ANCHORING SYSTEM TO IMPROVE PERFORMANCE OF CARBON FIBER REINFORCED POLYMER MITIGATED CONCRETE SLABS UNDER CLOSE IN BLASTS}

presented by Matthew Cedar Wheeler, a candidate for the degree of Master of Science in Civil Engineering, and hereby certify that, in their opinion, it is worthy of acceptance.

Professor Sarah Orton

Professor Sam Kiger

Professor P. Frank Pai 


\section{DEDICATION}

For Kendra, who kept me going

Kate, who made an investment

and Eric, who gave me a second chance 


\section{ACKNOWLEDGEMENTS}

I owe a debt to Professor Sarah Orton for mentoring me for the better part of the past decade. I must also thank Mr. Rex Gish and Mr. Richard Oberto for lending me their decades of experience but above all for helping me figure it out for myself. Likewise thanks goes to Matt 'Tree' Muenks and Aaron Saucier for their constant guidance.

Finally, a round of applause for Garret Havens and Zach Treece, two truly outstanding undergraduates who have surprised me every step of the way.

This research was funded in part by a National Science Foundation Graduate Research Fellowship, with additional support by the Science and Technology Directorate of the Department of Homeland Security. Carbon fiber reinforced polymer materials donated by Sika U.S., Sika Corporation. 


\section{TABLE OF CONTENTS}

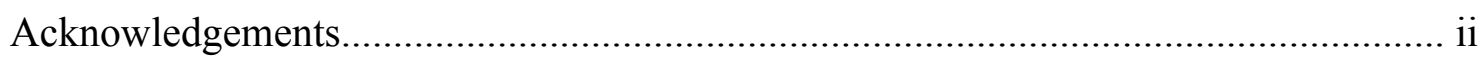

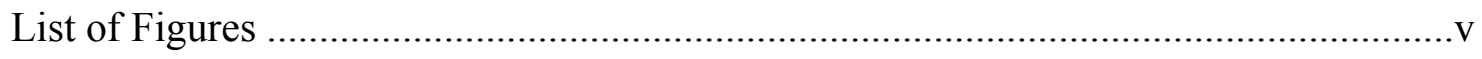

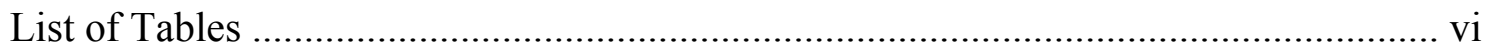

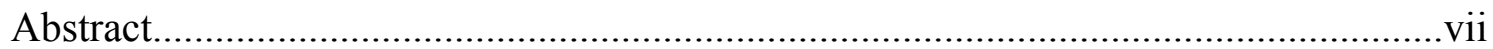

Chapter

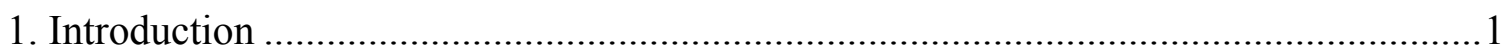

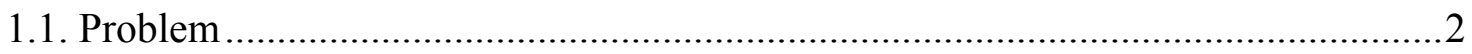

1.2. Objectives and Research Approach ……………...............................................

1.3. Scope

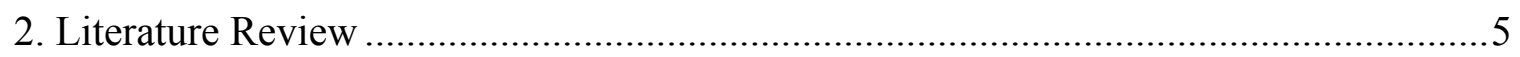

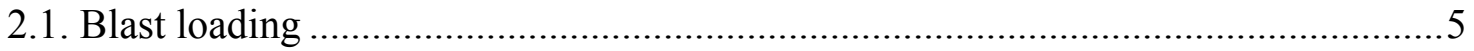

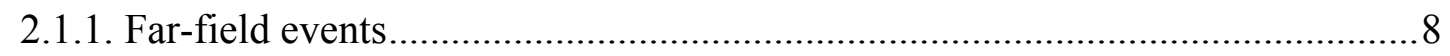

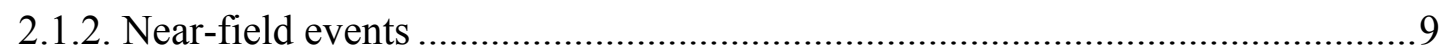

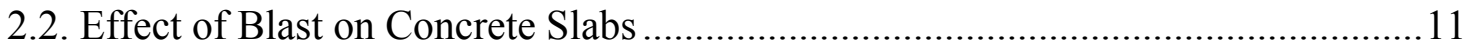

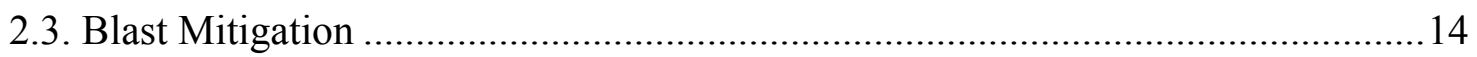

2.4. Composite Materials for Structural Applications …………………………….......15

2.4.1. Wet-layup versus Pultruded FRP ...............................................................19

2.4.2. Anchorage of Fiber reinforced polymers .....................................................22

2.5. Composite retrofits for blast loading ..............................................................28

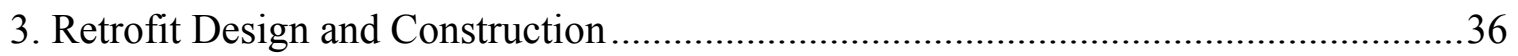

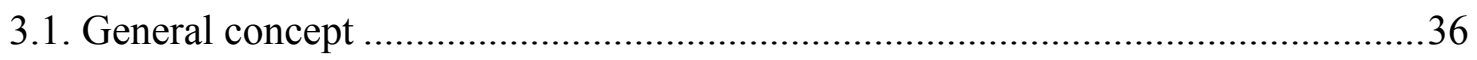

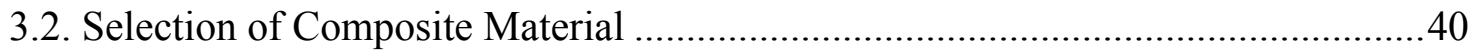

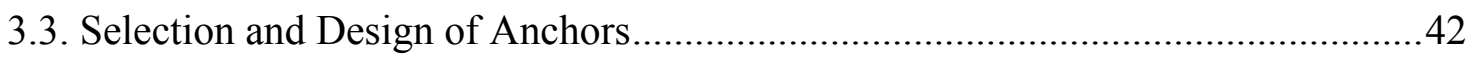

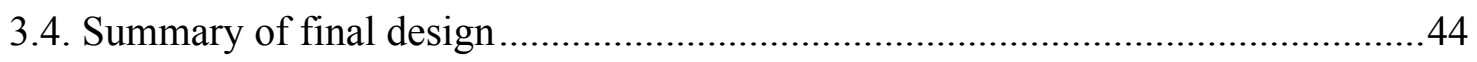

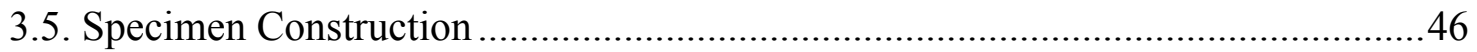

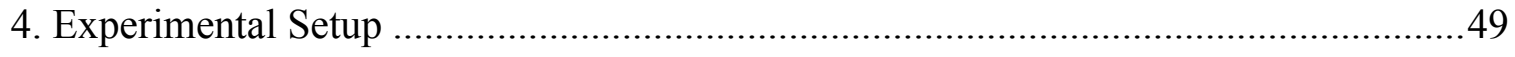

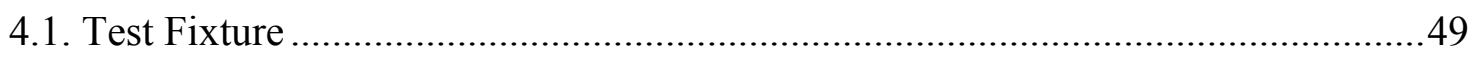

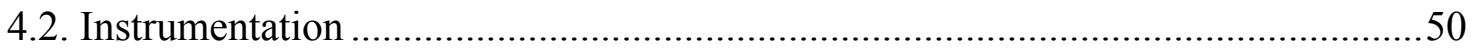

4.3. Reconstruction of lost deflection data …………….............................................54

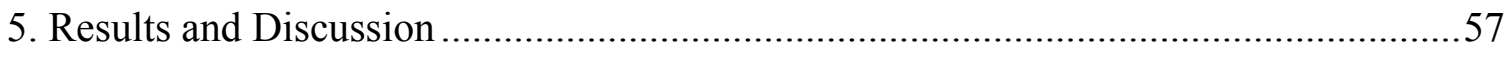




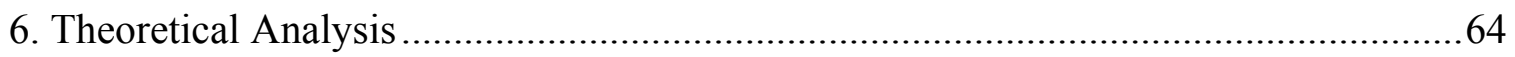

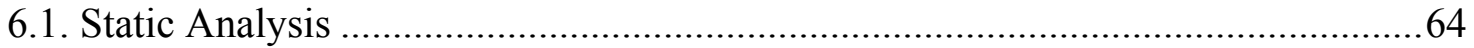

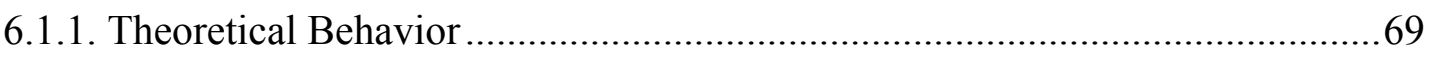

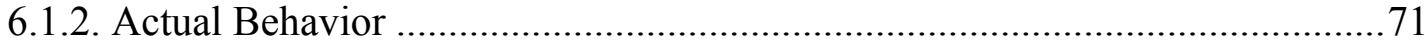

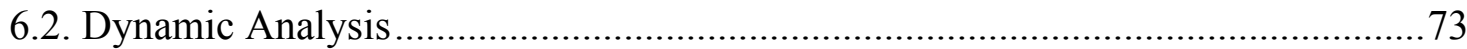

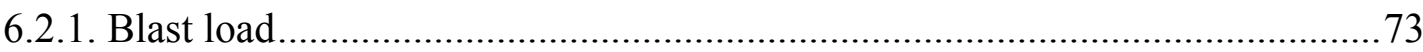

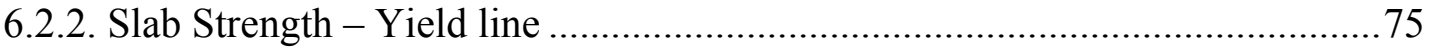

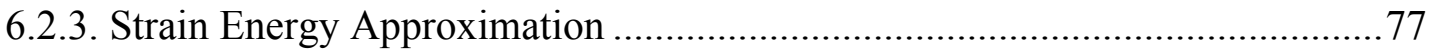

6.2.4. Single Degree Of Freedom Analysis....................................................... 78

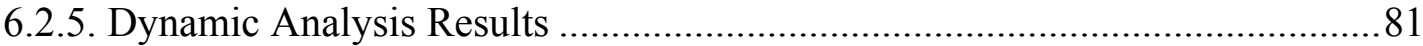

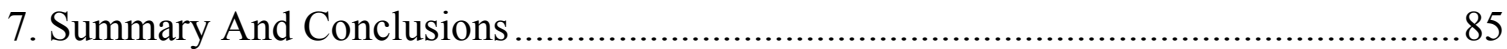

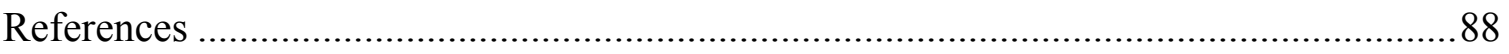

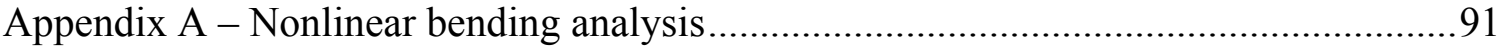




\section{LIST OF FIGURES}

Figure 2-1 - Blast pressure time history (UFC 2008).

Figure 2-2 - Air blast shock wave parameters as a function of scaled distance (UFC 2008)

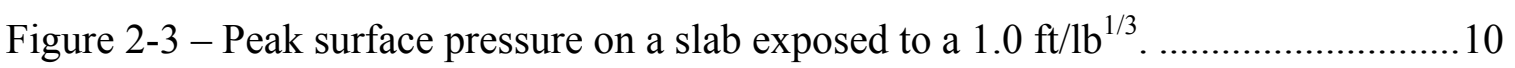

Figure 2-4 - Modes of failure with increasing blast intensity .........................................12

Figure 2-5 - Un-strengthened reinforced concrete slab after blast at a scaled range of 1.5

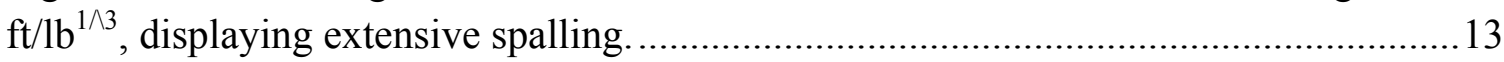

Figure 2-6 - Massive concrete walls provide shielding from blast loads and debris........14

Figure 2-7 - Workers apply wet lay-up glass fiber reinforced polymer (GFRP) to a

concrete slab. A large quantity of fabric can be easily shipped and stored, as it rolls

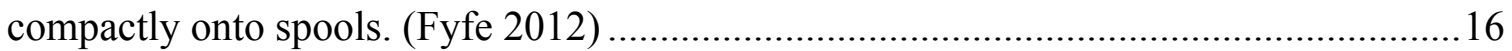

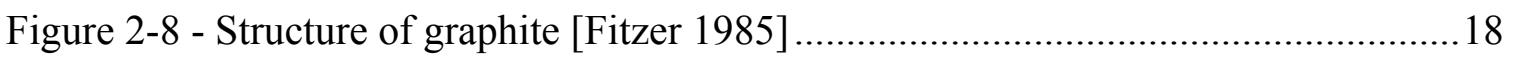

Figure 2-9 - Wet-layup FRP arrives to the jobsite on rolls ..........................................19

Figure 2-10 - Workers install wet-layup glass fiber reinforced polymer (GFRP) on a

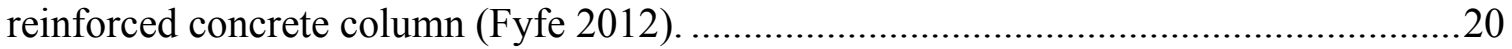

Figure 2-11 - Pultruded FRP packaged for shipping. ...............................................21

Figure 2-12 - Workers install pultruded FRP. The product shown is being installed with mechanical anchors (Strongwell 2006)...................................................................22

Figure 2-13 - De-bonding failure of unanchored CFRP from a reinforced concrete beam.

Note that the concrete remains mostly intact (Kim 2008).............................................23

Figure 2-14 - De-bonding of an unanchored CFRP sheet from a reinforced concrete beam. Note the separation of the concrete cover at the level of the outermost reinforcing steel (Orton 2011).

Figure 2-15 - Mechanical clamp anchors used to limit de-bonding of FRP (Orton 2011).

Figure 2-16 - Near surface mounting systems developed by Khalifa et al. (1999)..........26

Figure 2-17 - U-wrap anchorage on a reinforced concrete beam (Orton 2007) ...............26

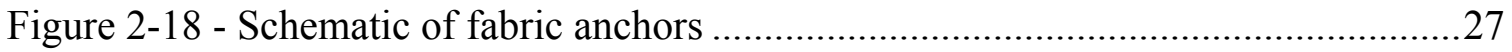

Figure 2-19 Mechanical fastening of pultruded CFRP plate (Lamanna 2002). ..............28

Figure 2-20 - Splitting occurs around mechanical fasteners in pultruded CFRP without cross fibers (Lamanna 2002).

Figure 2-21 - Wet-layup CFRP applied to the tension face of a concrete slab to be tested at a scaled range of 1.5. Note the extensive use of fiber anchors (Orton 2013).

Figure 2-22 - Wet-layup CFRP strengthened slab tested at scaled range 1.5, post-test. The slab did not breach.

Figure 2-23 Wet-layup CFRP strengthened slab tested at scaled range 1.5, post-test, reverse side. Though the CFRP fractured, the slab did not breach. 
Figure 2-24 - Unmitigated concrete slab tested at a scaled range of $1 \mathrm{ft} / \mathrm{lb}^{1 / 3}$ (Orton 2013)

Figure 2-25 - CFRP mitigated slab subjected to a close-in blast at a scaled range of

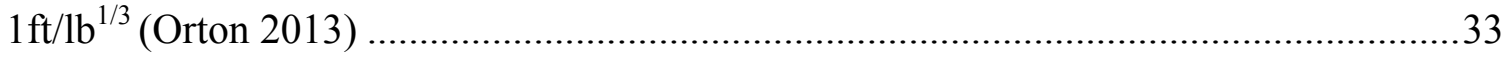

Figure 2-26 - Result of blast test on CFRP strengthened slab. Scaled range of $1.0 \mathrm{lb} / \mathrm{ft}^{1 / 3}$

(Orton et al. 2011).

Figure 2-27 - Comparison of un-strengthened and strengthened deflections (dashed line indicates area of breach) (Orton 2013).

Figure 3-1 - Damage experienced in a past blast test of an un-mitigated concrete slab at $0.35 \mathrm{ft} / \mathrm{lb}^{1 / 3}$ scaled range. Slab was exposed to a peak pressure over 50,000 psi and catastrophic breaching of the slab occurred (Ray et al. 2011)........................................36

Figure 3-2 - Damage effects in a past blast test of a strengthened concrete slab at 0.35 $\mathrm{ft} / \mathrm{lb}^{1 / 3}$ scale range. $1 / 2$ in $100 \mathrm{ksi}$ steel plate was placed on the blast face of the slab (Ray et al. 2011). Edited.

Figure 3-3 - Damage effects from a past blast test of a concrete slab with steel cladding on both faces through-bolted. Some bolt heads were sheared off, but the slab was not

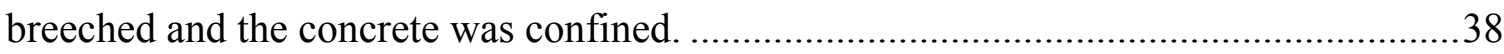

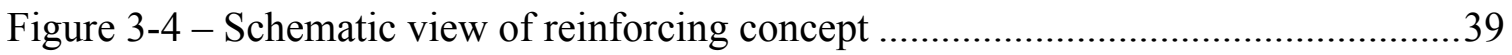

Figure 3-5 - Sika CarboDur CFRP strengthening material ....................................... 42

Figure 3-6 - Schematic of FRP and steel reinforcing scheme ..................................42

Figure 3-7 - Anchor schematic. The channel size used represents a $1 / 4$ scale of a readily available structural shape. ......................................................................................43

Figure 3-8 - Specimen elevation view ...................................................................45

Figure 3-9 - Slab specimen formwork immediately before pouring concrete. Wooden dowels were used to leave voids which would later be drilled out for the anchor bolts...46 Figure 3-10 - Annular cutter used to drill CFRP. CFRP was found to very rapidly dull,

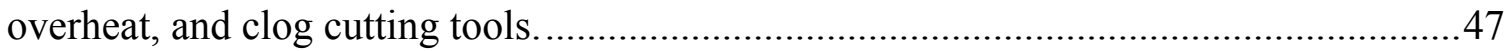

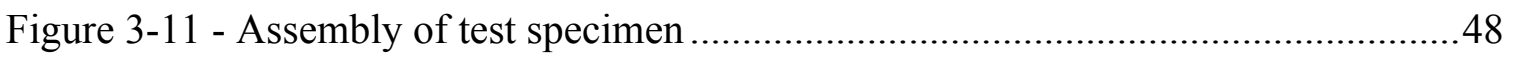

Figure 4-1 - Schematic diagram of test fixture..........................................................49

Figure 4-2 - Test specimen and fixture immediately before testing ..............................50

Figure 4-3 - Data acquisition system showing power supply, data acquisition cards, strain gage completion bridges, and connection points for all sensors. ..................................51

Figure 4-4 - Load cell configuration. Steel plates ensure the load is distributed to the intended area of the load cell. Rubber bearing pads guarantee even load application and

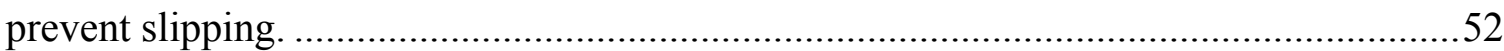

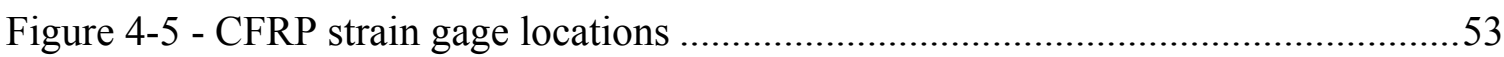

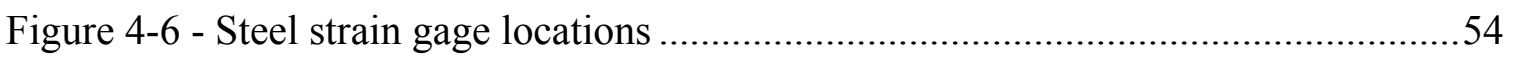

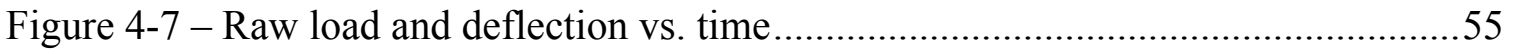

Figure 4-8 - String potentiometer deflection vs. video deflection..................................56 
Figure 5-1 - Load/Deflection plot for the test. Unloading was required to add additional deflection to the ram. Points in red are reconstructed from video footage.

Figure 5-2 - Plot of recorded strains vs. load. Termination of FRP strain readings occurred when violent fiber fracture severed data acquisition leads or at $\sim 9000$ microstrains, the upper measurement limit of the strain gauges.

Figure 5-3 - The slab exhibited very large deflections, much of it permanent as seen here at the conclusion of the test after unloading.

Figure 5-4 - The longitudinal CFRP sheets split next to many of the bolt holes. This may have contributed to extensive slipping of the CFRP sheets.

Figure 5-5 - End view of the slab showing significant displacement and splitting in the FRP sheets. The edges of the FRP sheets were initially aligned.

Figure 5-6 - Much of the longitudinal FRP at midspan was fractured, despite slipping and splitting.

Figure 5-7 - Extensive shear cracking was observed.

Figure 5-8 - Most of the concrete cover was sloughed off, and the CFRP completely

delaminated.

Figure 6-1 - Internal strain and stress distribution for a rectangular section under flexure

at ultimate limit state .64

Figure 6-2 - Stress-Strain behavior of confined concrete (Kent and Park 1971)

Figure 6-3 - Load Deflection and Strain Deflection Relationships. Load at which FRP reaches rupture strain indicated with an $\mathrm{X}$.

Figure 6-4 - Theoretical and actual load deflection relationships . Load at which FRP reaches rupture strain indicated with an $\mathrm{X}$. .72

Figure 6-5 - Peak pressures from hydro-code analysis as scaled range $0.4 \mathrm{~m} / \mathrm{kg}^{1 / 3} \ldots \ldots \ldots .74$

Figure 6-6 - External load (total pressure) for SDOF analysis.....................................75

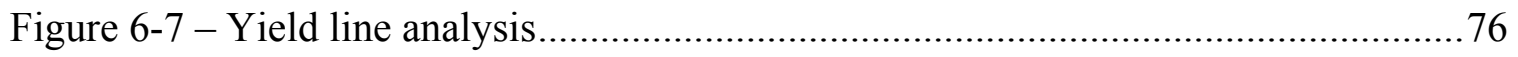

Figure 6-8 - Representation of a slab by a spring-mass system ....................................78

Figure 6-9 - Load deflection relationship used in SDOF analysis ..................................83

Figure 6-10 - Response time history from SDOF analysis. Peak deflection of approximately $1.5 \mathrm{in}$ is much less than the deflection associated with failure during the static tests. 


\section{LIST OF TABLES}

Table 3-1- Comparison of mechanical properties of five pultruded FRP products ..........41

Table 6-1 - Material Properties....................................................................................69

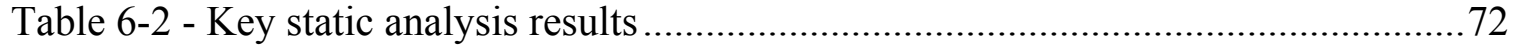

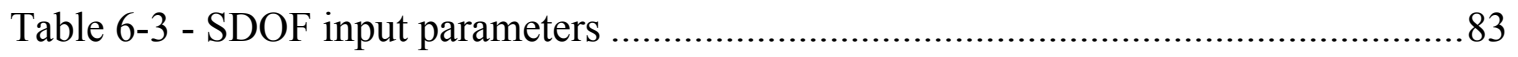




\begin{abstract}
Recent events, including the bombings of the Murrah Building in Oklahoma City in 1995 and the World Trade Center in New York in 2001, have drawn attention to the fact that explosive loads can cause extreme damage and loss of life through catastrophic damage to structural components. Reinforced concrete slabs are an extremely common structural component in transportation, military, commercial, and utility infrastructure. Often, reinforced concrete slabs are not designed for blast loads and a threat reassessment during the structure's service life suggests the need for improved resilience to blasts.
\end{abstract}

This research identifies a promising retrofit system utilizing structural steel plating and carbon fiber reinforced polymer (CFRP) sheets. CFRP is used to lower dead loads and to permit the installation of the system in close quarters. A slab section is retrofitted with steel armor plating on the compression face and CFRP on the tension face, and a mechanical anchoring scheme is used to ensure the development of the full CFRP strength during flexure. A static three-point-bending test is performed in order to evaluate the efficacy of the anchoring system and to determine a static resistance function.

Finally, nonlinear bending analysis is used to validate the test results, and the static test results are used in a single degree of freedom (SDOF) dynamic analysis to make predictions of dynamic behavior under blast loads. 


\section{INTRODUCTION}

Reinforced concrete slabs are ubiquitous in buildings, bridges, and other structures. Most of these structures have not been designed for explosive loads, leaving them vulnerable to blast events. The bombings of the Murrah Building in Oklahoma City in 1995 and the World Trade Center in New York in 2001 are stark reminders that, though rare, these events can cause extreme damage and loss of life. Due in part to the heightened awareness of the risk of these events, extensive research has been devoted to developing effective strengthening technologies to help mitigate this threat. While there are many options for building blast resistance into a new structure, strengthening the many thousands of at-risk existing structures has proven to be challenging due to the limitations of existing structural geometry, cost, physical access, and cultural and aesthetic significance.

When concrete structures are engineered and constructed, they are designed for hazards based on the best available data about the loads and risk for extreme events. At the time of initial construction there are many options for increasing the blast resistance of a structure if that is deemed necessary. However, during the life of the structure the hazard assessments can evolve. This is not surprising, given the many potential sources of an explosive event. Unintentional causes of blast events may include gas leaks, grain explosions, or petrochemical and manufacturing accidents. Intentional causes of blast events include terrorism, warfare, or demolition (Mosalam and Mosallam 2001). Regardless of the rationale, facility owners often desire to increase the resilience of their structures to extreme events (Baseheart 1983). 
Fiber reinforced polymer (FRP) may present a partial solution to some of these challenges. In recent years FRP has been used extensively for post-construction strengthening of concrete structures. It is highly valued for its speed of application, very high stiffness and tensile strength, formability to existing structural geometry, and very low dead weight. Applications have included bridge and building repair and strengthening, as well as seismic and blast retrofit of commercial, industrial, and residential occupancies. Components strengthened or repaired have included floors, walls, beams, columns, girders, and more. Careful research is needed, however, to fully leverage this material for extreme events. It can be challenging to apply FRP in such a way as to utilize its full strength without it separating from the underlying structure; and its low shear and compressive strengths mean care is required to achieve optimal results under blast conditions.

\subsection{Problem}

One component that often requires strengthening is the concrete slab. Slabs may take the form of load bearing walls, exterior cladding, flooring, box sections, or other components. While there has been significant research on strengthening concrete slabs for blast loads, not all blast events or analysis paradigms are created equal. Most previous research on this subject has focused on far-field blasts events - those with standoff distances great enough that the blast can be approximated as a uniform pressure front. Unfortunately, the design and analysis methods appropriate for those conditions do not apply or scale to blasts with very short stand-offs. These cases, though extreme, are entirely conceivable. The forces involved are not only of a much greater magnitude, but of a very different nature. A near-field blast cannot be approximated as a uniformly 
distributed load, and is capable of generating pressures on the order of 50,000 psi, high enough to powderize concrete leaving behind a bare rebar cage. Not only does this create a risk of structural collapse, but it creates the additional life hazard of a shrapnel and debris field. In order to combat this different type of threat, specialized strengthening systems must be developed. These systems must provide strength to the structure while protecting its occupants, be economically feasible, and be as easy to install as possible. A retrofit system must also permit the continuing use of the structure by avoiding excessive additions to the dead load or significantly reducing the usable area of a structure.

\subsection{Objectives and Research Approach}

The primary objective of this research is to design a fiber reinforced polymer-based retrofit system for concrete slabs subjected to near field blasts, and conduct a preliminary static evaluation of that system. This will allow modifications or design changes to be made before an explosive test. The results of a static test will provide invaluable data as to static strength and stiffness of the system, which should be indicative of the suitability of the system to resist dynamic loads. A future blast test will attempt to confirm these findings.

\subsection{Scope}

This document is organized into seven chapters. Chapter 2 offers a review of relevant literature discussing blast loading and its impact on reinforced concrete as well as composite materials, anchoring, and composite material applications in civil engineering. Chapter 3 describes the design of the retrofit system and its construction. Chapter 4 details the test fixtures and instrumentation used. Chapter 5 presents experimental results and discussion. Chapter 6 explains the theoretical analysis performed and provides both 
quantitative analysis results and a qualitative discussion. Chapter 7 gives a summary of notable results and conclusions. Finally, a bibliography and appendix of calculations conclude this thesis. 


\section{LITERATURE REVIEW}

The resistance of concrete structures to blast loads has long been an area of research interest. Previous studies have examined the nature of blast loads and the blast response of various types of concrete structures and retrofits. The behavior of carbon fiber reinforced polymer (CFRP) strengthening has been studied for concrete structures in general, and for blast applications specifically. Anchoring techniques for CFRP have also been considered.

\subsection{Blast Loading}

The energy in a conventional (non-nuclear) blast event comes from a rapid expansion of hot gasses, normally the result of a violent oxidation reaction consuming the chemical potential energy of a substance. The sudden increase in volume can lead to the formation of a supersonic pressure front capable of causing extreme damage. For example, the common explosive cyclotrimethylenetrinitramine, often known as RDX, produces a shockwave velocity of 5.4 miles per second (Luo et al. 2002). This was the explosive used in the 1993 Bombay bombings which killed 257 people and injured 713 more (Press Trust of India 2007 ).

An explosive blast loads a structure with an impulsive pressure wave, as seen in Figure 2-1. Within civil engineering, a typical blast analysis considers only the positive pressure phase. The area below the positive pressure phase is termed the 'impulse' of the blast. Both the pressure and impulse are important properties in evaluating the blast response of a structure. However, the precise properties of an explosion, such the magnitude, duration, and propagation velocity of the positive and negative phases, are highly variable and dependent on the explosive composition and configuration. Each combination of 
physical circumstances including confinement of the blast, standoff distance, and the composition and construction of explosive device itself can lead to tremendously varying explosive loads (Kim et al. 2009).

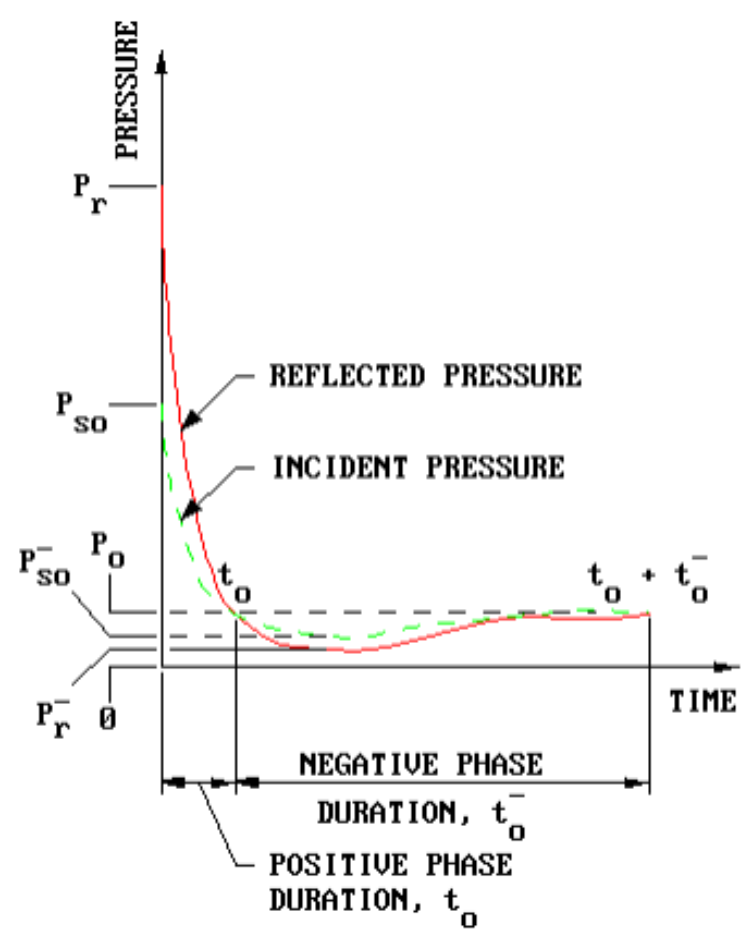

Figure 2-1 - Blast Pressure Time History (UFC 2008)

Procedures have been developed to help determine the explosive loading, but to determine the blast parameters the scaled stand-off distance, $Z_{\mathrm{G}}$, is first required. $\mathrm{Z}_{\mathrm{G}}$ is calculated as

$$
Z_{G}=\frac{R_{G}}{W^{\frac{1}{3}}}
$$

where $W$ is the explosive charge weight as TNT equivalent, and $\mathrm{R}_{\mathrm{G}}$ is the is the distance from the center of the charge to the structure under consideration. Additional adjustments can be applied to account for blasts near the ground or elevated structures. 
Explosions are sometimes characterized by this scaled stand-off distance, as described in the Unified Facilities Criteria Manual 3-340-02, Structures to Resist the Effects of Accidental Explosions (US Department of Defense 2008). This method of characterizing blasts is useful in its simplicity and ability to produce design load parameters without being overly concerned with the precise configuration of the blast event. However, it is valid only if the blast is far enough away from the structure.

Blasts can be divided into two categories: far-field and close-in events, although it can be difficult to precisely define the division between the two. Most researchers designate a blast as close-in based on the distance from the target structure to the blast. Those blasts within 3 to 50 times the volume of the gas expansion on detonation would be considered close-in (Drotleff et al. 1996). Another metric used to distinguish between blast types is the scale range parameter, $Z_{\mathrm{G}}$, described above. $Z_{\mathrm{G}}$ values less than or equal $1.0 \mathrm{ft} / 1 \mathrm{~b}^{1 / 3}$ correspond to a close-in blast (UFC 2008). When the $\mathrm{Z}_{\mathrm{G}}$ value exceeds $2.5 \mathrm{ft} / \mathrm{lb}{ }^{1 / 3}$ the blast is generally considered to be a far-field event (Orton et al. 2013).

Regardless of the quantitative measure used to describe the range of a blast, consideration must be given to the physical circumstances of the target structure. Part of impetus for distinguishing far-field from close-in events is to identify how an engineer might analyze the target structure under the load in question. For far-field blasts the pressure over the target is often assumed to be uniform, and the mode of failure to be flexural (Orton et al. 2013). For near-field events the pressure distribution is very non-uniform with extremely high peak pressures (as high as $23 \mathrm{ksi}$ for a $1.0 \mathrm{ft} / \mathrm{b}^{1 / 3}$ event). Clearly, the configuration of the target structure (narrow beam vs expansive slab) can influence when it is appropriate to make uniform pressure assumptions. The high pressures of a near-field 
event can create non-flexural failure modes including breaching and direct shear failure. Breach can be caused by degradation of the concrete paste itself through brisance or concrete crushing from the intensity of the blast (Baseheart 1983).

\subsubsection{Far-field Events}

Far-field events are generally defined as those with a scaled standoff distance greater than $2.5 \mathrm{ft} / \mathrm{b}^{1 / 3}$. For these types of blasts, the load seen by the structure can often be idealized as a uniform pressure distribution. This is because the structure is far enough from the blast that the shockwave reaches each part of the structure at essentially the same time. A plot of air blast shock wave parameters for far-field events in show in Figure 2-2. Though this diagram shows parameters for scaled stand-off distances below $2.5 \mathrm{ft} / \mathrm{b}^{1 / 3}$, it is important to note that this method becomes increasingly invalid at distances much less than this (UFC 2008). 


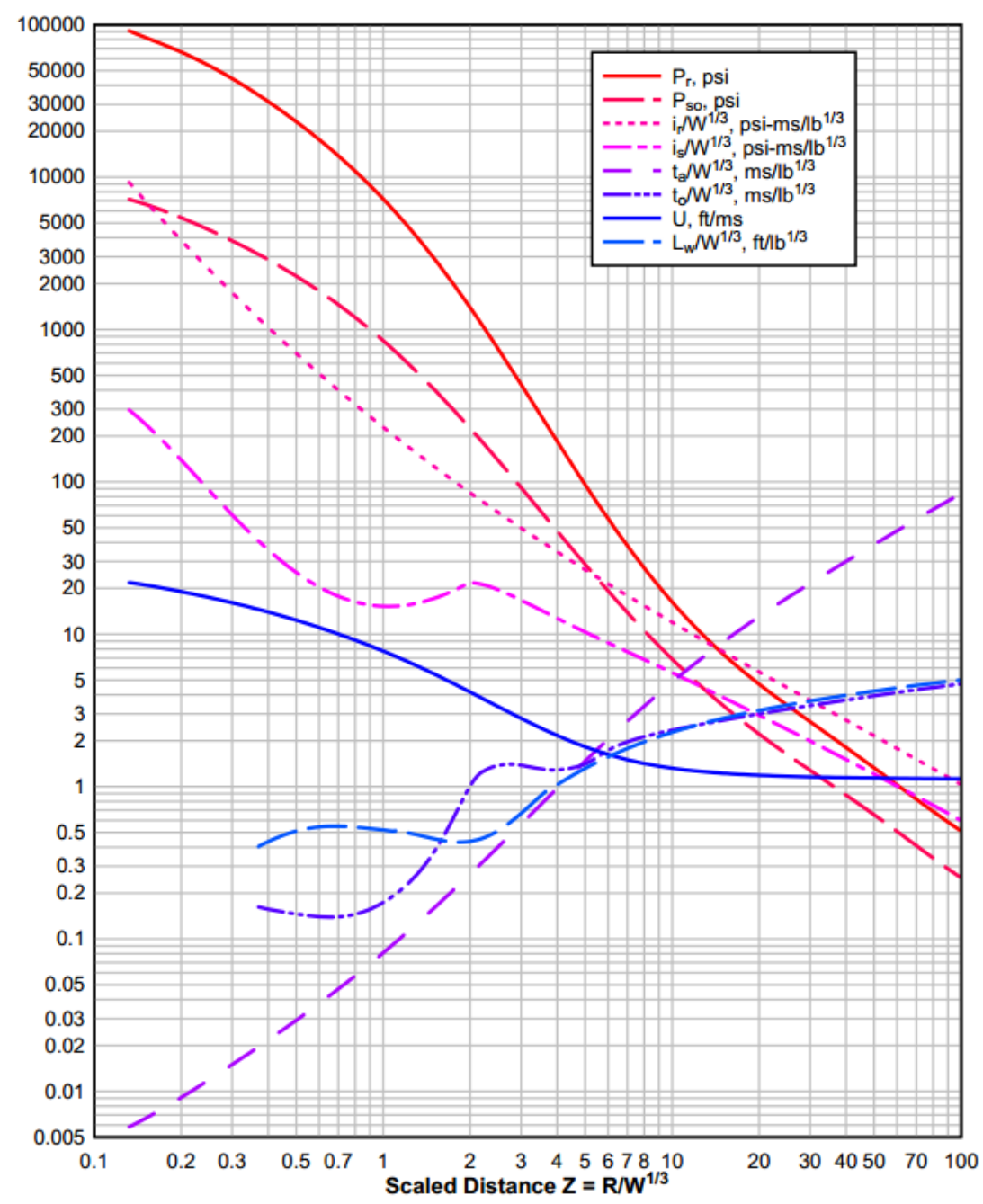

Figure 2-2 - Air Blast Shock Wave Parameters as a Function of Scaled Distance (UFC 2008)

\subsubsection{Near-field Events}

Near-field, or close-in, blasts (those with a scaled stand-off distance less than about 1 $\mathrm{ft} / \mathrm{lb}^{1 / 3}$ ) are fundamentally different from far-field blasts. Because of this, the design and analysis methods appropriate for far-field events do not apply to near-field blasts.

Unlike the uniform pressure assumption appropriate for far-field events, the pressure distribution across a structure exposed to a near-field event is extremely non-uniform and 
non-linear. As can be seen in Figure 2-3, a uniform pressure assumption simply does not accuratley represent the pressure field resulting from a near-field event. As the blast occurs, the pressure wave first loads the nearest point of the slab, before radiating outward. This difference in arrival time can change the behavior of the structure (Baseheart 1983).

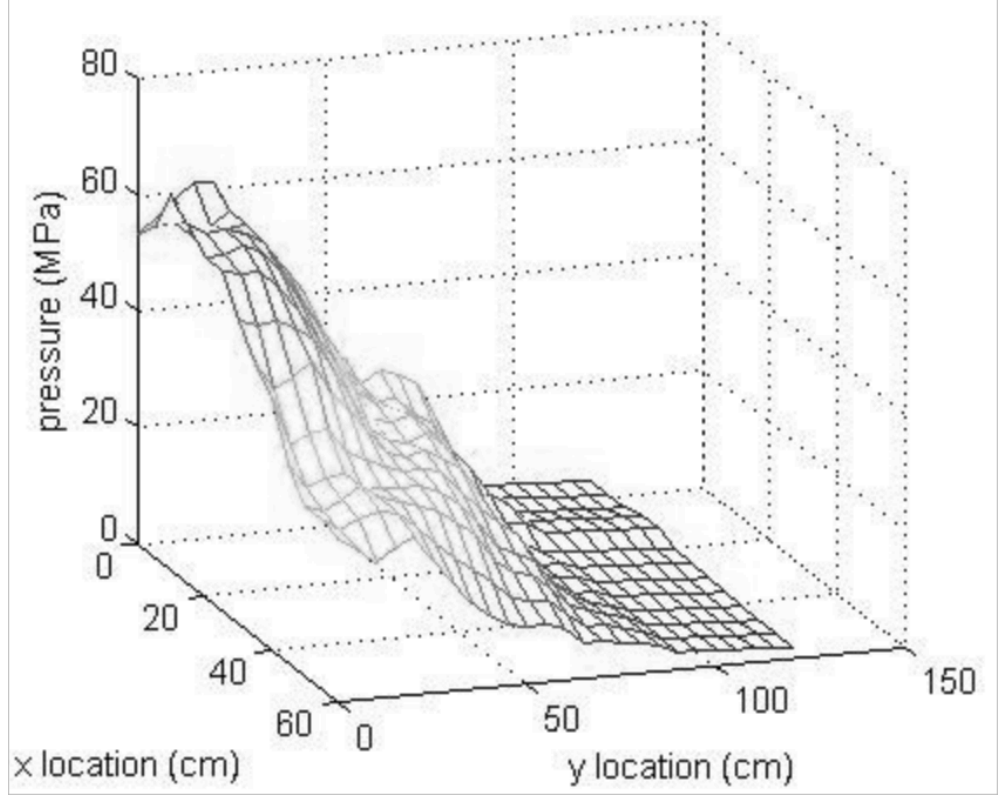

Figure 2-3 - Peak surface pressure on a slab exposed to a $1.0 \mathrm{ft} / 1 \mathrm{~b}^{1 / 3}$.

In addition to the non-linear pressure distribution, the magnitude of the pressures involved are much higher than with a far-field blast, as high as 50,000 psi (Kim et al. 2009). This is a high enough pressure to cause immediate degradation of the materials involved. At these very small scaled ranges, the shape of the explosive device itself begins to matter. For a close in blast, a cylindrical explosive charge can have a much higher peak pressure than a spherical charge of the same weight (Marchand et al. 1994). It must also be noted that close-in blasts are typically of a very short duration. This can 
cause failure modes not normally seen under other conditions (Baseheart 1983; Orton 2013).

Several strategies have been employed to determine a blast loading from a near-field event. Computational analysis programs such as CONWEP and ANSYS can accurately predict the pressure-time history and 2 dimensional spatial variation of a near-field event (Williams 2002). Producing an accurate and detailed blast pressure model using this technology involves very significant complexity and a large time investment by a skilled technician. Marchand et al. (1994), described how to make computational adjustments to blast data to account for charge shape, scale, impulse, and strain rate effects.

\subsection{Effect of Blast on Concrete Slabs}

There is no one typical close-in blast or standard configuration for a concrete slab. Because of this, a variety of failure modes can be encountered when concrete slabs are subjected to close-in blasts. A review of several experimental research programs by Baseheart (1983) found a total of six failure mechanisms for such circumstances, as shown in Figure 2-4. 


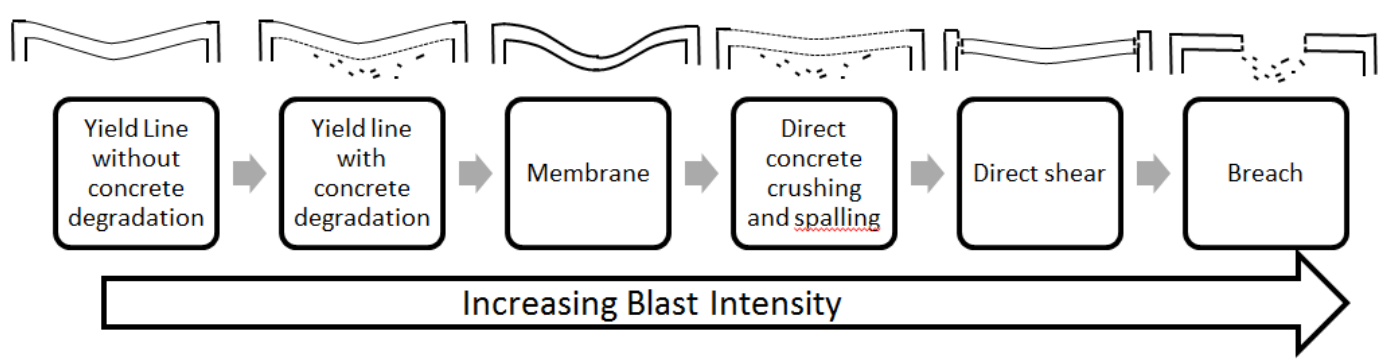

Figure 2-4 - Modes of failure with increasing blast intensity

1) Yield line without concrete degradation - formation of plastic hinges along points of maximum flexural stress. The concrete between the yield lines remains intact.

2) Yield line with concrete degradation - in addition to flexural failure, concrete between yield lines fails dues to the intensity of the blast.

3) Membrane with severe spalling or scabbing - occurs when the edges of the slab are restrained. This, combined with large deflections, results in tensile membrane action. Spalling (ejection of fragments from the unloaded side of the slab) occurs as the blast pressure is transmitted through the element, resulting in a tensile failure in the concrete normal to the free surface. Scabbing is associated with large strains in the reinforcing steel late in the response of the slab. Scabbing and spalling both can be seen in Figure 2-5.

4) Direct concrete crushing and spalling, with membrane action - intensity of the blast crushes concrete, shockwave transmission causes spalling, and the bulk of the flexural capacity of the member is lost. Remaining capacity is through membrane action of the reinforcing steel mat. 
5) Shear - catastrophic failure mode without flexural behavior. Boundaries show direction shear failures, not tensile failure.

6) Overbreach - concrete is disintegrated and blown away. Reinforcing steel is broken.

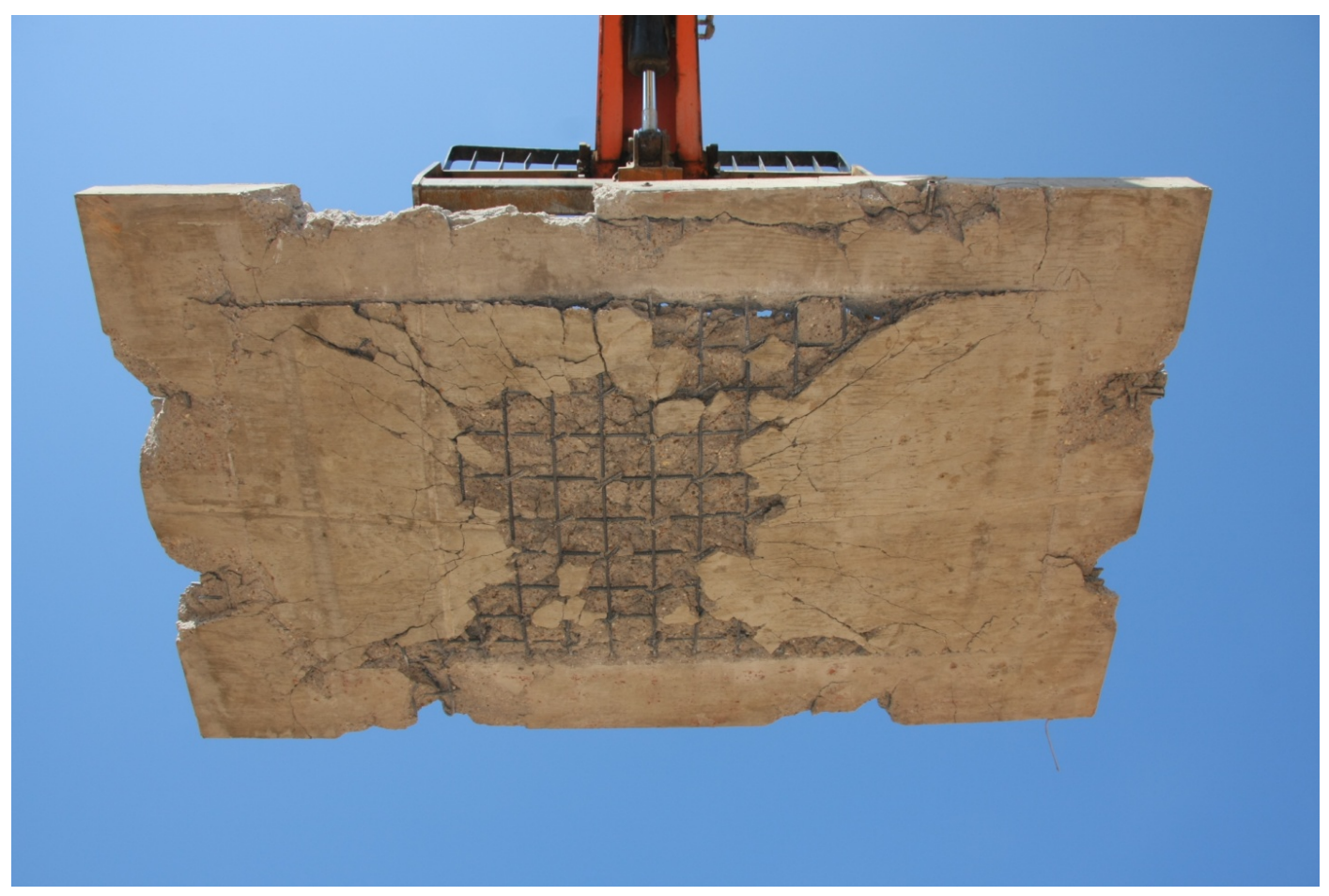

Figure 2-5 - Un-strengthened reinforced concrete slab after blast at a scaled range of 1.5 $\mathrm{ft} / / \mathrm{b}^{1 / 3}$, displaying extensive spalling.

As the intensity of the blast increases, the failure mode generally trends towards the $6^{\text {th }}$ mechanism, with the exception of shear failure, which governs in shear critical (short span length) cases. A versatile and robust retrofit system should address these failure mechanisms. 


\subsection{Blast Mitigation}

The easiest way to improve a structure's resilience to blasts is to increase the standoff distance between the structure and the blast itself. This may take the form of access control such as vehicle barriers and physical security. Installing massive barriers of concrete or sandbags can help absorb or deflect blast energy. In many cases these are sacrificial systems that do not directly strengthen a structure, but rather reduce the load such as the reinforced concrete blast wall show in Figure 2-6. Heavy steel plating has also been applied to concrete structures to add additional strength and armoring.

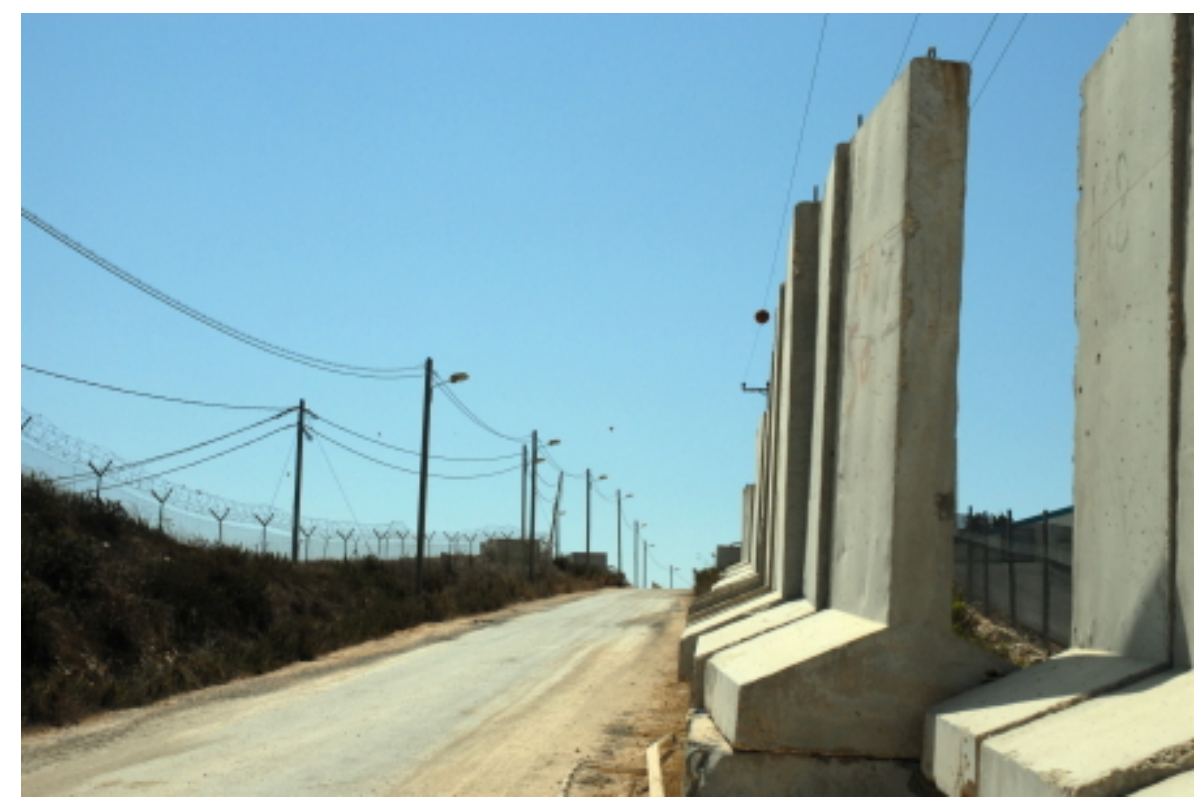

Figure 2-6 - Massive concrete walls provide shielding from blast loads and debris.

Unfortunately, many of these retrofits have similar drawbacks. The placement of large barriers is impractical in cases where vehicular access must be preserved, such as bridges or buildings that stand only feet from a vital road. Erection of steel plating may present insurmountable access issues, and dramatically increase the dead load on a structure. 
Faced with a design problem not well solved by traditional materials, engineers have turned to innovative technologies. The use of fiber reinforced polymer (FRP) composites presents solutions to many of these issues (Razaqpur et al. 2007).

\subsection{Composite Materials for Structural Applications}

When new concrete structures are constructed there are several ways to increase the member strength as needed. To meet the design loads the engineer can increase the quantity or strength of the reinforcing steel or increase the dimensions of the member. Significant gains in strength can be achieved by improving the material properties of the concrete itself. However, none of these options are available when a structure is to be retrofitted after construction to meet a new design load.

Externally applied fiber reinforced polymer (FRP) strengthening provides an option for retrofit of existing structures and has become favored in structural applications for its high strength to weight ratio, ease of application, and suitability for post construction retrofit (Correia et al. 2010). Some FRP products can obtain a strength to weight ratio over 30 times greater than steel, and a complete retrofit system can be applied in only a few minutes per structural member, often only days for an entire structure. Unlike steel retrofits where skilled metalworkers, crane operators, and welders may be required, a small crew can be trained to install FRP in only a few days, Figure 2-7 (ACI 440 1996). 


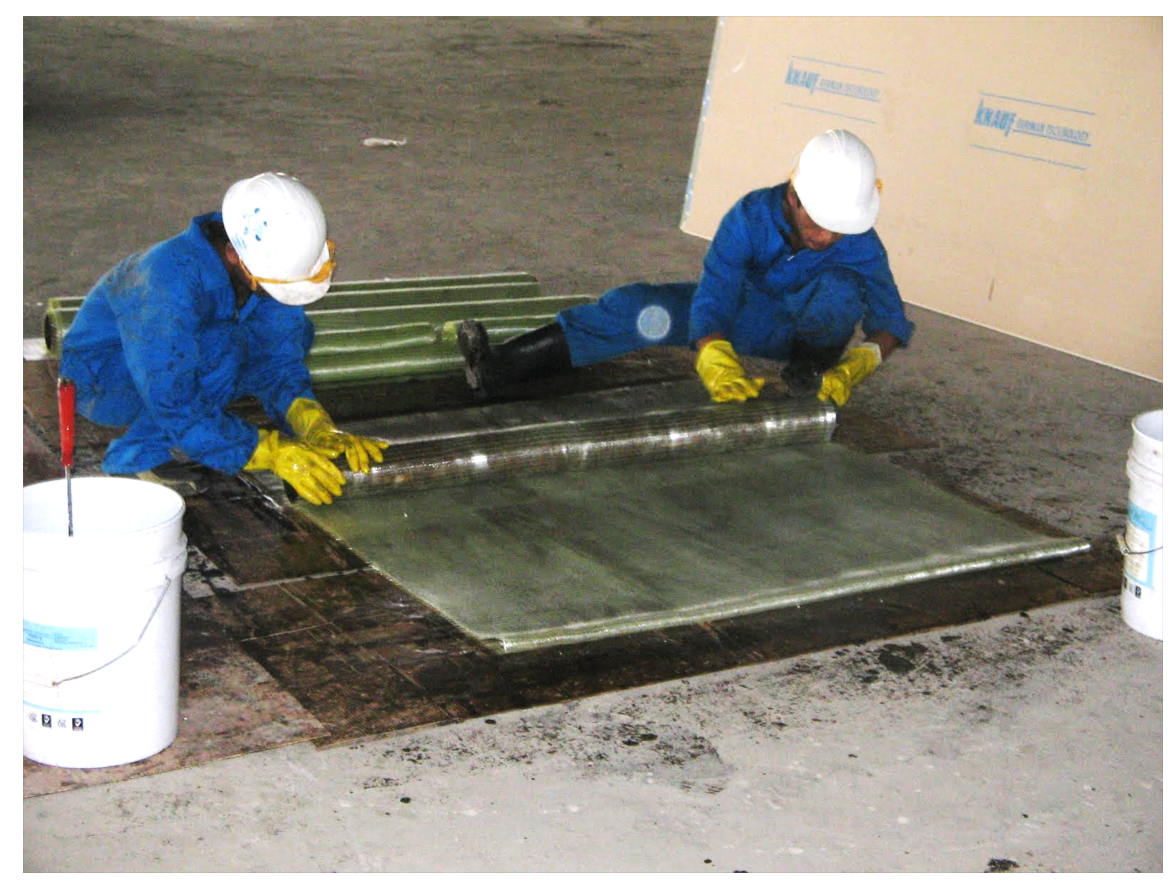

Figure 2-7 - Workers apply wet lay-up glass fiber reinforced polymer (GFRP) to a concrete slab. A large quantity of fabric can be easily shipped and stored, as it rolls compactly onto spools. (Fyfe 2012)

Most fiber reinforced polymer materials share several general characteristics. They consist of two main components: a high tensile strength fiber, which may be carbon, glass, aramid, or other material, and a matrix, which may be epoxy, polyester, vinyl ester, nylon, etc. The fibers provide the tensile strength of the material and the matrix helps to distribute the load between fibers, bind them together, and bind the fibers to the substrate. The matrix ensures shear transfer between the components, providing a linear strain distribution in the cross section with respect to flexural analysis (Orton et al. 2011). FRP generally exhibits a very linear elastic response, with no yielding, until it experiences a brittle failure as the fibers fracture.

Structural applications of FRP have been standardized by American Concrete Institute Publication 440 (ACI 440). This document includes guidelines on use of FRP composite 
materials for columns, beams, and shear walls. FRP is generally applied as thin sheets and designed to work only in tension. ACI 440 discourages the use of FRP in compression zones due to the tendency of the thin FRP sheet to buckle and debond.

Employing FRP can help reduce dead loads under challenging conditions where strength must be increased. FRP may also be chosen so that the retrofit maintains a slim profile. Adding steel plating or additional beams can reduce ceiling height or add bulky additions to columns. This can reduce the usable space of an industrial occupancy, or damage the economic and aesthetic value of a residential or commercial occupancy. This is particularly of concern for structures with cultural or landmark significance, including many bridges. FRP retrofits are extremely thin, often just a tenth of an inch, which can preserve existing architectural sight lines.

The choice of a particular fiber reinforced polymer product starts with selection of a fiber composition. Carbon, aramid (Kevlar), and glass fibers have all seen usage in structural engineering applications (Khalifa et al. 1999). Generally speaking, carbon FRP has a strength and stiffness advantage over aramid FRP and particularly glass FRP. However the greater elongation of glass FRP can be an asset in certain circumstances, such as to ensure a ductile failure mode. Aramid FRP is often used for lightweight applications or those where cut resistance is required.

Perhaps the most commonly used fiber reinforced polymer in structural applications is carbon fiber reinforced polymer (CFRP). In CFRP, the fibers which provide the strength of the material are made out of almost pure carbon. The carbon atoms are arranged in rings to form graphite as shown in Figure 2-8. Carbon fibers are arranged in the planes of 
the graphite. When loaded, stress is transferred to the strong covalent bonds of the graphite rings, giving the carbon fiber its high strength. Through a complex industrial process, a precursor material such as polyacrylonitrile (PAN) is spun into filaments.

These filaments undergo repeated chemical, mechanical, and thermal processes to produce carbon fibers with a diameter of about $250 \mu$-in (Zoltek 2011). Many thousands of these fibers are then grouped together into bundles called 'tows,' generally about 0.2 in diameter. It is these tows which are woven to form a fabric.

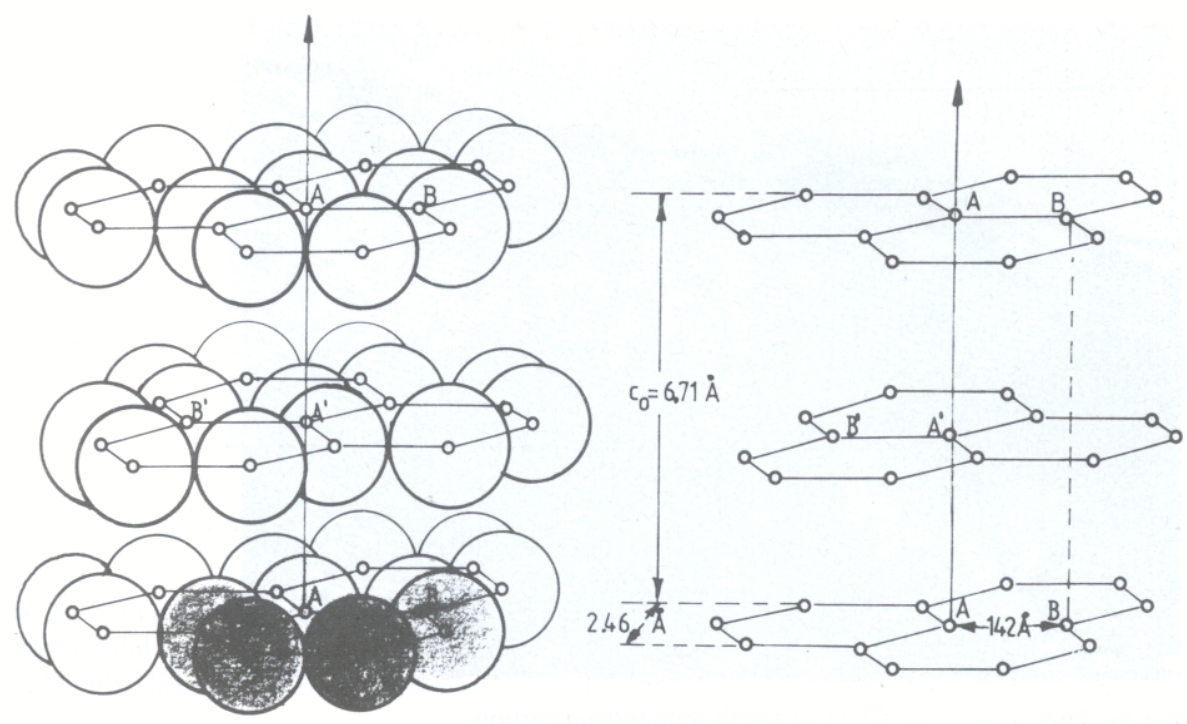

Figure 2-8 - Structure of Graphite (Fitzer 1985)

CFRP is very lightweight and extremely strong. It has a density of around $110 \mathrm{lb} / \mathrm{cubic}$ foot, less than a quarter of the density of structural steel. The tensile strength of a CFRP composite varies from around $120 \mathrm{KSI}$ to over $400 \mathrm{KSI}$, or up to 8 times the tensile strength of standard structural steel. In the aggregate, this gives CFRP a strength to 
weight ratio up to 32 times greater than that of structural steel. These physical properties make the material extremely valuable in many circumstances.

\subsubsection{Wet-layup versus Pultruded FRP}

Many form factors exist for structural FRP. Perhaps the two largest categories are wetlayup FRP and pultruded FRP. With wet-layup FRP, a flexible fabric is shipped to the jobsite on rolls, such as that shown in Figure 2-9. This fabric will become the loadbearing fibers in the finished composite. It may be woven out of carbon fibers, glass fibers, aramid (Kevlar) or other material.

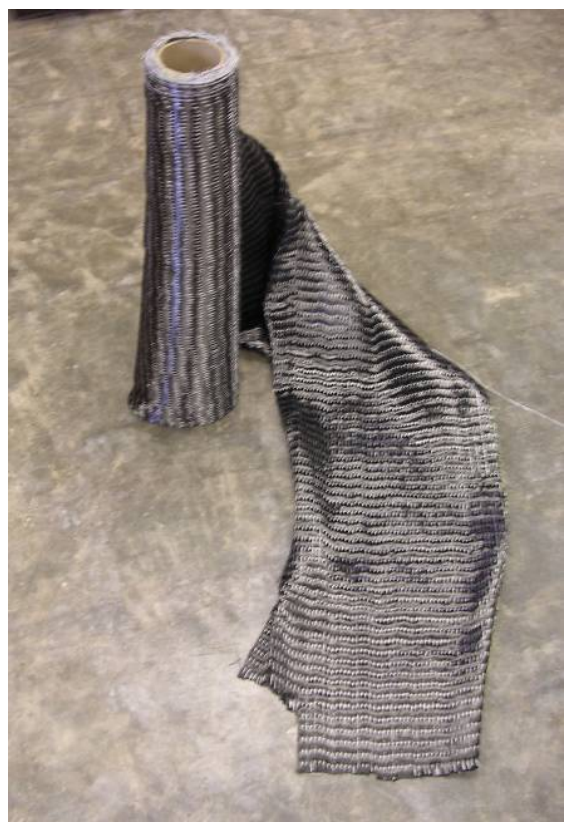

Figure 2-9 - Wet-layup FRP arrives at the jobsite on rolls.

Before application of the FRP, the substrate surface must be prepared. For most concrete structures a thorough sand blasting and pneumatic cleaning are sufficient. After the surface is prepared, the fabric is dipped into a liquid matrix. The matrix is usually a 2 part 
epoxy. Mechanical rollers are used to force matrix between the fibers of the fabric. The matrix-logged fabric is then immediately pressed against the prepared structure, as seen in Figure 2-10. The epoxy serves both to transfer force between carbon fibers and to adhere the fabric to the surface. Some wet-layup products cure at room temperature and pressure, others cure best under vacuum clamping and steam heating. Benefits of these products include easy application, high flexibility in installation geometry, and a monolithic matrix-bond structure. Typical strengths for carbon fiber wet-layup systems are in the 110 ksi range.

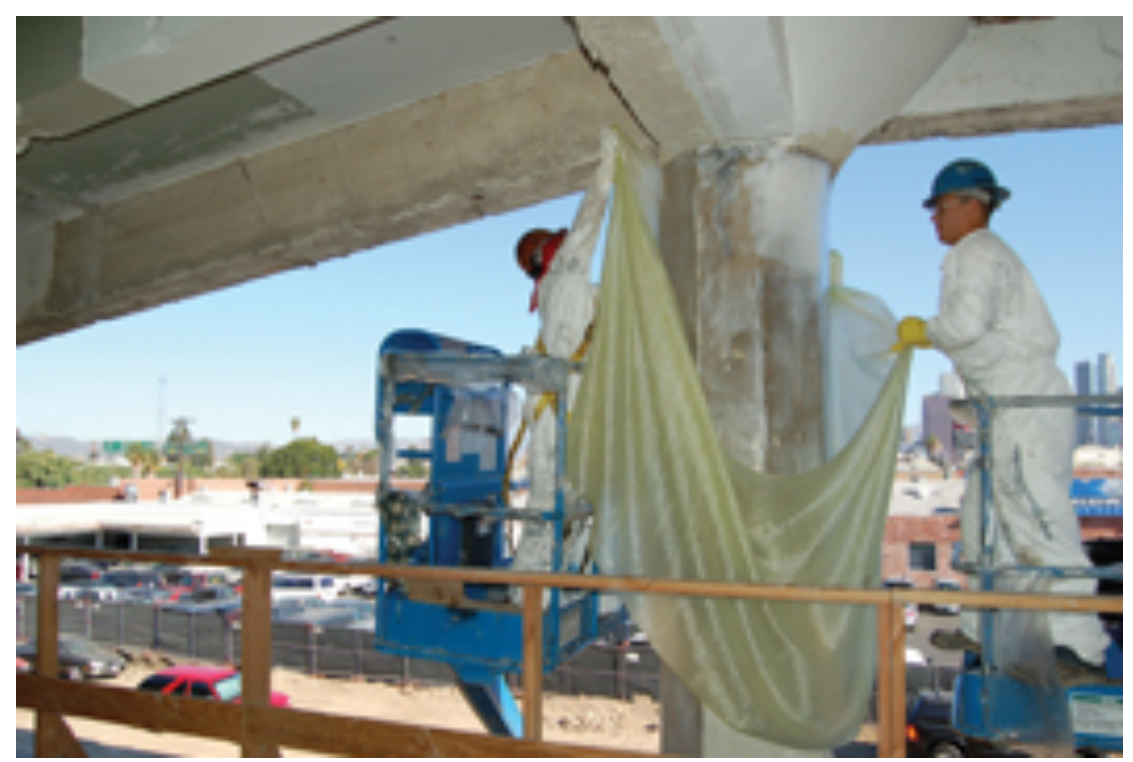

Figure 2-10 - Workers install wet-layup glass fiber reinforced polymer (GFRP) on a reinforced concrete column (Fyfe 2012).

Pultruded FRP products arrive at the jobsite with the matrix already cured into the fiber fabric. This produces a rigid sheet, which can be many hundreds of feet long and rolled into spools with a radius as tight as 18 in, Figure 2-11. To make the pultruded FRP, individual reinforcing fibers are drug through a liquid matrix at a specialized factory. The 
fibers are brought together through a heated die that sets the final cross section shape and polymerizes the matrix. The FRP is fully cured before it leaves the production facility. Because the fibers are laminated in carefully controlled factory conditions, the fiber to matrix ratio is very high. This results in exceedingly strong laminates, around 400-500 ksi for carbon systems.

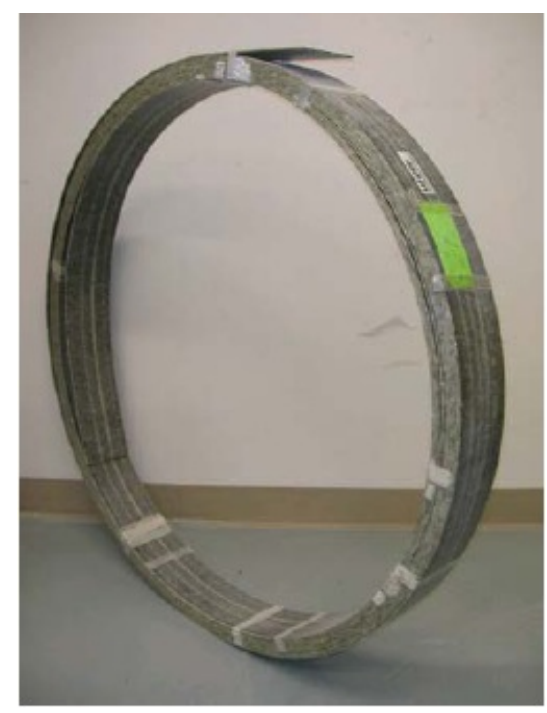

Figure 2-11 - Pultruded FRP packaged for shipping.

Installing a pultruded FRP product is similar to installing a wet-layup product, but without the step of dipping the FRP in a matrix. For pultruded FRP, an adhesive is applied to the contact surface of the prepared structure. The FRP is pressed on with a roller, and the adhesive is allowed to cure. Occasionally the material is also mechanically fastened to the structure, as in Figure 2-12. The primary benefit of pultruded FRP products are their very high strengths, not obtainable with wet-layup materials, that are the result of a very high fiber to matrix ratio. The disadvantages of pultruded FRP include greater cost and less flexibility in dimensions. 


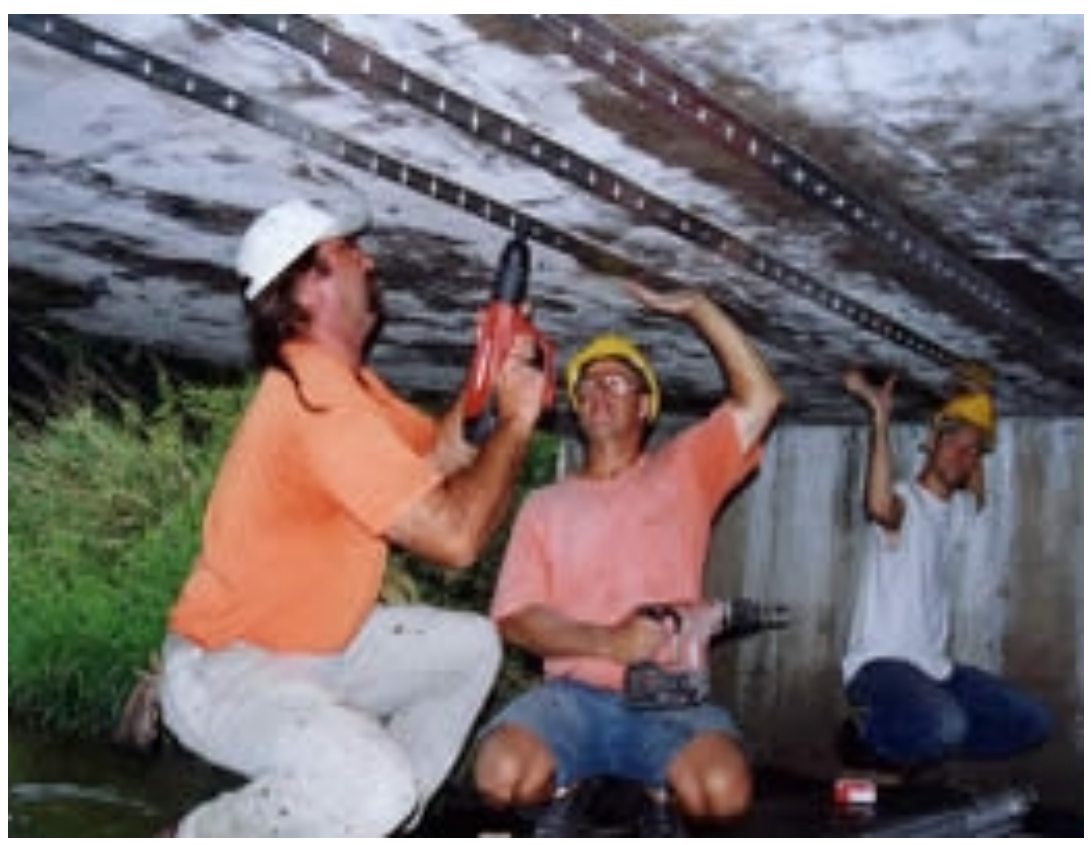

Figure 2-12 - Workers install pultruded FRP with mechanical anchors (Strongwell 2006).

\subsubsection{Anchorage of Fiber Reinforced Polymers}

De-bonding is a common failure mode in many FRP applications. It is a basic structural engineering principle that the strength of a reinforced concrete member depends on the strain compatibility, and therefore the bond, of the rebar imbedded in the concrete. The same principle can be applied to an FRP strengthened member. The strength of an FRP retrofit system is dependent on the bond between the applied sheet of laminate and the concrete member. If that strain compatibility is compromised, the member will be permitted to deflect independent of the FRP sheet, rendering the retrofit ineffective. Indeed, Bonacci and Maalej (2001) found that on average CFRP de-bonds at only $50 \%$ of its tensile capacity. 
Failure of the FRP bond normally occurs with one of two mechanisms. Either failure will take place in the concrete cover just below the FRP-concrete interface, or in the concrete cover at the level of the rebar (Kim et al. 2009). Failure is the adhesive layer itself is possible, but not likely with properly cured structural adhesives such as epoxy. Blast tests by Muszynski and Purcell (2003) encountered such delamination failures, as did Kim (2008), and Orton et al. (2011) during static testing of impact damaged CFRP. The first failure mode, delamination just below the FRP-concrete interface, can be seen in Figure 2-13. The second failure mode, separation of the concrete cover at the level of the rebar, can be seen in Figure 2-14.

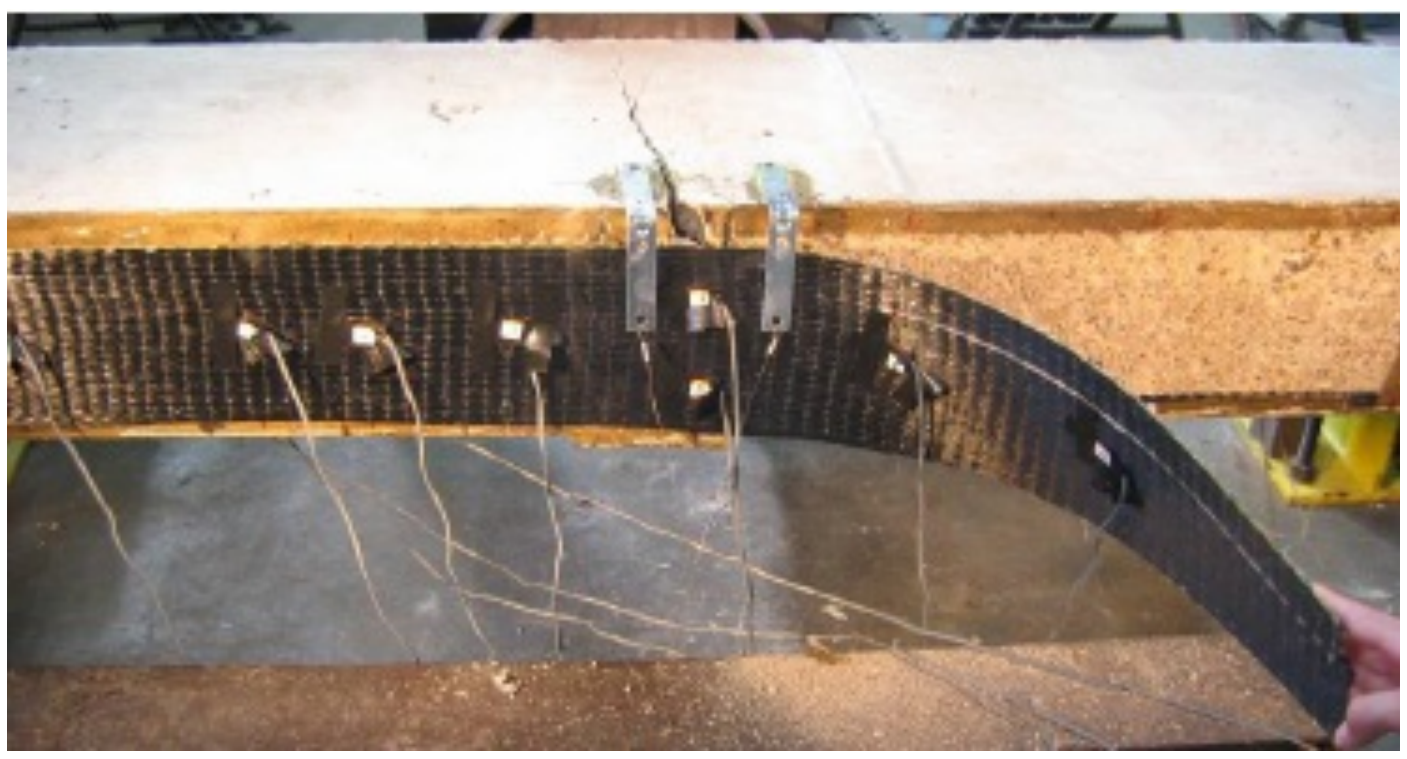

Figure 2-13 - De-bonding failure of unanchored CFRP from a reinforced concrete beam. Note that the concrete remains mostly intact (Kim 2008). 


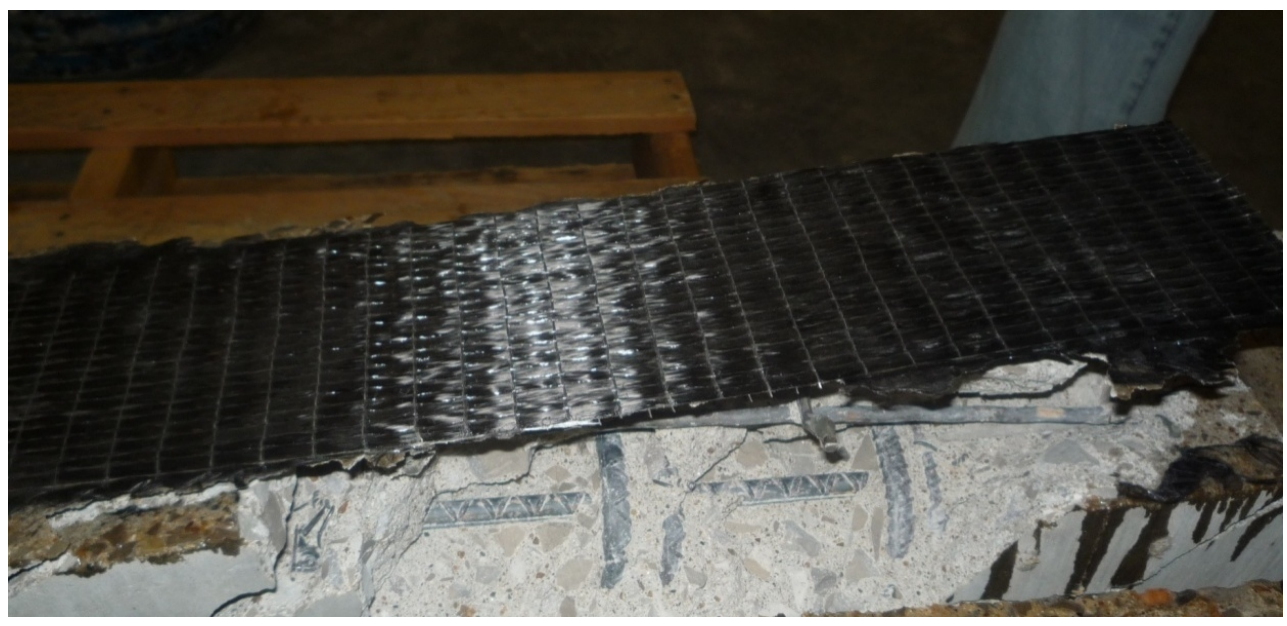

Figure 2-14 - De-bonding of an unanchored CFRP sheet from a reinforced concrete beam. Note the separation of the concrete cover at the level of the outermost reinforcing steel (Orton 2011).

Regardless of which de-bonding failure mode will occur, it almost always occurs at a load less than the capacity of the FRP material itself (Orton et al. 2011). If the engineer wishes to design for the full capacity of the composite material, additional measures must be taken to secure the composite to the member. This is particularly true for very high strength composite materials, or those applied in greater thickness, due to the increased demand on the bond to carry shear.

A variety of FRP anchoring methods have been tested by past researchers, all with the goal of utilizing more of the strength of the FRP. Razaqpur et. al. (2007) tested concrete slabs with CFRP reinforcement by wrapping the ends of the carbon fiber fabric around the sides and rear of the slab specimen. This significantly increased the effective bond area, and confined the concrete cover. By doing this, the researchers were able to achieve heavy fiber rupture, indicating the CFRP had achieved its ultimate strength. 
Orton et al. (2013) placed mechanical clamps on the ends of CFRP strengthened beams to limit the initiation of de-bonding, Figure 2-15. The clamping force prevented the concrete cover from cracking and lifting off the member.

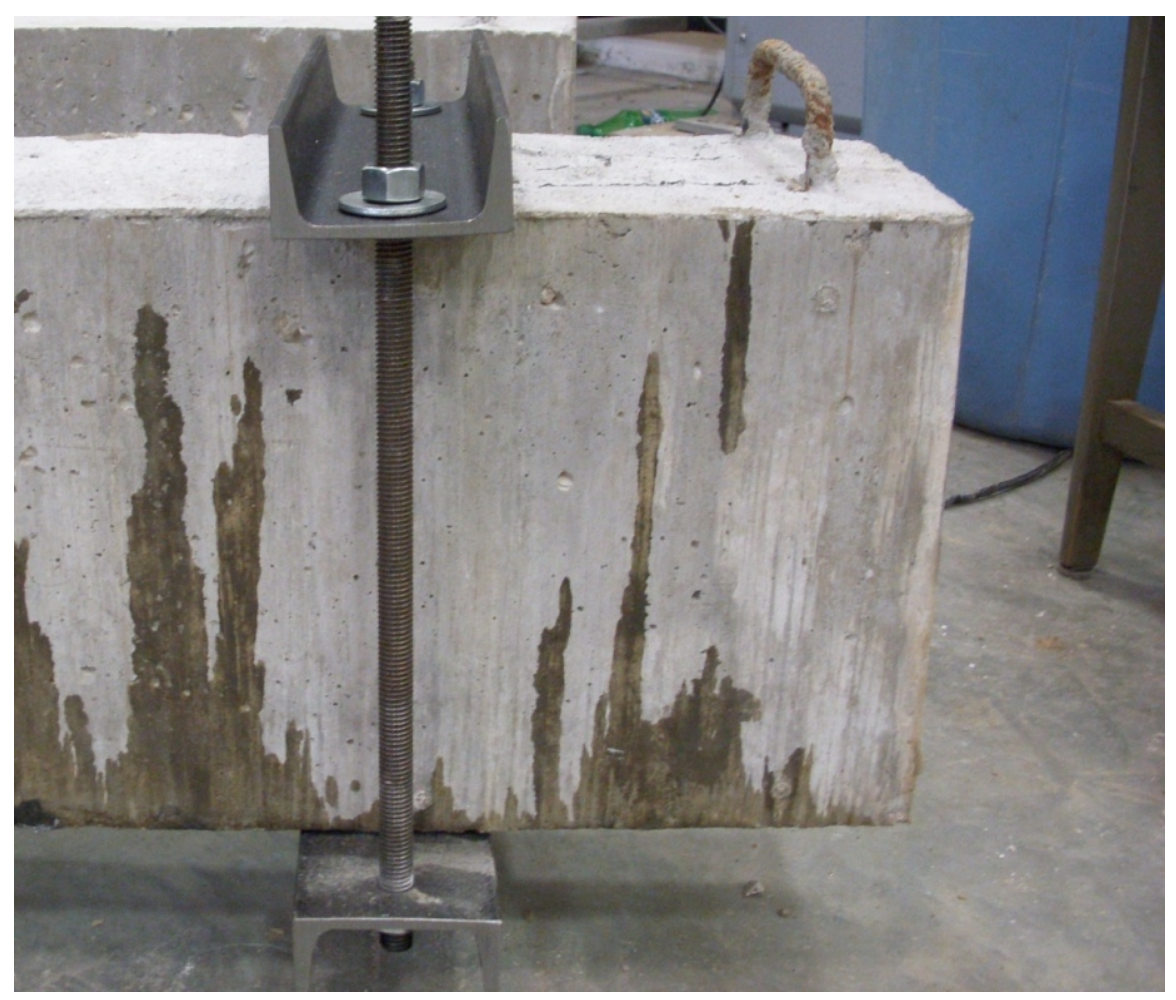

Figure 2-15 - Mechanical clamp anchors used to limit de-bonding of FRP (Orton 2011).

Khalifa et al. (1999) developed a system of near surface mounting they termed a "UAnchor". With this method, shown in Figure 2-16, the FRP is tucked into a groove that is cut in the concrete member perpendicular to the fiber direction. Wedged in on top of the FRP sheet is a pre-cured FRP bar. The entire assembly is backfilled with an epoxy paste. Researchers found a $42 \%$ increase in strength when using this system relative to no anchorage. 


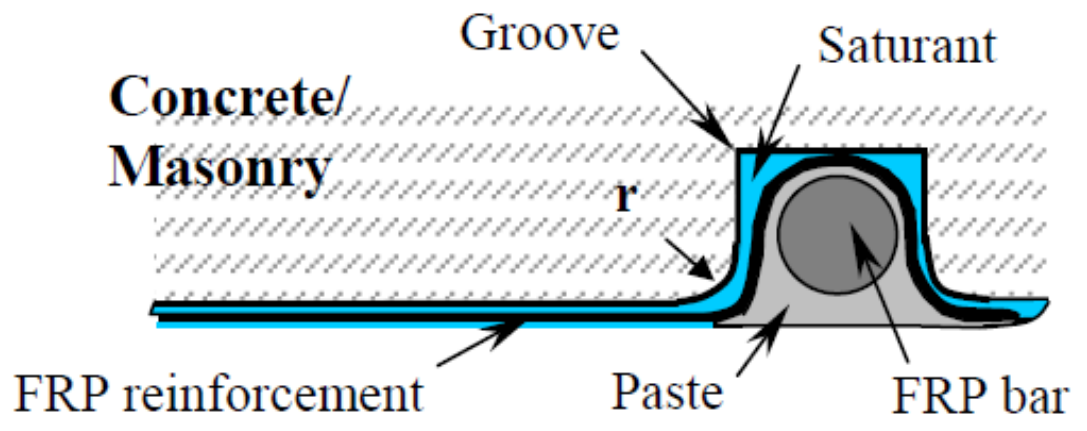

Figure 2-16 - Near surface mounting systems developed by Khalifa et al. (1999)

Another option for improving strength is the application of FRP as a U-wrap with the fibers perpendicular to the long axis of the member, seen in Figure 2-17. Anchoring FRP sheets with U-wraps increases the amount of bonded area of the FRP sheet, thereby allowing more stress to be developed before debonding.

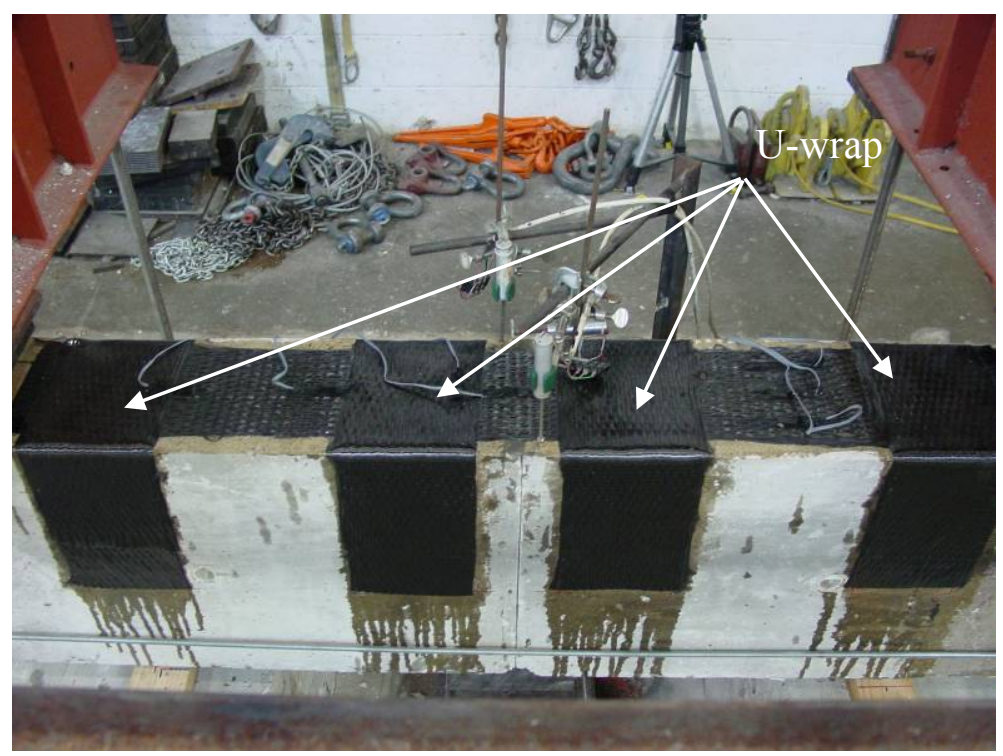

Figure 2-17 - U-wrap anchorage on a reinforced concrete beam (Orton 2007) 
Orton et al. (2008) evaluated the use of a fiber anchor system for CFRP. With these anchors, holes are drilled into the concrete core through the outer cover layer. When the wet-layup CFRP is first applied, a strip of CFRP is saturated with epoxy and pushed through the wet-layup fabric and down into the hole. This configuration can be seen in Figure 2-18.

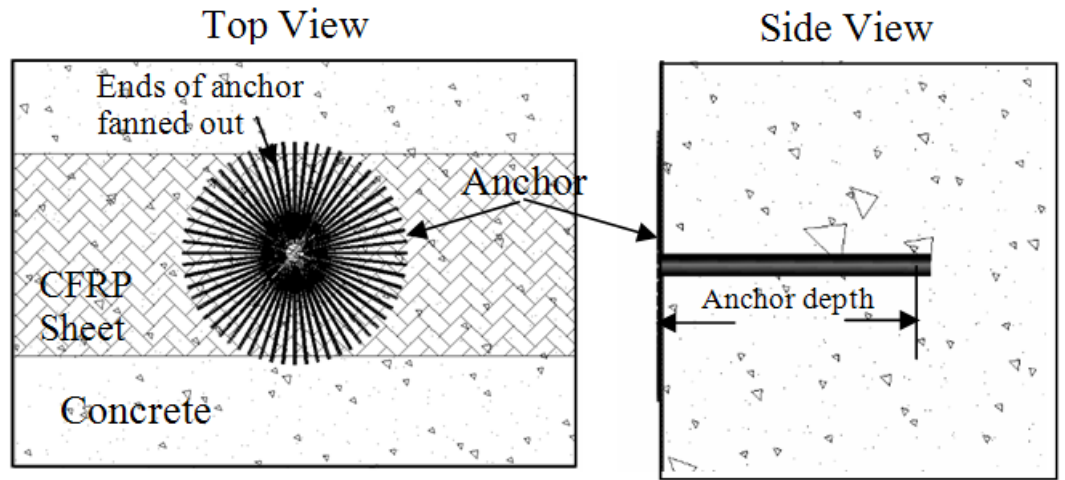

Figure 2-18 - Schematic of fabric anchors

Orton et al. (2011) found that the addition of fiber anchors increased the capacity of a CFRP strengthened reinforced concrete beam by $57 \%$. The researchers also found that use of fiber anchors acts as a safeguard against loss in capacity due to impact damage, since instigation of de-bonding is a primary concern with impact damage on FRP.

For pultruded plates, anchoring can be accomplished by mean of mechanical fasteners placed through the FRP plate and into the concrete, Figure 2-19. These anchors can develop the full capacity of some FRP plates (Lamanna 2002). However, to avoid splitting the plate, plates with transverse fibers should be used, Figure 2-20. At least one commercial system have been developed incorporating pultruded CFRP with cross fibers and preformed holes (Strongwell 2006). 


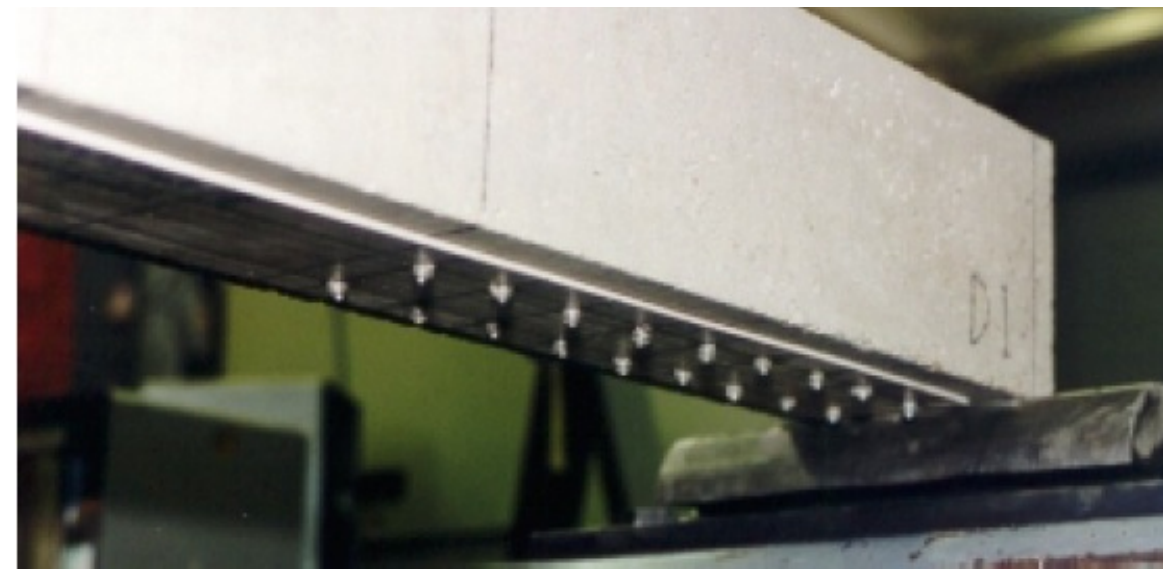

Figure 2-19 Mechanical fastening of pultruded CFRP plate (Lamanna 2002).

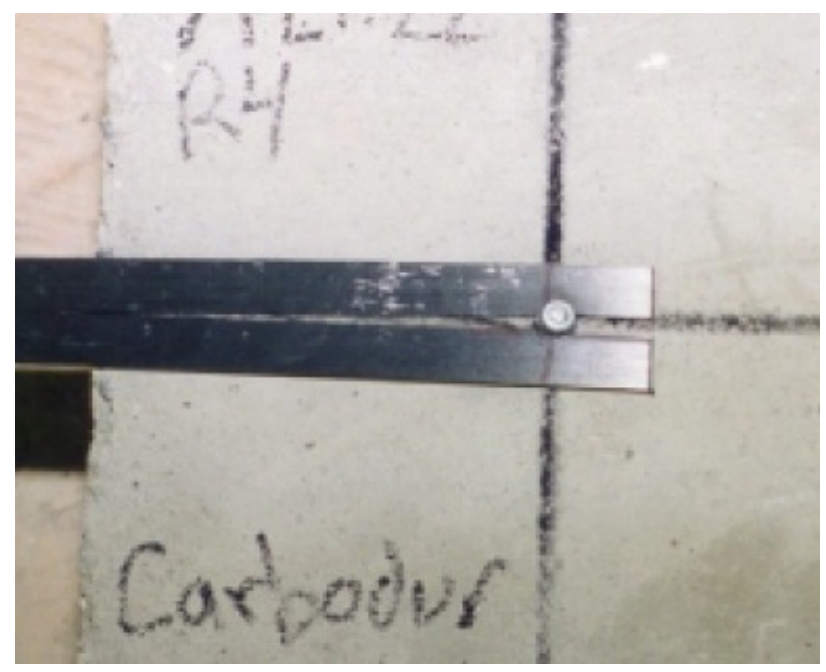

Figure 2-20 - Splitting occurs around mechanical fasteners in pultruded CFRP without cross fibers (Lamanna 2002).

\subsection{Composite Retrofits for Blast Loading}

Previous research has documented the suitability of fiber reinforced polymer for blast resistance retrofit of concrete. Kim et al. (2009) found that externally applied CFRP can reduce displacements of blast-loaded slabs by as much as $38 \%$, but noted evidence of de- 
bonding. Glass FRP (GFRP) has also been found effective. Nam et al. (2010) tested a GFRP strengthened slab under blast loading and noted a reduction in displacement of $30 \%$ relative to un-strengthened reinforced concrete. Nam et al. (2010) also found evidence of a de-bonding failure.

Mosalam and Mosallam (2001) conducted static testing of reinforced concrete slabs strengthened with CFRP under a uniform area load. Load was applied by a water filled bag at a rate of around $0.5 \mathrm{psi} / \mathrm{min}$. This research found that CFRP retrofitting of slabs can increase the strength by up to $200 \%$. Researchers also noted the retrofit was significantly more effective when the material was applied to both sides of the slab, that is both the side exposed to and the side shielded from the blast. Using FRP on the front face, as opposed to a thick steel plate or other bulky material, could also have an additional advantage of not putting the structure even closer to the blast, which would further increase the intensity. It must be noted that little of this prior research has considered true close-in blasts and all the previous tests were with wet lay-up fabrics.

Recent research involving near-field blasts has been conducted by the US Army Corps of Engineers Engineering Research and Development Center (ERDC). This research has investigated separately the use of steel and CFRP for blast retrofit under close-in conditions (Orton et al. 2013). The slabs tested were 5.25 in thick with \#3 steel reinforcement bars at 4 in on center in each direction, 0.5 in from both the tension and compression faces. The slabs measured $6 \mathrm{ft}$ by $10 \mathrm{ft}$ and were simply supported around a $1 \mathrm{ft}$ perimeter, leaving a $4 \mathrm{ft} \times 8 \mathrm{ft}$ clear span. 
Two tests with FRP were performed. The first design consisted of 4 layers of wet-layup CFRP laid at a 45 degree angle as seen in Figure 2-21. Fiber anchors were used heavily to improve the blast response, and the specimen was tested at a scaled standoff distance of $1.5 \mathrm{lb} / \mathrm{ft}^{1 / 3}$. Though heavy damage occurred, the slab did not breach, Figure 2-22 and Figure 2-23.

A second test used one layer of CFRP longitudinally across the slab, with two additional layers at a 30 degree angle. This retrofit also made use of fiber anchors, and was tested with an even larger blast with a scaled range of $1.0 \mathrm{lb} / \mathrm{ft}^{1 / 3}$. An un-strengthened control test is shown in Figure 2-24. The result of the second test can be seen in Figure 2-25 and Figure 2-26. Though the slab was still breeched, this retrofit was effective at reducing displacement of the loaded slab, as seen in Figure 2-27. 


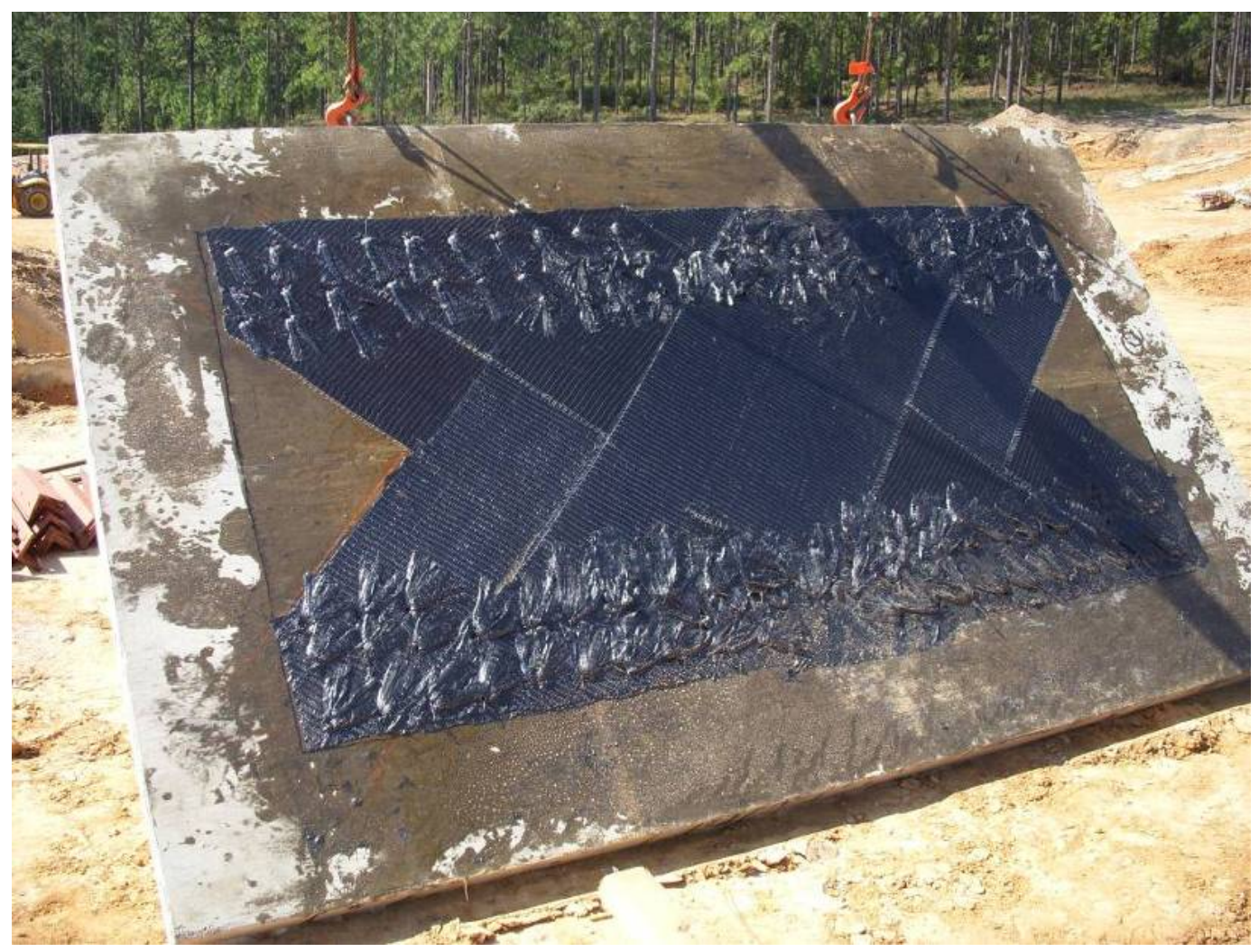

Figure 2-21 - Wet-layup CFRP applied to the tension face of a concrete slab to be tested at a scaled range of 1.5. Note the extensive use of fiber anchors (Orton 2013).

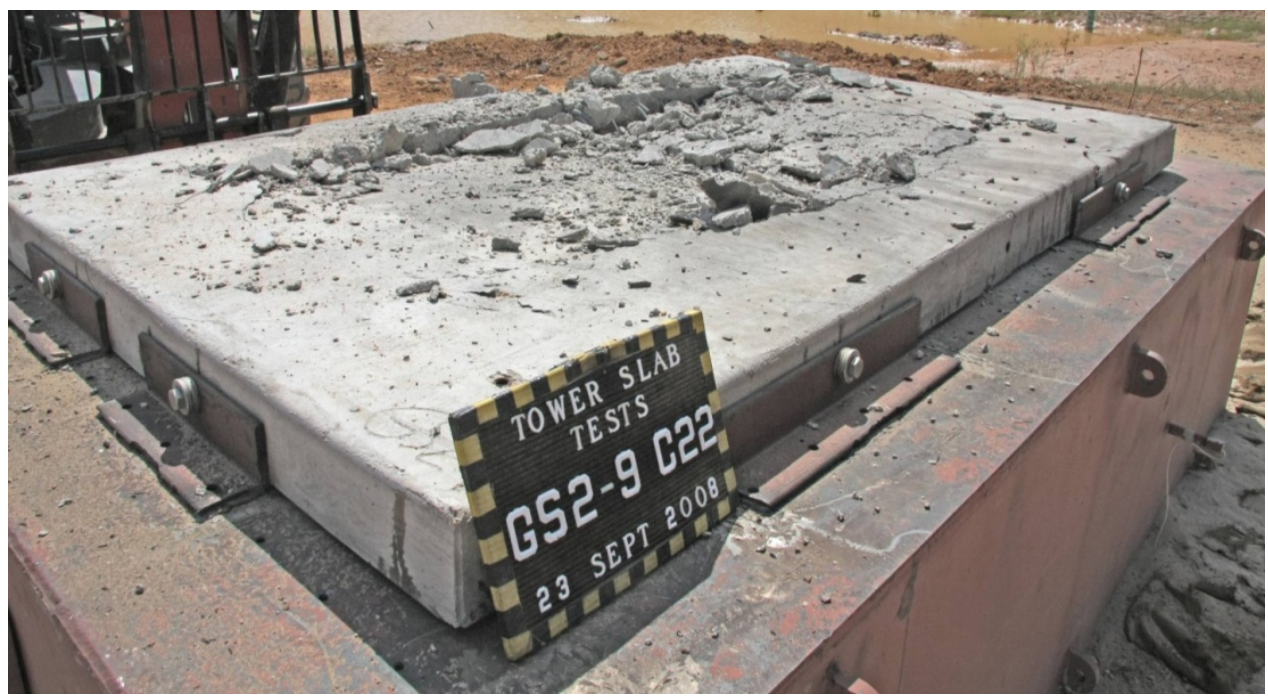

Figure 2-22 - Wet-layup CFRP strengthened slab tested at scaled range 1.5, post-test. The slab did not breach. 


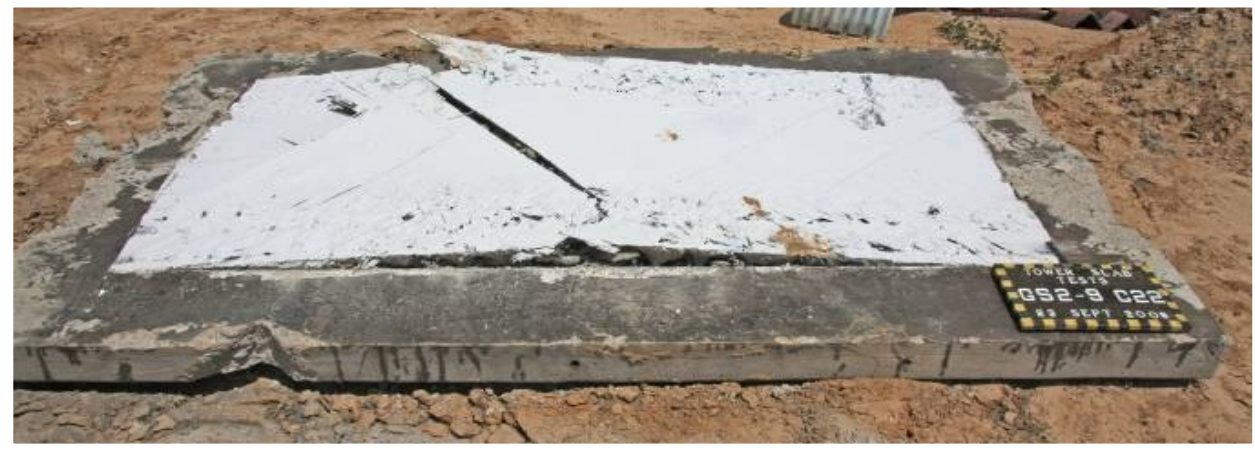

Figure 2-23 Wet-layup CFRP strengthened slab tested at scaled range 1.5, post-test, reverse side. Though the CFRP fractured, the slab did not breach.

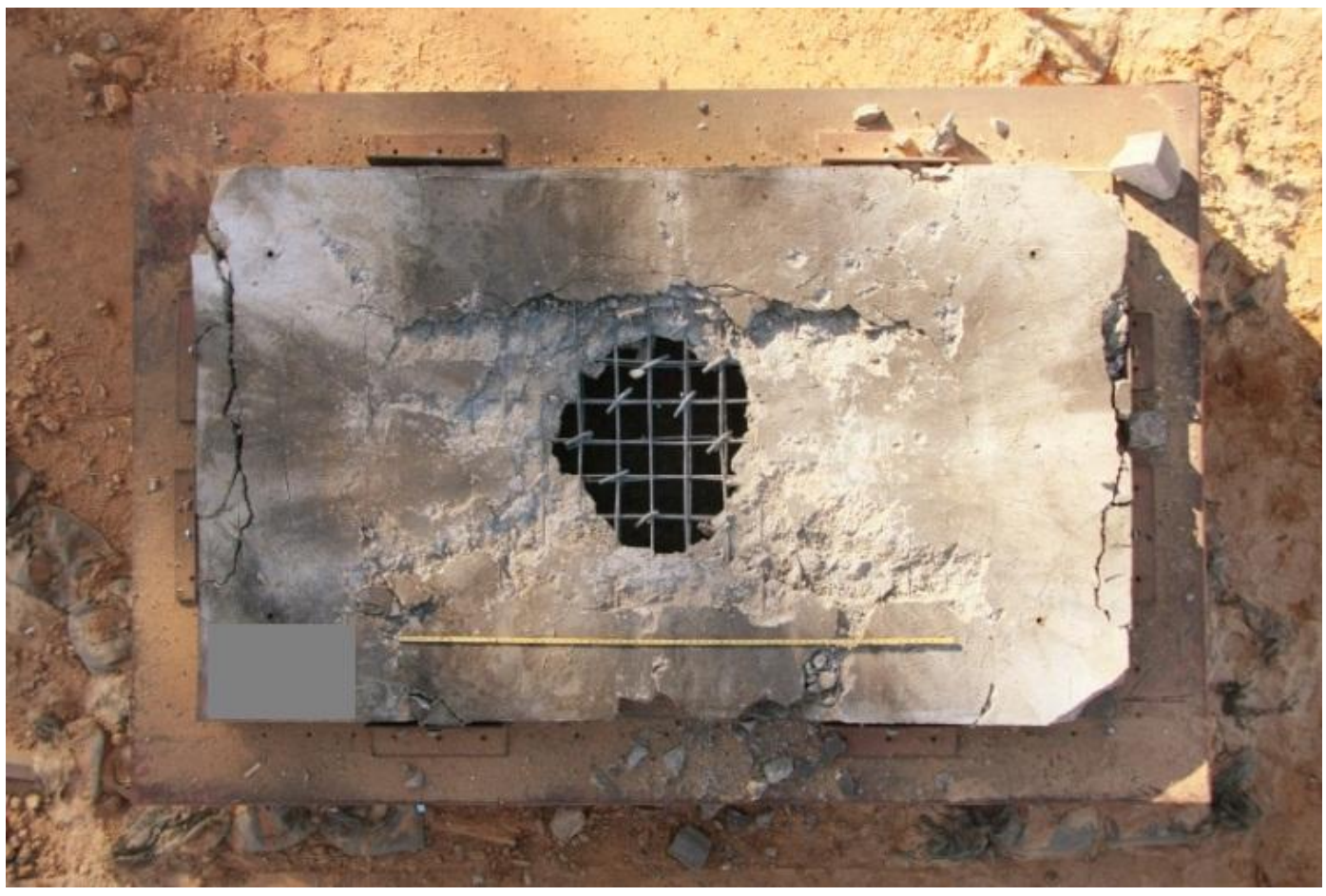

Figure 2-24 - Unmitigated concrete slab tested at a scaled range of $1 \mathrm{ft} / \mathrm{lb}^{1 / 3}$ (Orton 2013) 


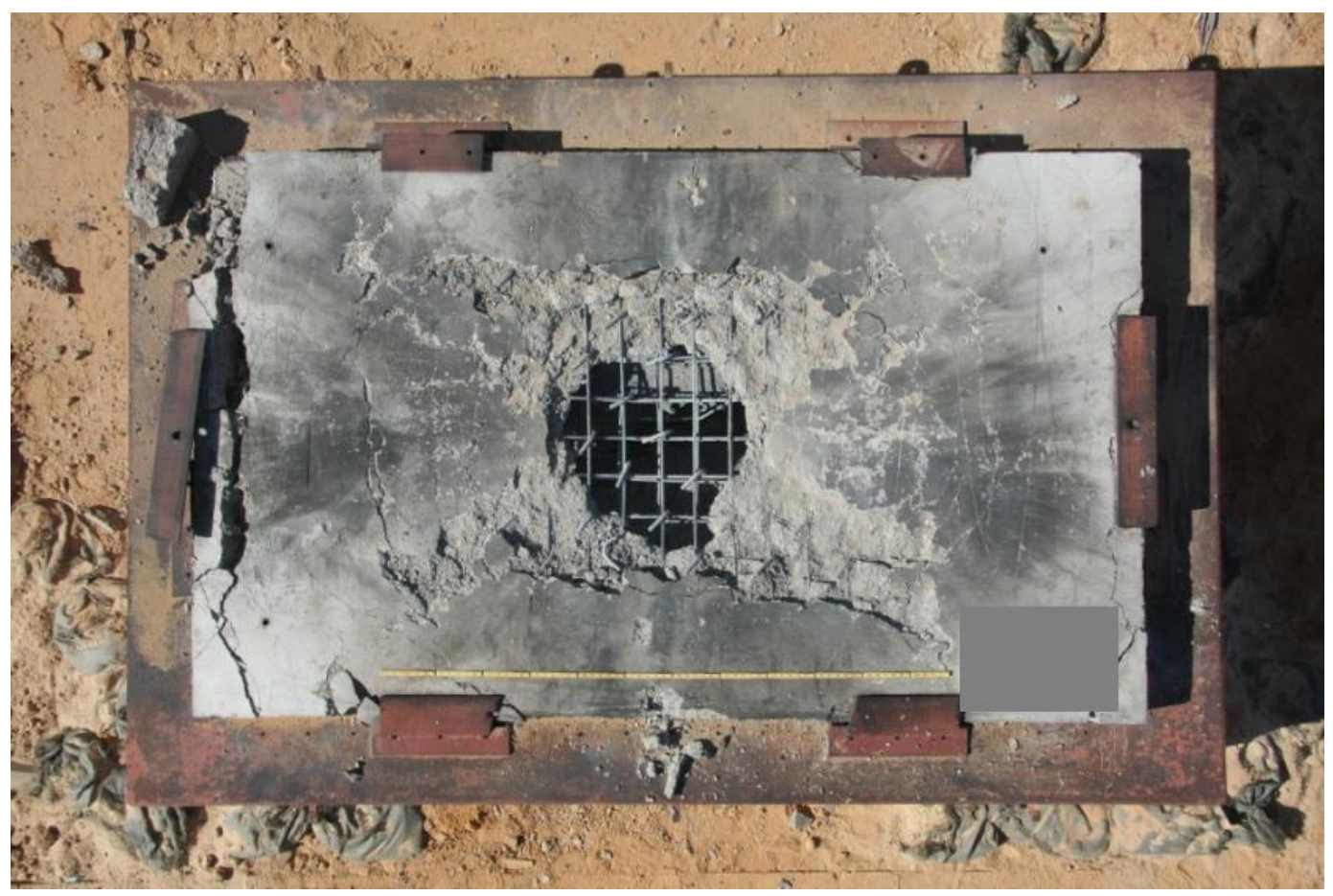

Figure 2-25 - CFRP mitigated slab subjected to a close-in blast at a scaled range of $1 \mathrm{ft} / \mathrm{lb}^{1 / 3}$ (Orton 2013).

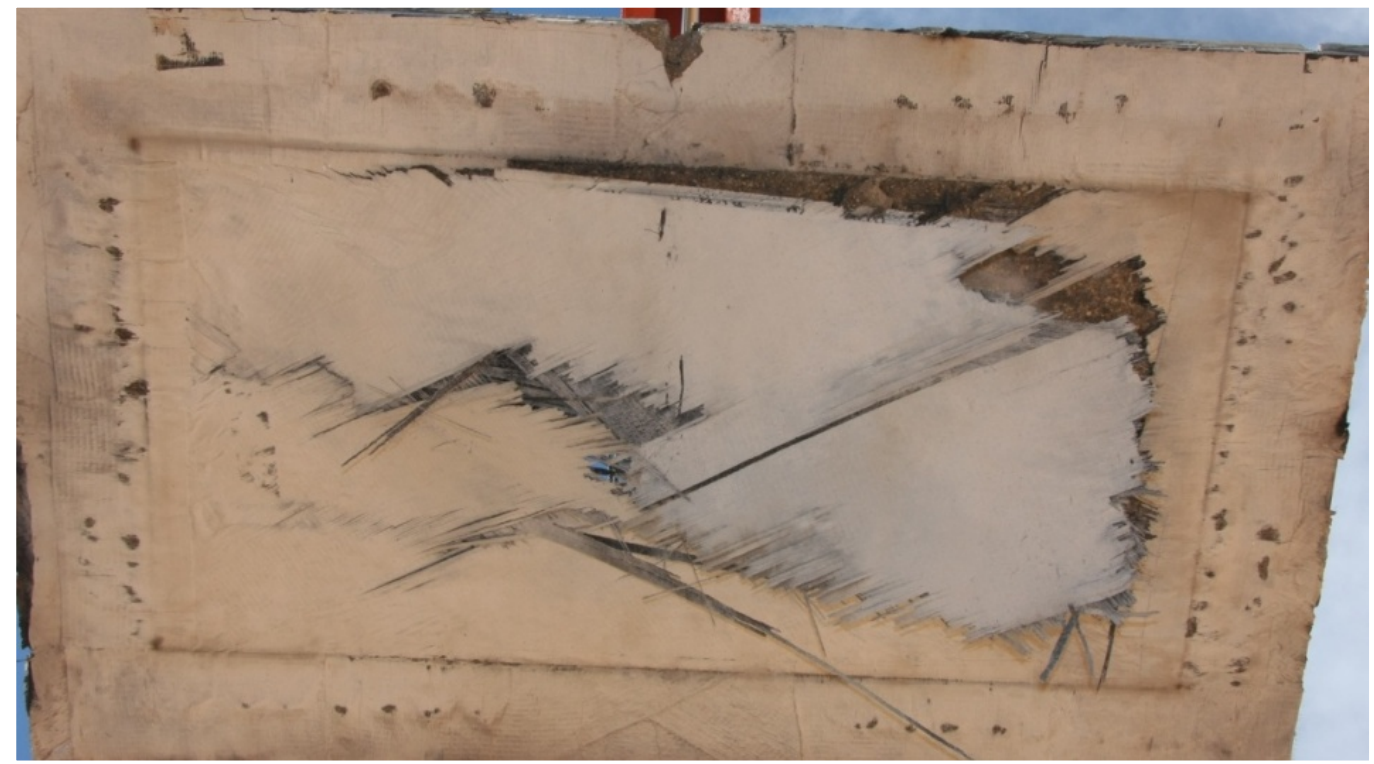

Figure 2-26 - Result of blast test on CFRP strengthened slab. Scaled range of $1.0 \mathrm{lb} / \mathrm{ft}^{1 / 3}$ (Orton et al. 2011). 


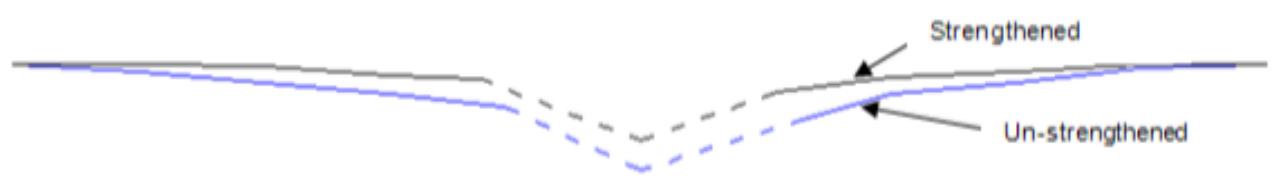

Figure 2-27 - Comparison of un-strengthened and strengthened deflections (dashed line indicates area of breach) (Orton 2013).

In addition to the CFRP tests performed by ERDC, a steel retrofit test was performed. $1 / 2$ in thick $100 \mathrm{ksi}$ steel plates were placed on both faces of the slab, and bolted through the concrete every 4 in on center. This retrofit was found to be very effective, as the front plate of steel was able to partially shield the concrete from the blast shockwave, and the concrete remained well confined. This allowed the steel plates to continue having a flexural moment-couple action even as the concrete contained within them was badly deteriorated by the blast. This test formed the basis for the retrofit system tested in this research. Further details can be found in Chapter 3 - Retrofit Design and Construction. 
There are several conclusions that reoccur in much of the past research on FRP retrofits for reinforced concrete subjected to blasts. Wrapping the tension side of the slab with FRP is effective at increasing strength, reducing deflection, and capturing shrapnel. However, de-bonding is likely to occur. Anchoring the FRP significantly improves the effectiveness of the retrofit. Applying material to the blast-facing side of the slab improves the results even further, both by blunting the highest blast pressures and by providing confinement to the concrete. It seems that ideally an FRP-based retrofit for a blast-loaded concrete slab should

1) provide extensive anchorage of the FRP in order to utilize its full strength,

2) have some mitigation material on the blast side of the slab and

3) provide a high degree of confinement to the concrete. 


\section{RETROFIT DESIGN AND CONSTRUCTION}

\subsection{General Concept}

The objective when designing the retrofit for this research was that it be capable of withstanding a near-field blast with a scaled range of $1.0 \mathrm{ft} / \mathrm{lb}^{1 / 3}$, a challenging benchmark not reached by past research with FRP. The US Army Corps of Engineers Engineering Research and Development Center (ERDC) tested an unstrengthened reinforced concrete control slab at a scaled range of $0.35 \mathrm{ft} / 1 \mathrm{~b}^{1 / 3}$ and found that the slab was breeched catastrophically, with complete destruction of even the rebar cage in some regions, as shown in Figure 3-2.

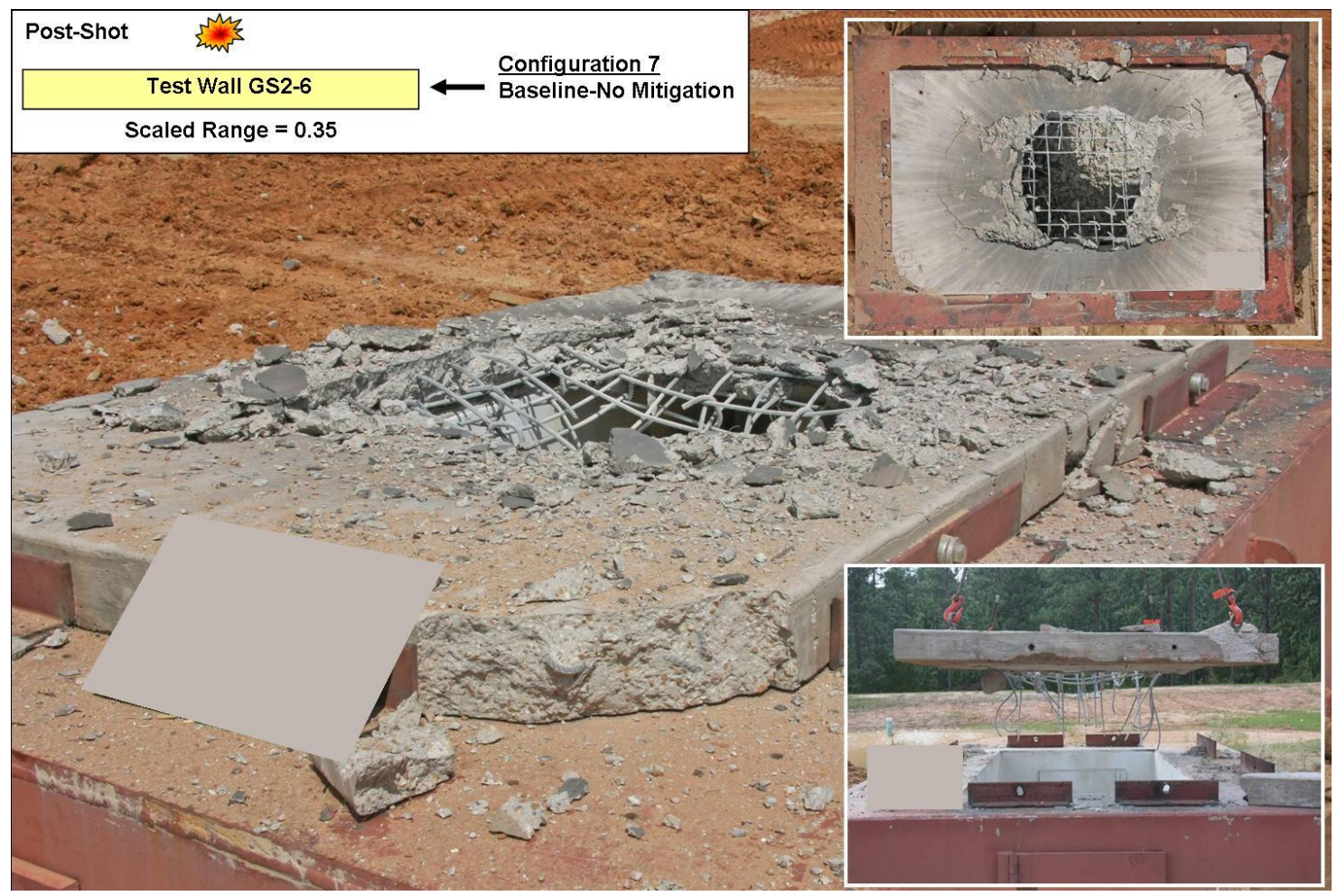

Figure 3-1 - Damage experienced in a past blast test of an un-mitigated concrete slab at $0.35 \mathrm{ft} / 1 \mathrm{~b}^{1 / 3}$ scaled range. Slab was exposed to a peak pressure over $50,000 \mathrm{psi}$ and catastrophic breaching of the slab occurred (Ray et al. 2011). 
Later tests found that the application of a $1 / 2$ in $100 \mathrm{ksi}$ steel plate to the blast face was not sufficient to maintain slab integrity. The steel plate was breeched and the concrete substrate was blown completely out of the rear of the slab, as can be seen in Figure 3-2. While the damage was reduced from the un-mitigated control slab, it seems that simple shielding on the front face of a slab is not sufficient at the severe pressures produced by such close blasts.

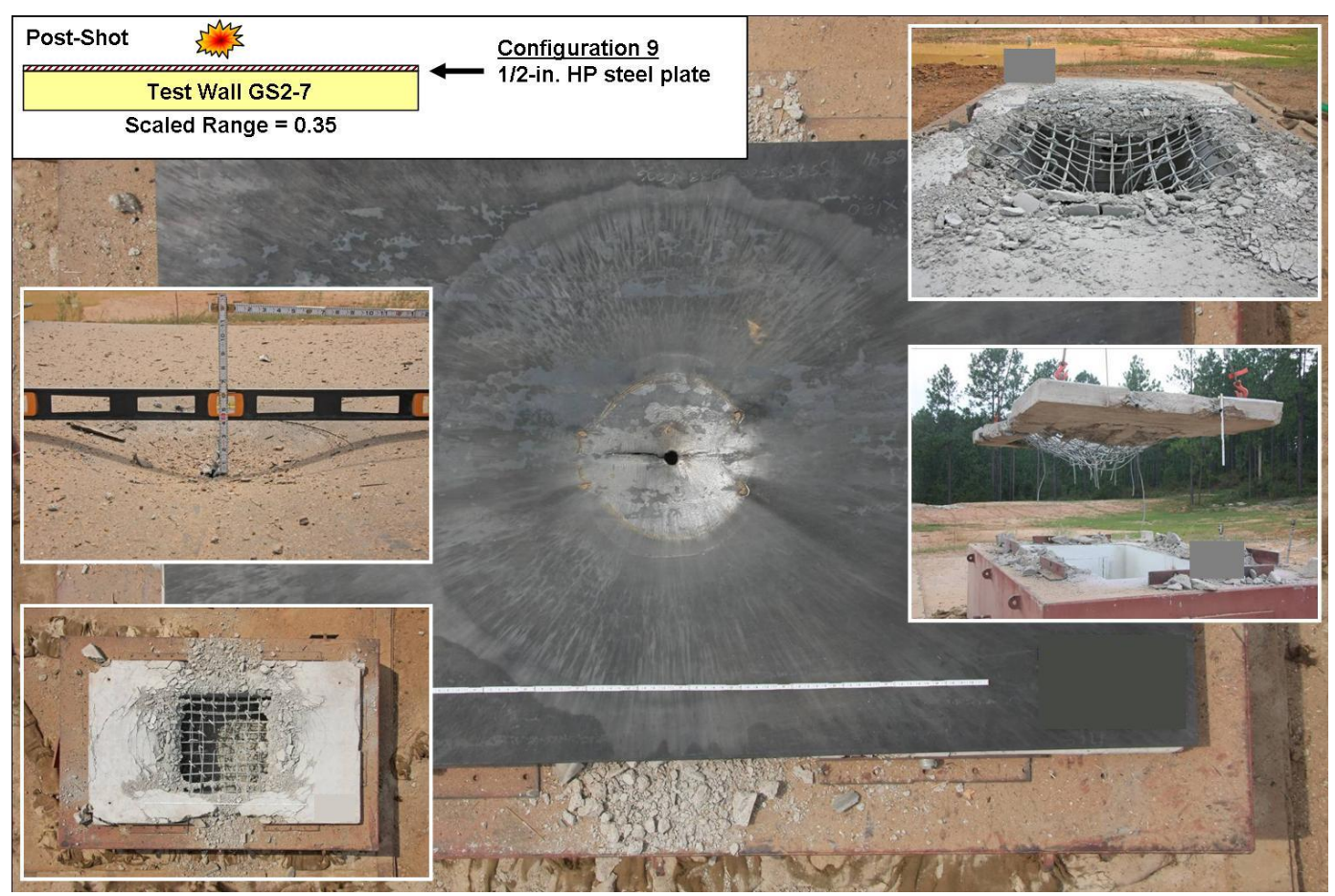

Figure 3-2 - Damage effects of a blast test of a strengthened concrete slab at 0.35 $\mathrm{ft} / \mathrm{lb}^{1 / 3}$ scale range. $1 / 2$ in $100 \mathrm{ksi}$ steel plate was placed on the blast face of the slab (Ray et al. 2011). Edited.

ERDC has also tested a system that may address the issue of concrete debris confinement. This system consisted of a $1 / 2$ in $100 \mathrm{ksi}$ steel plate on both sides of a concrete slab, bolted through at a regular spacing. This system was tested at a scaled range of 0.35 . As seen in Figure 3-3, relatively little damage occurred. Through a divot 
was left in the specimen and several bolt heads were sheared off, the slab was not breeched and the concrete remained confined.

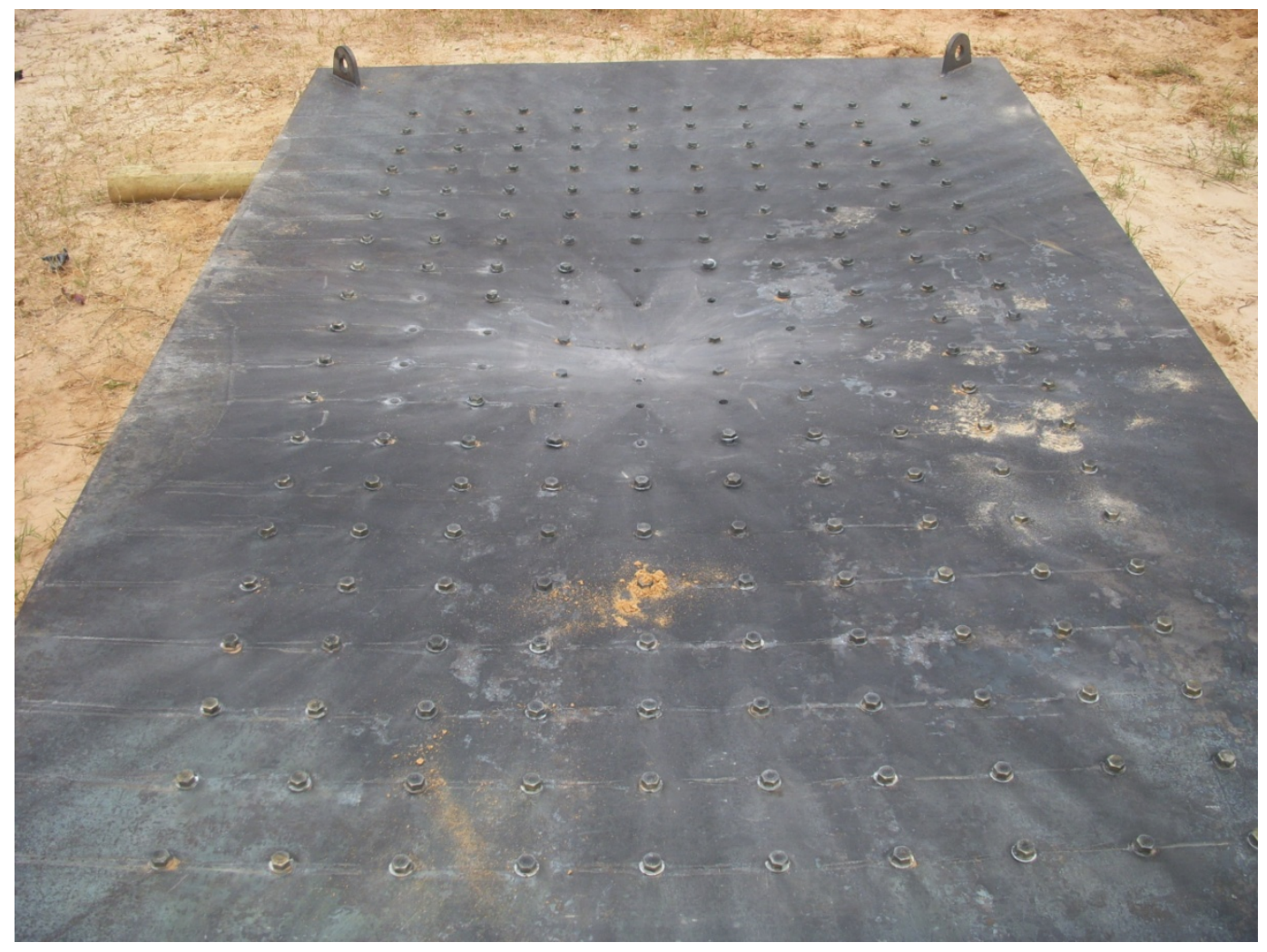

Figure 3-3 - Damage effects from a past blast test of a concrete slab with steel cladding on both faces through-bolted. Some bolt heads were sheared off, but the slab was not breeched and the concrete was confined.

The retrofit system designed for this research was based on combining successful systems tested by other research teams, with modifications meant to address known deficiencies. Dimensions and scale $(1 / 4)$ were adopted from the ERDC blasts tests discussed previously. The previous success of the ERDC test with steel bolted though on both faces of the slab shows that the slab can be mitigated to withstand the very close blast of 0.35 $\mathrm{lb} / \mathrm{ft}^{1 / 3}$ scaled range. However, the installation of heavy steel plates on the back side of the slab may not be feasible in all cases. There are many real-world applications where 
access issues make the installation of such a plate ( 2 in thick in the full scale), impractical or impossible. CFRP is both lightweight and very strong, making it an excellent option for the back face of the slab. Therefore, this research considered options such as FRP for the tensile face of the slab and a $1 / 2$ in thick $100 \mathrm{ksi}$ A514 steel plate on the compression face, as shown in Figure 3-4. CFRP was chosen for the tensile face due to the consistently good results achieved by previous researchers.

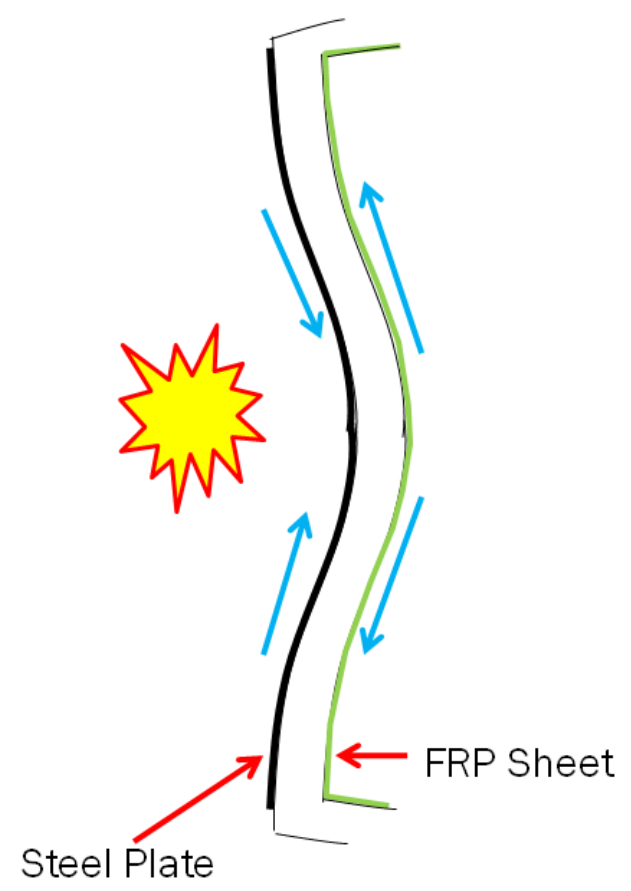

Figure 3-4 - Schematic view of reinforcing concept

Steel was chosen for the front face for three reasons. First, there are typically not access issues preventing the installation of plate on the exterior surface. Second, steel is less expensive than CFRP, so it makes sense to use it where practical. Finally, prior research 
suggests that steel is effective at protecting the concrete from the degredating effects of the blast while maintaining significant confinement.

\subsection{Selection of Composite Material}

Selecting a suitable FRP product is a major part of any retrofit involving such materials.

This can be a daunting task, as a huge variety of FRP products are available with a myriad of mechanical properties, sizes, and costs. Before selecting a product for this project, a set of criteria was established with which to evaluate each offering.

As discussed earlier in this chapter, past research found good results for a $1 / 4$ scale reinforced concrete slab strengthened with $1 / 2$ in thick $100 \mathrm{ksi}$ steel plates on both sides. Therefore, the strength criterion was to match that 50 kips/in strength for $1 / 4$ scale test, keeping in mind the retrofit should achieve a $200 \mathrm{kip} /$ in strength if constructed at full scale. Using a typical wet-layup product this would have required on the order of 30 layers, far too many to be practical. The very high strength requirement necessitated the use of pultruded FRP which, with its factory controlled fiber to epoxy ratio and very high ultimate strength, could be applied in only a few layers.

Selecting appropriate dimensions was complex. For a full scale retrofit, the quantity of FRP required may be many hundreds or thousands of square feet. This is enough that many manufacturers are willing and able to produce custom CFRP products, both of the pultruded and wet-layup varieties. Cross sections with up to 6 square inches of material are possible in custom runs, with lengths as long at $1000 \mathrm{ft}$. However, for this single $1 / 4$ scale test, the lack of economy of scale limited choices to the commercially available, 
non-custom options. It was important that the size chosen be available in quadruple dimensions, at least in custom batches.

The nation of origin was also considered. As many of the applications for this technology are defense related, a domestic supplier of material was preferred. Finally, suitability for mechanical anchoring was desired. A representative sample of commercially available pultruded CFRP products can be seen in Table 3-1.

Table 3-1- Comparison of mechanical properties of five pultruded FRP products

\begin{tabular}{ccccccc}
\hline Product & Domestic & $\begin{array}{c}\text { Tensile } \\
\text { Strength } \\
\text { (ksi) }\end{array}$ & $\begin{array}{c}\text { Tensile } \\
\text { Mod. } \\
\text { (ksi) }\end{array}$ & $\begin{array}{c}\text { Thickness } \\
\text { (in) }\end{array}$ & $\begin{array}{c}\text { Width } \\
\text { (in) }\end{array}$ & $\begin{array}{c}\text { Layers } \\
\text { required } \\
\text { in 1/4 } \\
\text { scale }\end{array}$ \\
Sika CarboDur & Yes & 406 & 23900 & 0.047 & $\begin{array}{c}\text { up to } \\
4\end{array}$ & 2.61 \\
$\begin{array}{c}\text { CST Composites } \\
\text { Structural Laminate }\end{array}$ & No & 450 & 30000 & 0.157 & 6 & 0.71 \\
$\begin{array}{c}\text { Excell Composites } \\
\text { Extens }\end{array}$ & No & 725 & 35900 & 0.157 & 12 & 0.44 \\
$\begin{array}{c}\text { Strongwell } \\
\text { Safstrip }\end{array}$ & Yes & 121 & - & 0.125 & 4 & 3.31 \\
$\begin{array}{c}\text { Glasforms } \\
\text { CFRP }\end{array}$ & Yes & 400 & 24000 & 0.047 & 3.94 & 2.65 \\
\hline
\end{tabular}

For this project Sika brand CarboDur pultruded CFRP, seen in Figure 3-5, was selected. This material is 0.047 in thick and is available in widths of up to 4 in, in spools as long as $800 \mathrm{ft}$. These dimensions are such that a 4 times larger version could be created if custom ordered. The strength of the material is among the highest available domestically. Three layers were required to achieve $50 \mathrm{kip} /$ in strength for the $1 / 4$ scale test. Similarly, just three layers could be used in full scale, with each layer being scaled up . Since this application requires strength in both directions in plane with the slab surface, a total of 6 layers of 
FRP were used, 3 in each direction, shown schematically in Figure 3-6. At construction time, epoxy was applied between each layer.

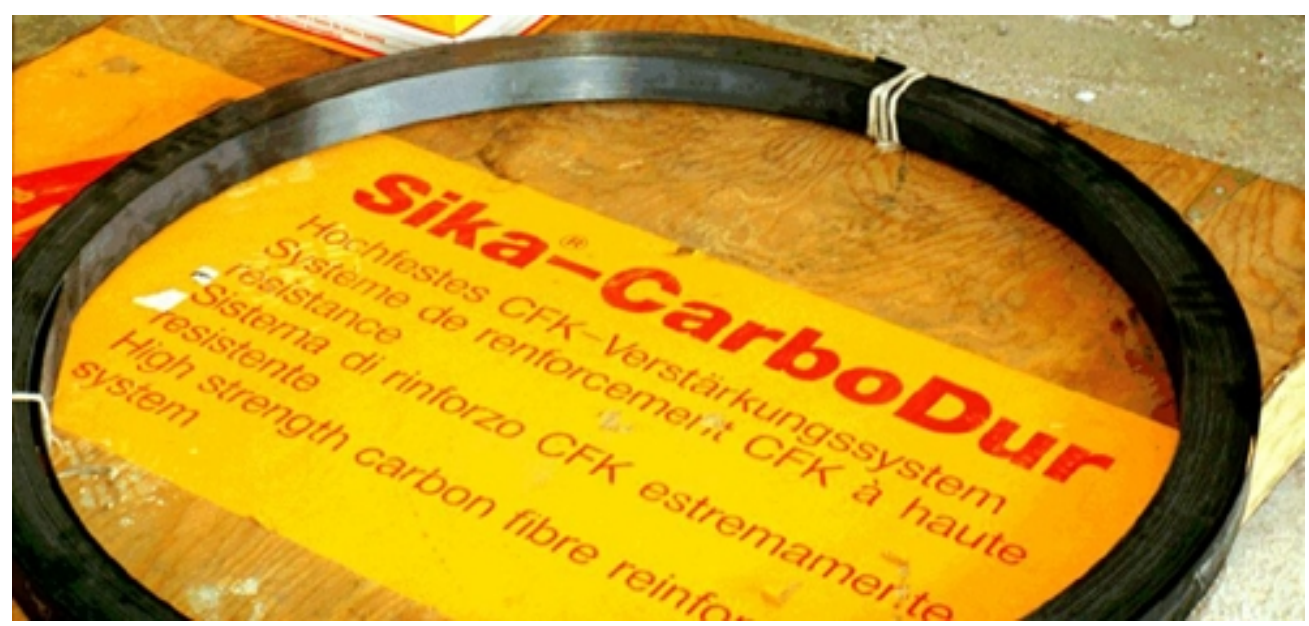

Figure 3-5 - Sika CarboDur CFRP strengthening material

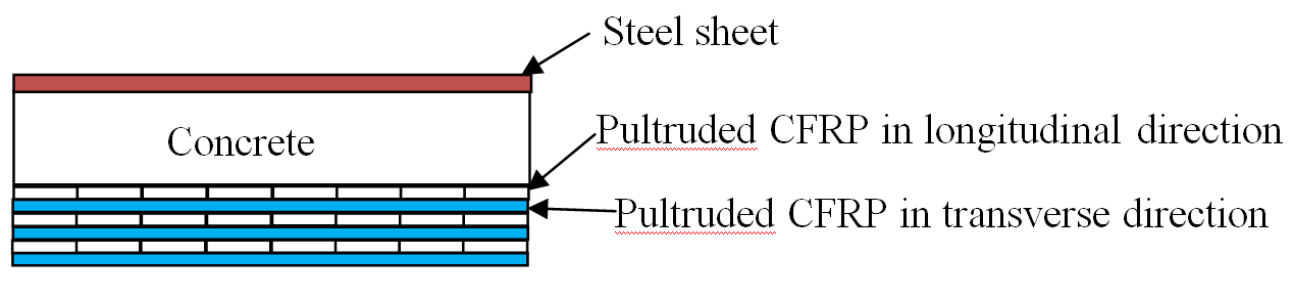

Figure 3-6 - Schematic of FRP and steel reinforcing scheme

\subsection{Selection and Design of Anchors}

Many researchers have found that CFRP sheets will delaminate from the concrete substrate if anchoring is not provided. Since thorough confinement of the concrete is also a goal, the design needed to firmly anchor the steel plate to front of the slab and CFRP to the back. An anchor spacing of 3 in on center in each direction was chosen to match the 3 in width of the pultruded CFRP strips. Furthermore, the anchor design needed to distribute the bolt normal force over a wider area. This was accomplished by using mechanical C-clamps similar to those used by Orton et al. (2011). 
Holes were drilled completely through the thin dimension of the slab, steel plate, and CFRP, as seen in Figure 3-7. A steel channel section was placed over the CFRP. Channel was used instead of a simple plate to provide additional bending strength in the anchor, thereby more effectively distributing the normal force from the bolt. The channel size used was 1.5 in wide with 0.5 in legs and a 0.125 in thick web. This size was chosen as it is very close to a $1 / 4$ scale of the commercially mass produced American Institute of Steel Construction (AISC) standard structural C-section C6x13. After placement of the drilled channel, a bolt was passed through the entire assembly. These bolts were tightened with an impact driver before the adhesive epoxy had cured. This normal force helped to drive the epoxy into void spaces, creating a more monolithic bond.
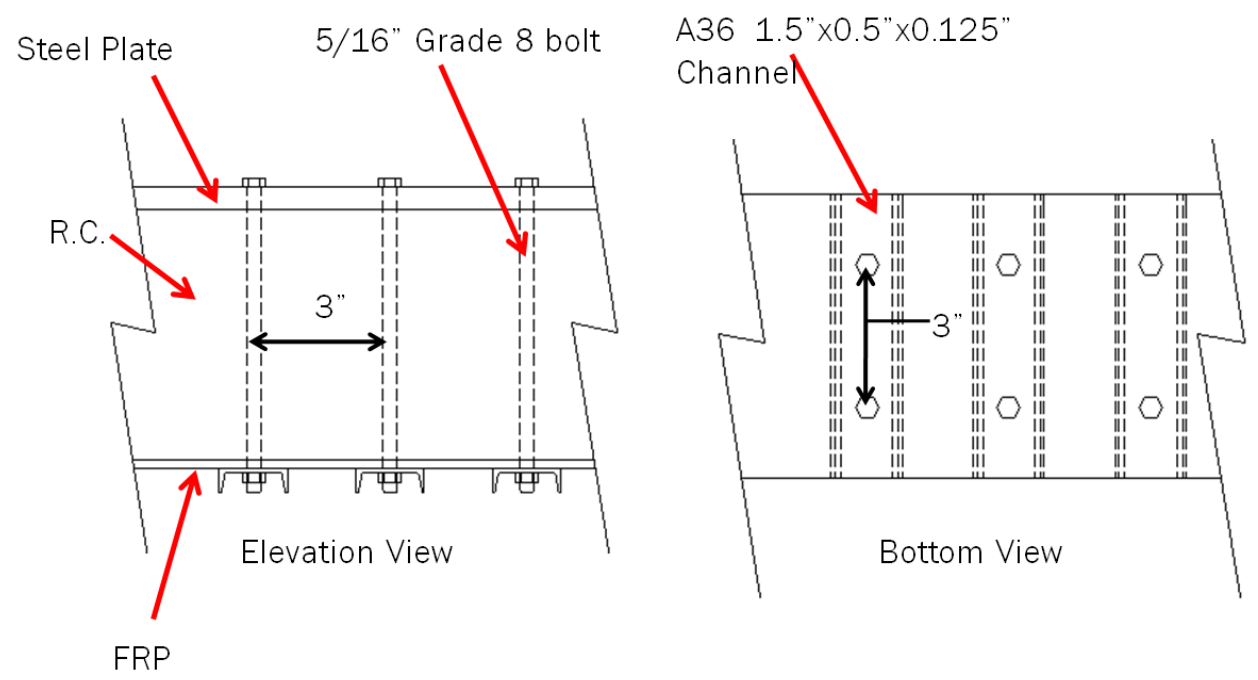

Figure 3-7 - Anchor schematic. The channel size used represents a $1 / 4$ scale of a readily available structural shape. 


\subsection{Summary of Final Design}

The test specimen for this research was designed at $1 / 4$ scale. As this was a preliminary test in preparation for a blast study, only a 6 in wide section of slab was tested, representing two consecutive rows of anchors. The width of the specimen was limited by the available test fixtures. A wider specimen would have presented challenges in developing sufficient load to test to failure. The overall behavior and strength per unit width should be consistent with a wider slab. The specimen was 5.5 in deep by $10 \mathrm{ft}$ long. It was reinforced with $2 \# 3$ bars of tension steel and 2 \#3 bars of compression steel, each $1 / 2$ in in from the concrete face. 4000 psi concrete was used.

As the specimen represented a portion of a slab it did not have stirrups such as beam would. Instead \#3 bars were tied in the transverse direction every 4 in throughout the length of the specimen. A $1 / 2$ in thick $100 \mathrm{ksi}$ A514 steel plate was attached to the compression face of the slab, with pultruded CFRP sheets epoxied to the tension face. The CFRP used was Sika Carbodur structural strengthening material, a pultruded laminate 0.0472 in thick and 3.15 in wide. Nominal tensile strength of the material was 19.2 kips per in width. For this test six layers of the material were used. 3 layers were placed in the longitudinal direction and 3 in the transverse direction to add transverse strength to the slab and splitting resistance in the longitudinal CFRP.

To fully anchor the CFRP, 5/16 in diameter grade 8 bolts, were inserted through the steel plate, concrete slab, and CFRP. These bolts were placed 3 in on center in each direction. In order to distribute the bolt normal force to as much of the CFRP as possible, c-channel anchors were used, as seen in Figure 3-7. A schematic elevation view of the specimen can be seen in Figure 3-8. 


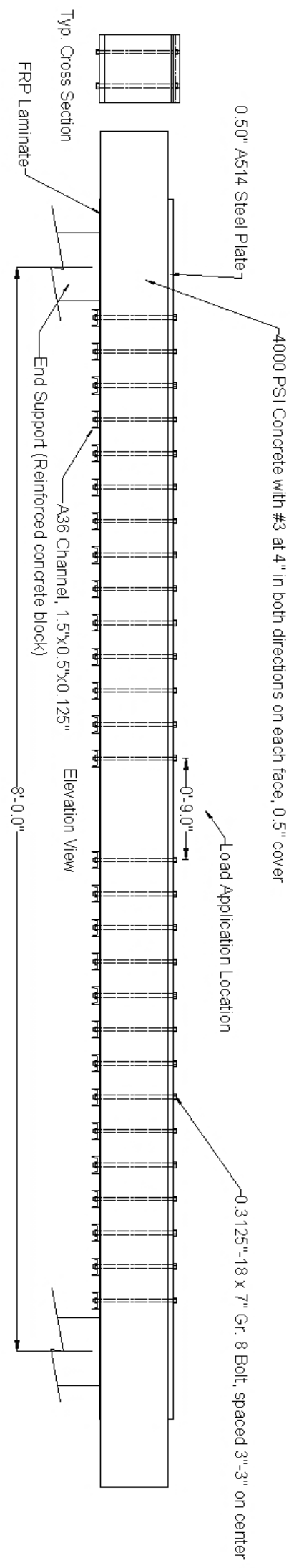

Figure 3-8 - Specimen Elevation View 


\subsection{Specimen Construction}

Initial construction of the specimen was fairly typical. Plywood formwork was

constructed, and rebar mats were tied using standard methods. However, special

measures were taken in preparation for installation of the 60 anchor bolts. Due to the tight tolerances of a $1 / 4$ scale specimen, it was necessary to preserve a path through the slab for the predetermined bolt layout.

A sheet of commercial pegboard with holes 1 in $\mathrm{x} 1$ in on center was placed in the bottom of the formwork, with unneeded holes taped off to obtain a 3 in by 3 in grid, the same as the intended spacing of the bolt-anchors. $1 / 4$ in wooden dowels were inserted into these holes, as seen in Figure 3-9. After the concrete was poured and had cured for seven days, the dowels were driven out with a punch. A rotary hammer drill was then used to enlarge the holes to $1 / 2$ in.

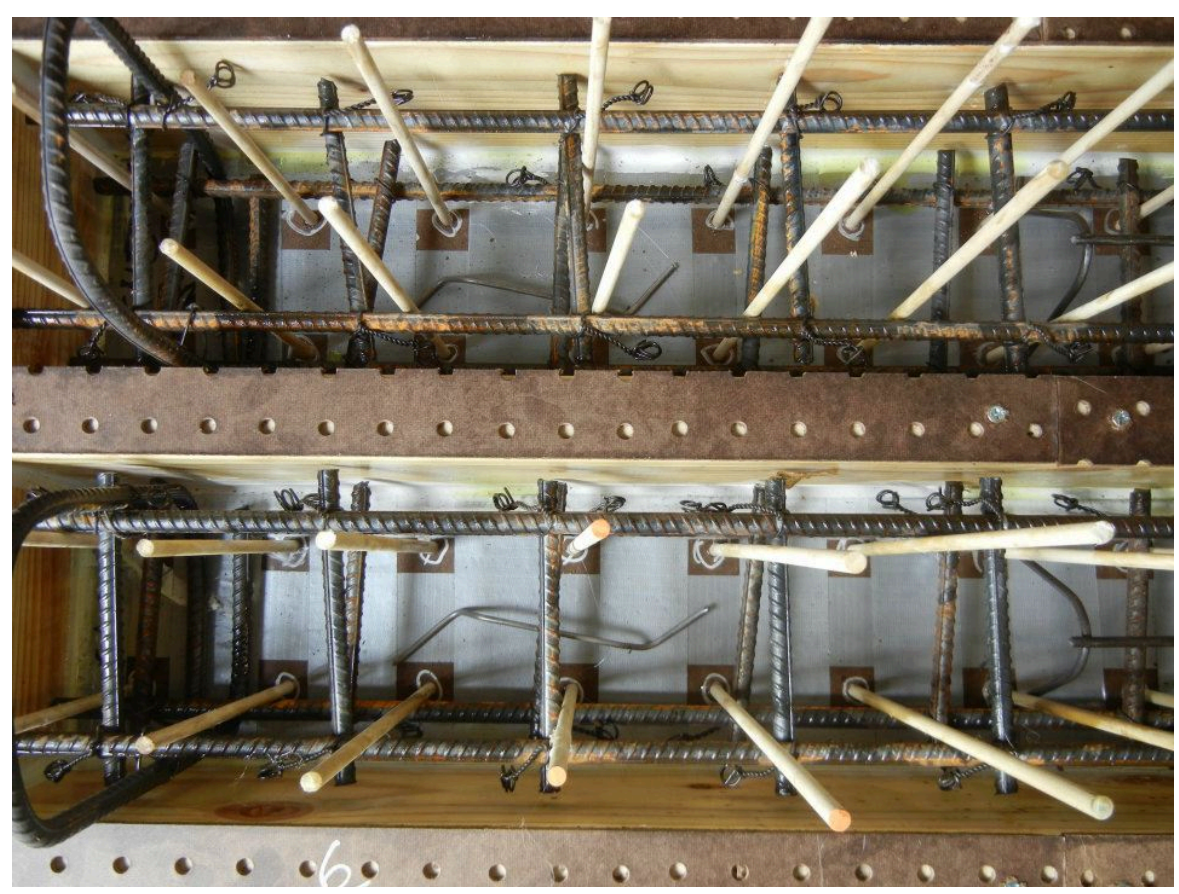

Figure 3-9 - Slab specimen formwork immediately before pouring concrete. Wooden dowels were used to leave voids which would later be drilled out for the anchor bolts. 
The design required us to drill many holes both through $100 \mathrm{ksi}$ A514 steel and through pultruded CFRP.

Working with the CFRP material required careful technique. Pultruded CFRP was found to splinter excessively during cutting with a shearing tool like tin snips, or a coarse saw such as a hacksaw. Much greater success was had with an abrasive cutting tool. Rough cutting was done with a pneumatic cut-off tool. More precise cuts were achieved with a diamond-carbide wheel on a table saw.

Drilling bolt holes through the FRP was more challenging still. As recommended by industry experts, an annular cutting tool was used for this task. Seen in Figure 3-10, this tool possesses a circumference of cutting teeth and was originally intended for sheet metal work. However, due to the very low shear strength of the FRP material, the cutting tool had a high tendency to wander, even on a drill press.

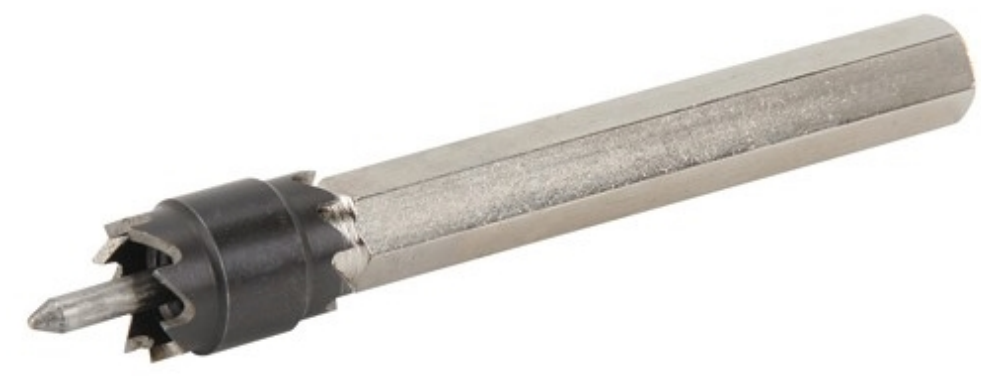

Figure 3-10 - Annular cutter used to drill CFRP. CFRP was found to very rapidly dull, overheat, and clog cutting tools.

Once all components, including the $60 \mathrm{C}$-channel anchors, steel plate, concrete slab, and over 100 pieces of FRP had been drilled, the entire assembly was dry fit to insure the bolts would slide quickly into place once epoxy had been applied. On assembly day, each piece of FRP was given a coat of Sikadur-30 two part epoxy paste with a "roof-shaped" 
spatula to a nominal thickness of $1 / 16$ in, per the manufacturer's recommendations. All components were assembled, and the bolts were placed through the slab. The bolts were tightened before the epoxy set-up, driving the epoxy into void spaces and creating a more monolithic bond. The final assembly process, shown in Figure 3-11, was completed in less than one hour.

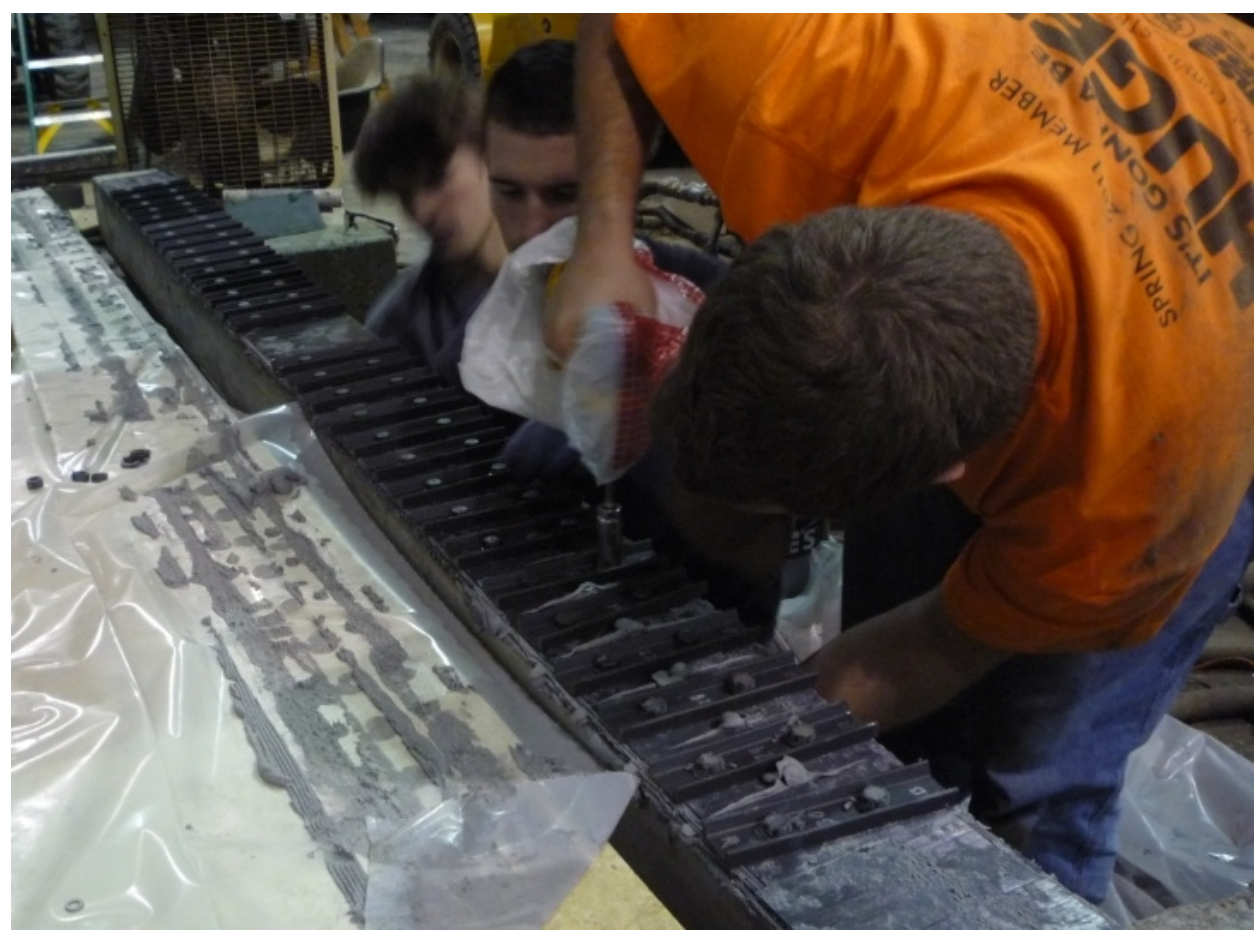

Figure 3-11 - Assembly of test specimen 


\section{EXPERIMENTAL SETUP}

\subsection{Test Fixture}

As near-field blast loads are roughly similar to a point load, the slab specimen was tested in three point bending on a laboratory strong floor. A schematic diagram of the test fixture can be seen in Figure 4-1. Reinforced concrete reaction blocks were placed at a clear spacing of $8 \mathrm{ft}$. To prevent concrete crushing at the reaction surfaces, hard rubber bearing pads with a thickness of 0.5 in were placed between the slab specimen and the reaction blocks.

At the centerline of the $8 \mathrm{ft}$ span a structural steel load frame was erected. This consisted of two columns pinned to the strong floor at the base and connected to a cross beam. A 170 kip hydraulic ram was suspended from this load frame. The ready-to-test specimen and test fixture can be seen in Figure 4-2.

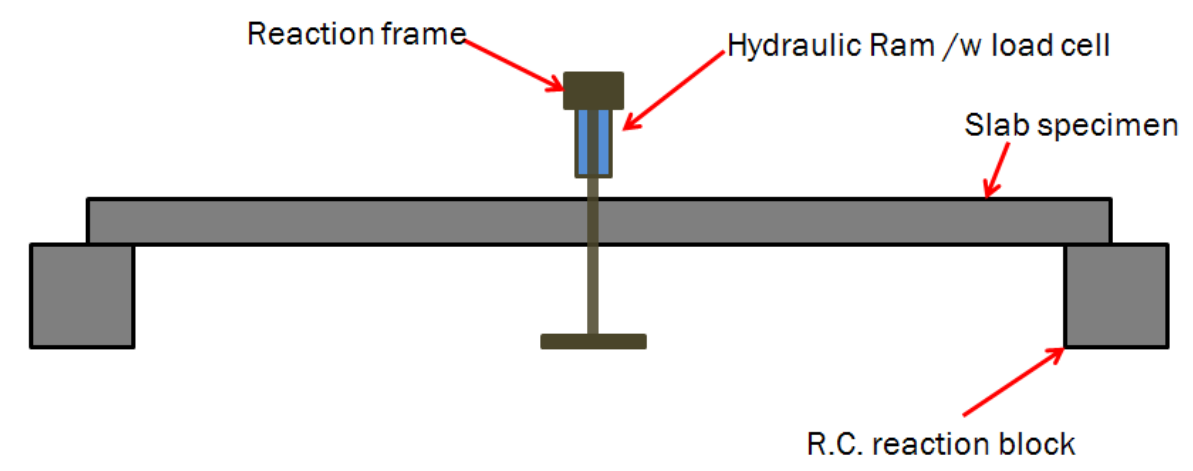

Figure 4-1 - Schematic Diagram of Test Fixture 


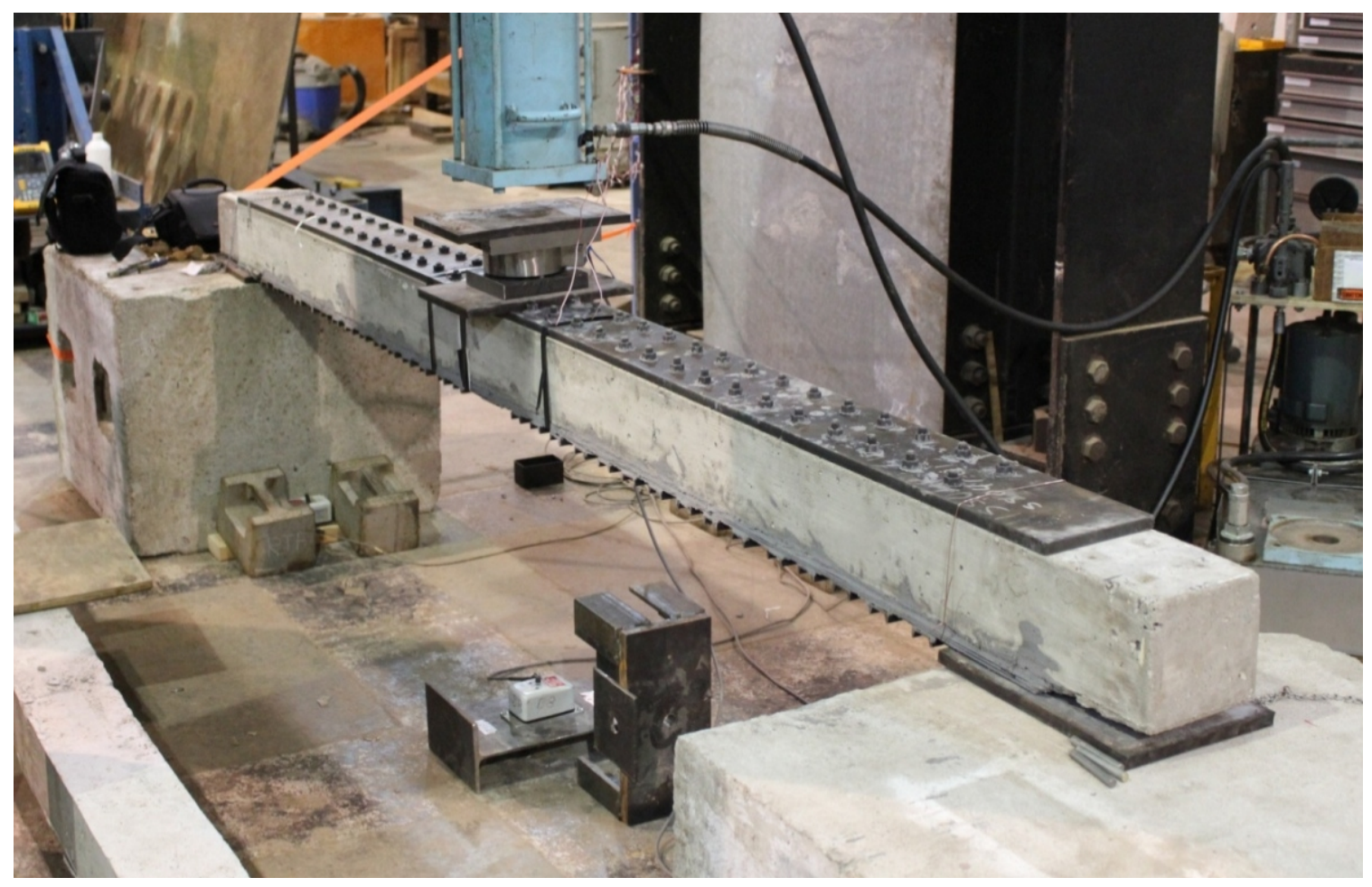

Figure 4-2 - Test specimen and fixture immediately before testing.

\subsection{Instrumentation}

Thorough instrumentation was employed in order to obtain a variety of strain, deflection, and load readings. Eight strain gages, three string potentiometers, and one load cell were connected to a computer controlled data acquisition system running Texas Instruments LabView measurement software, shown in Figure 4-3. Data was recorded directly to a computer hard drive for long-term storage and future analysis. A fixed-position video camera also recorded the test. The video footage was later used frame-by-frame to supplement the deflection instrumentation (see section 4.3 - Reconstruction of Lost Deflection Data). Still photography was used extensively to document the failure mechanisms and specimen behavior during and after the test. 


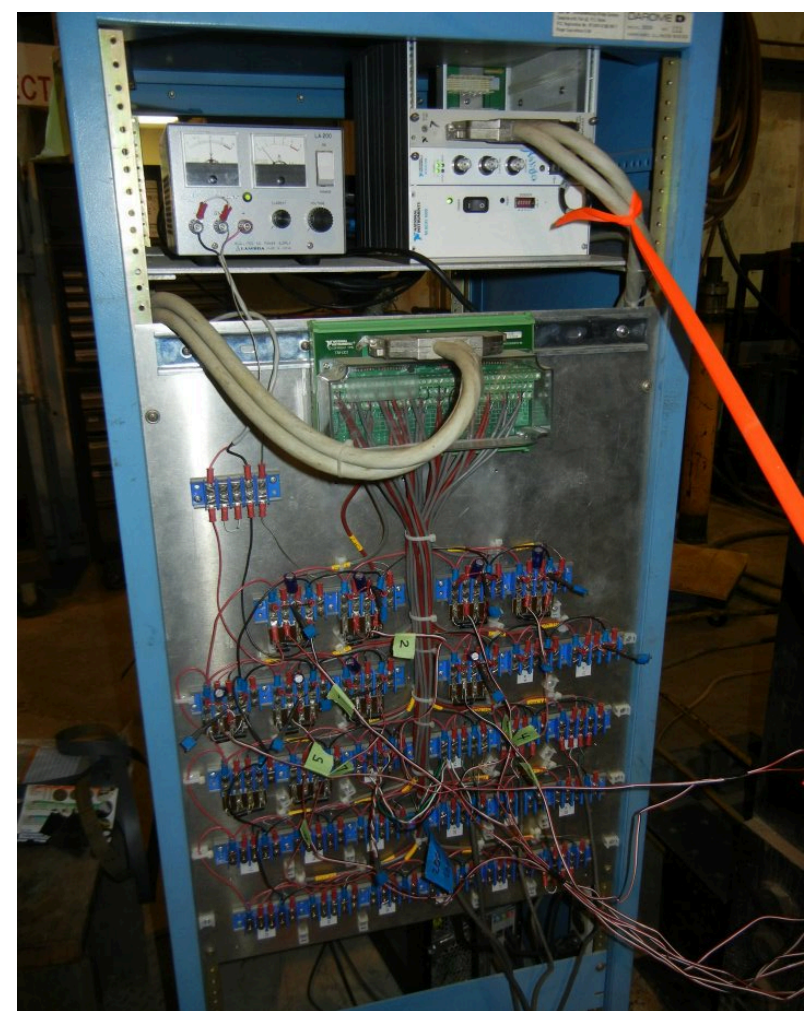

Figure 4-3 - Data acquisition system showing power supply, data acquisition cards, strain gage completion bridges, and connection points for all sensors.

In order to capture the load carried by the specimen, a 200kip low-profile pancake style load cell was placed directly below the hydraulic ram at midspan. The load cell was calibrated using original factory calibration values which were verified on a $10 \mathrm{kip}$ hydraulic testing machine. Steel bearing plates were placed above and below the load cell to ensure that the load was applied to the proper region of the instrument. These plates were topped with 0.5 in thick rubber bearing pads to prevent slipping and make sure of even load application. This configuration can be seen in Figure 4-4. 


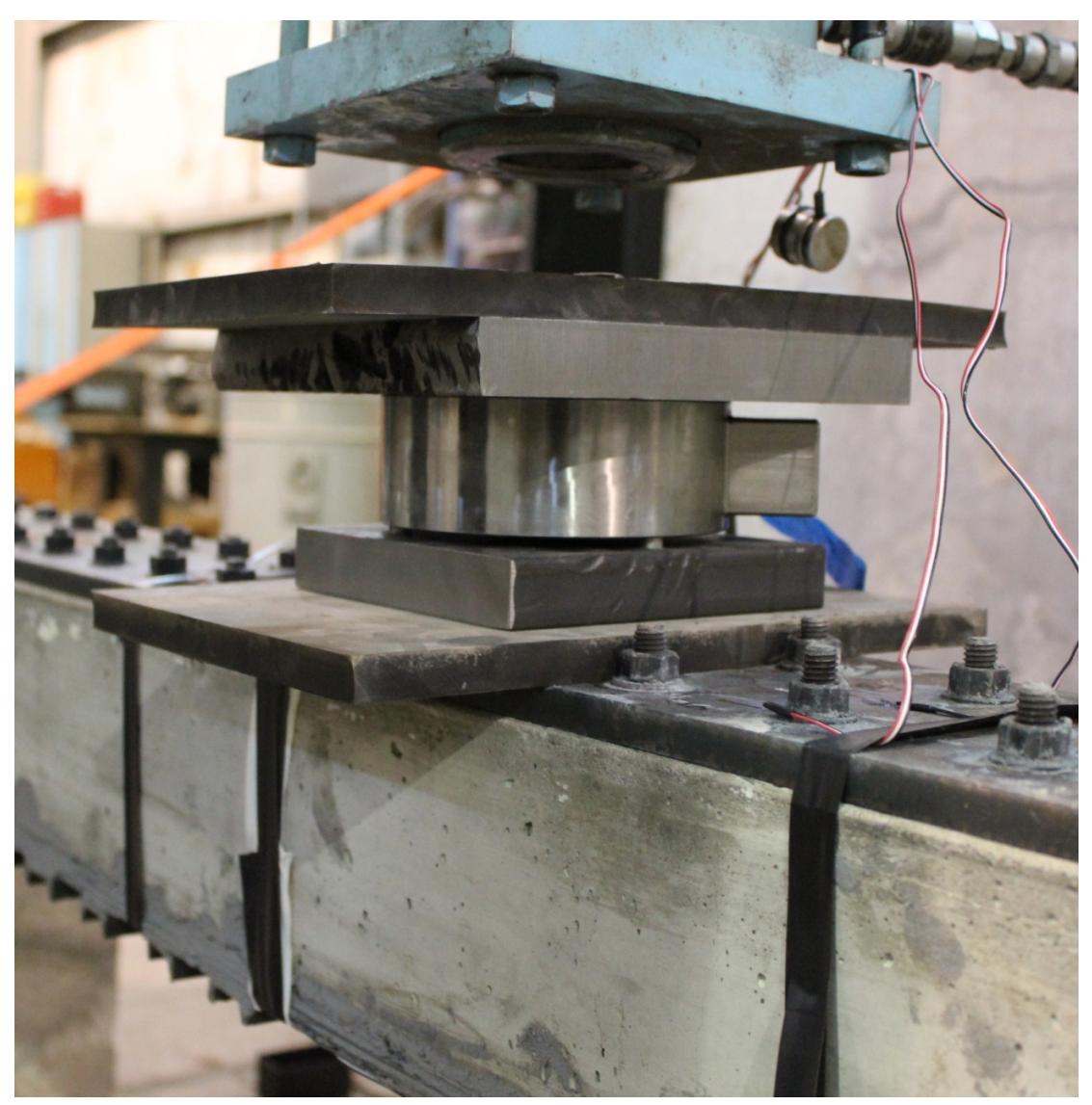

Figure 4-4 - Load cell configuration. Steel plates ensure the load is distributed to the intended area of the load cell. Rubber bearing pads guarantee even load application and prevent slipping.

To measure the specimen displacement, a total of three ten-turn string potentiometer deflection gages were installed: one at the midspan of the specimen and one at each end support. Because rubber bearing pads were used under each slab ends to prevent concrete crushing, it was necessary to monitor the deflection at the end supports. By subtracting the end deflection from the midspan deflection, a net deflection could be calculated.

Material strains were measured by 350-ohm electro-resistive Vishay strain gages. Gages were applied in accordance with the relevant Vishay installation guides, and used in a 
quarter-bridge configuration. Strain measurements were taken at eight locations, all near midspan.

Two longitudinal and two transverse gages were placed on the outermost layer of longitudinal CFRP. Since transverse FRP was installed over the outermost longitudinal layer, a high speed cutting tool was used to move a small section of the transverse layer. An additional two gages were installed in line with the bolt line on the steel plate, with a final two gages between the bolt lines on the steel plate. All steel gages were placed in the longitudinal direction. The CFRP gages are shown in Figure 4-5. The steel gages are shown in Figure 4-6.

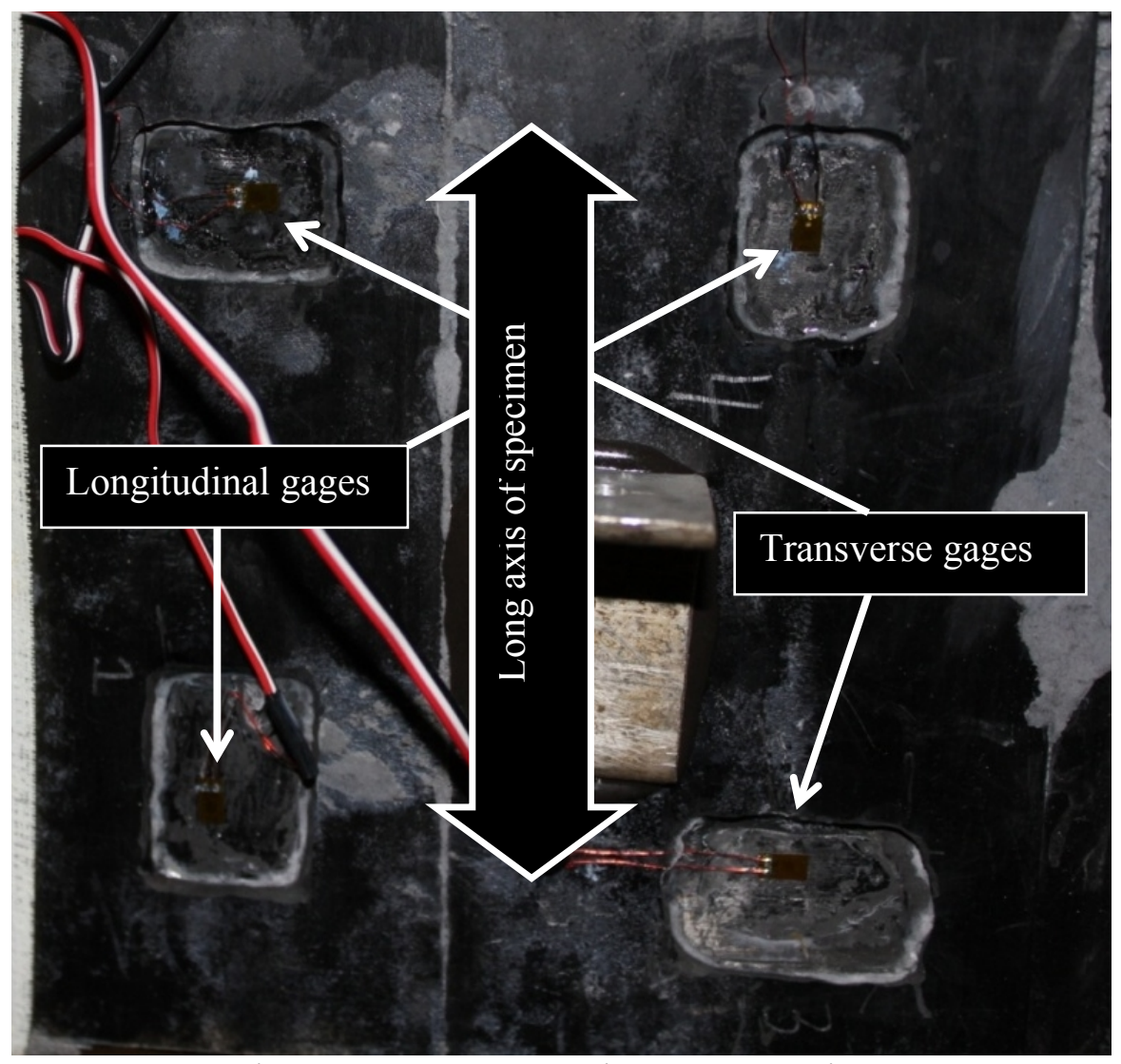

Figure 4-5 - CFRP Strain Gage Locations 


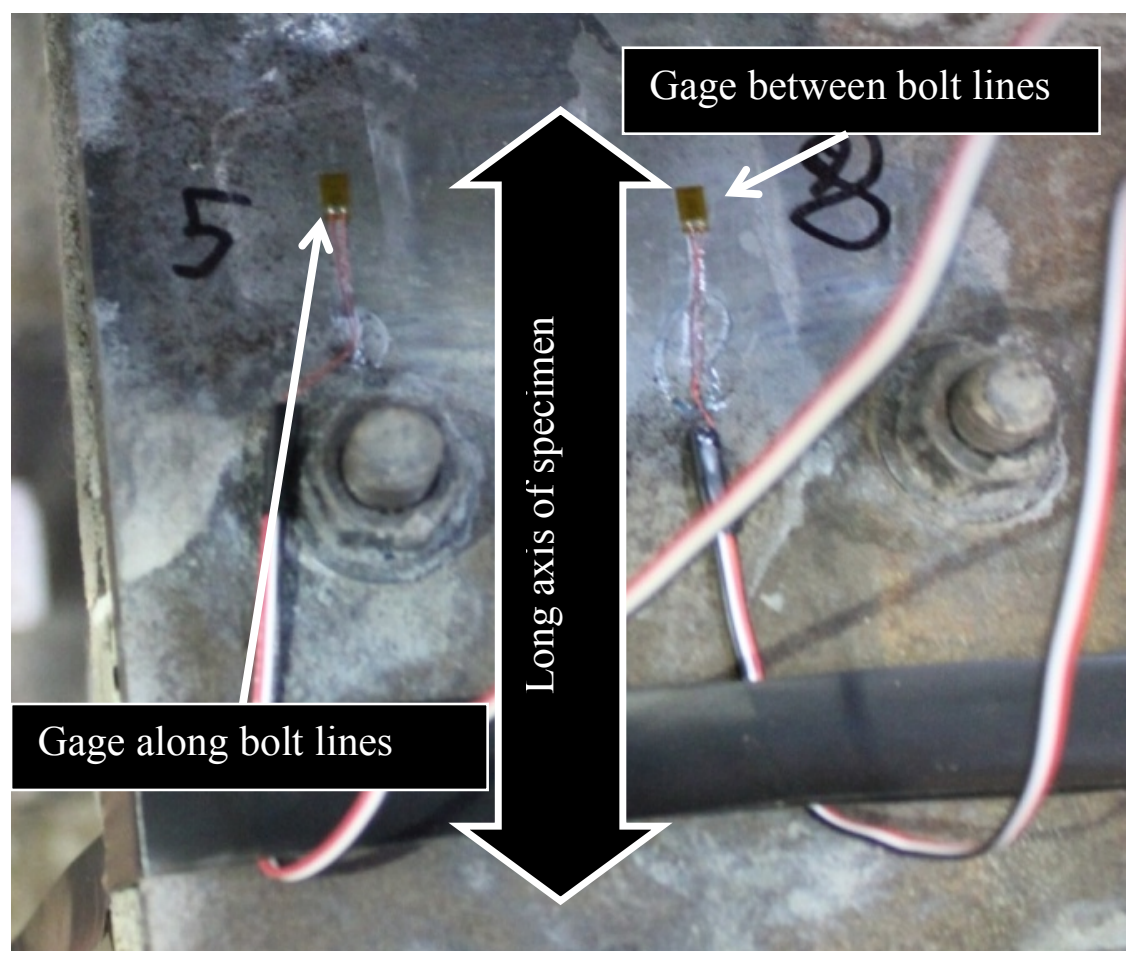

Figure 4-6 - Steel Strain Gage Locations

\subsection{Reconstruction of Lost Deflection Data}

During the tests there were several violent fractures of the CFRP which ejected sizeable fragments at high velocity. Early in the test one of these fragments was ejected from beneath the attachment point of the midspan string potentiometer. This caused the string potentiometer cable to detach, leaving us with the incorrect deflection plot shown in Figure 4-7. In order to overcome this, deflection data was reconstructed from video footage. 


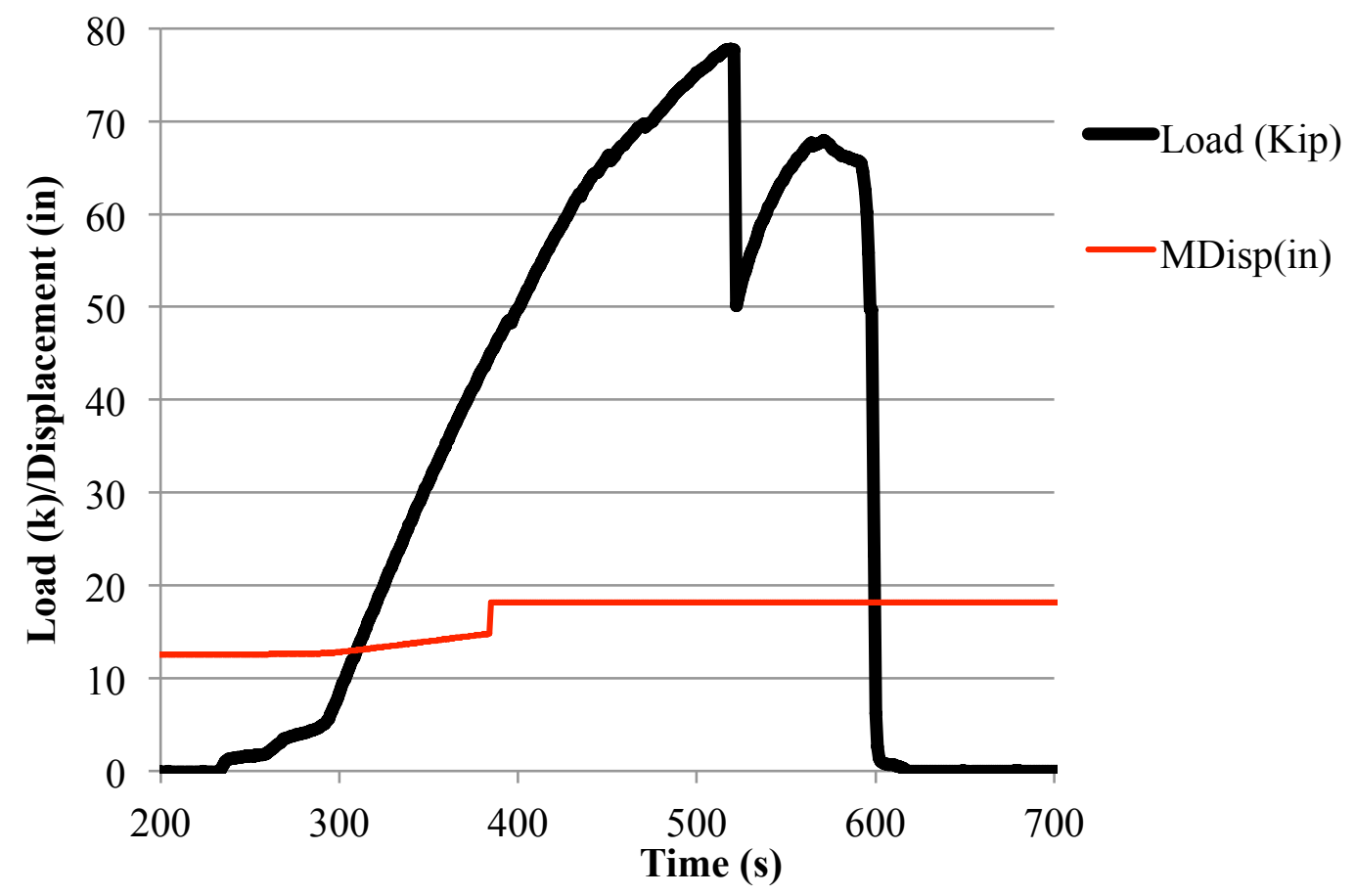

Figure 4-7 - Raw load and deflection vs. time

Video editing software was used to zoom in on a moving reference point on the slab while while keeping a fixed reference point in the background in frame. A measurement in pixels pixels of the slab location was taken at 8 different times while string potentiometer data was still present. A relationship was then developed between displacement in pixels as observed on the video monitor, and displacement in inches as recorded by the string potentiometer. This relationship is plotted in

Figure 4-8. The $\mathrm{R}^{2}$ value was found to be 0.9993 , indicating a very strong correlation.

This relationship was used to fill in the missing string potentiometer deflection data with that gathered from the video footage. 


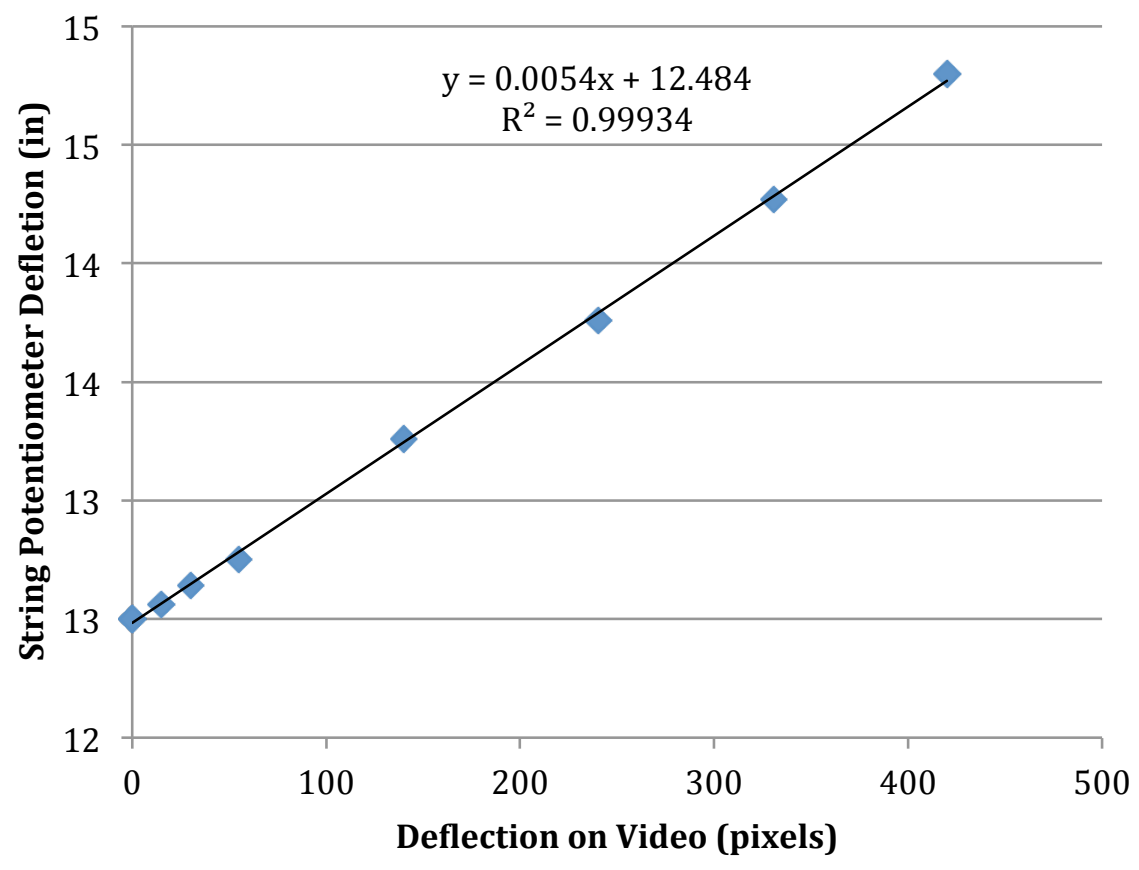

Figure 4-8 - String potentiometer deflection vs. video deflection. 


\section{RESULTS AND DISCUSSION}

During testing the slab achieved a maximum load of 77.6 kips (1800 kip-in moment) and a peak deflection of around 5 in before first fracture of the CFRP. This deflection exceeded initial expectations and therefore required unloading the slab during the test and adding shims below the ram before resuming of loading. As loading continued, periodic CFRP fractures occurred until a defection of around 7 in was reached, at which time rapid and extensive fracture of the CFRP severely compromised the load carrying capacity of the slab. The resultant load-deflection plot can be seen in Figure 5-1.

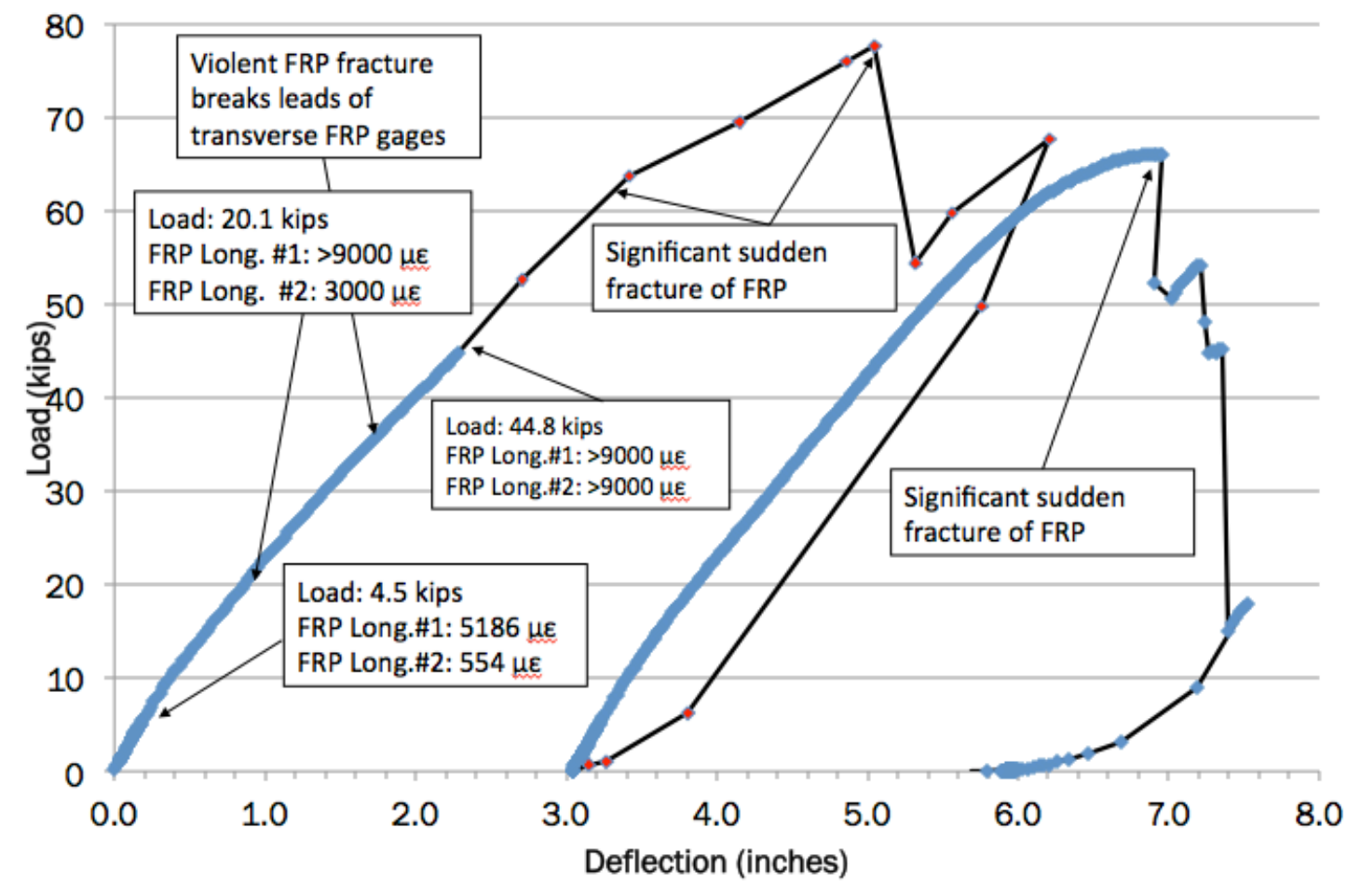

Figure 5-1 - Load/Deflection plot for the test. Unloading was required to add additional deflection to the ram. 
Strain data was recorded by gages on the face of the steel compression plate and on the face of the tensile CFRP. The measured strains suggest that slipping may have occurred. There was almost a tenfold difference in the slope of the stain versus load plot between the two gauges on the two longitudinal strips of CFRP in the outermost layer. The strip under lesser strain may have been slipping at the ends permitting it to shed load to other layers. However, both strips of CFRP reached about $9000 \mu \varepsilon$, which is near the maximum elongation of the material. The hypothesis that slipping reduced the strains in the CFRP is supported by the observation that the strip of CFRP showing reduced strains also showed substantially more slipping upon physical inspection post-test. Strain gages in the transverse direction (cross) showed little strain throughout the test. This indicates that there was little distribution of load across the CFRP strip.

The strain on the steel plate at maximum load was approximately $4000 \mu \varepsilon$, greater than the approximately $3500 \mu \varepsilon$ yield strain of $100 \mathrm{ksi}$ steel. This indicates that the steel was yielding in compression at the maximum load. A plot of the strain readings can be seen in Figure 5-2. 


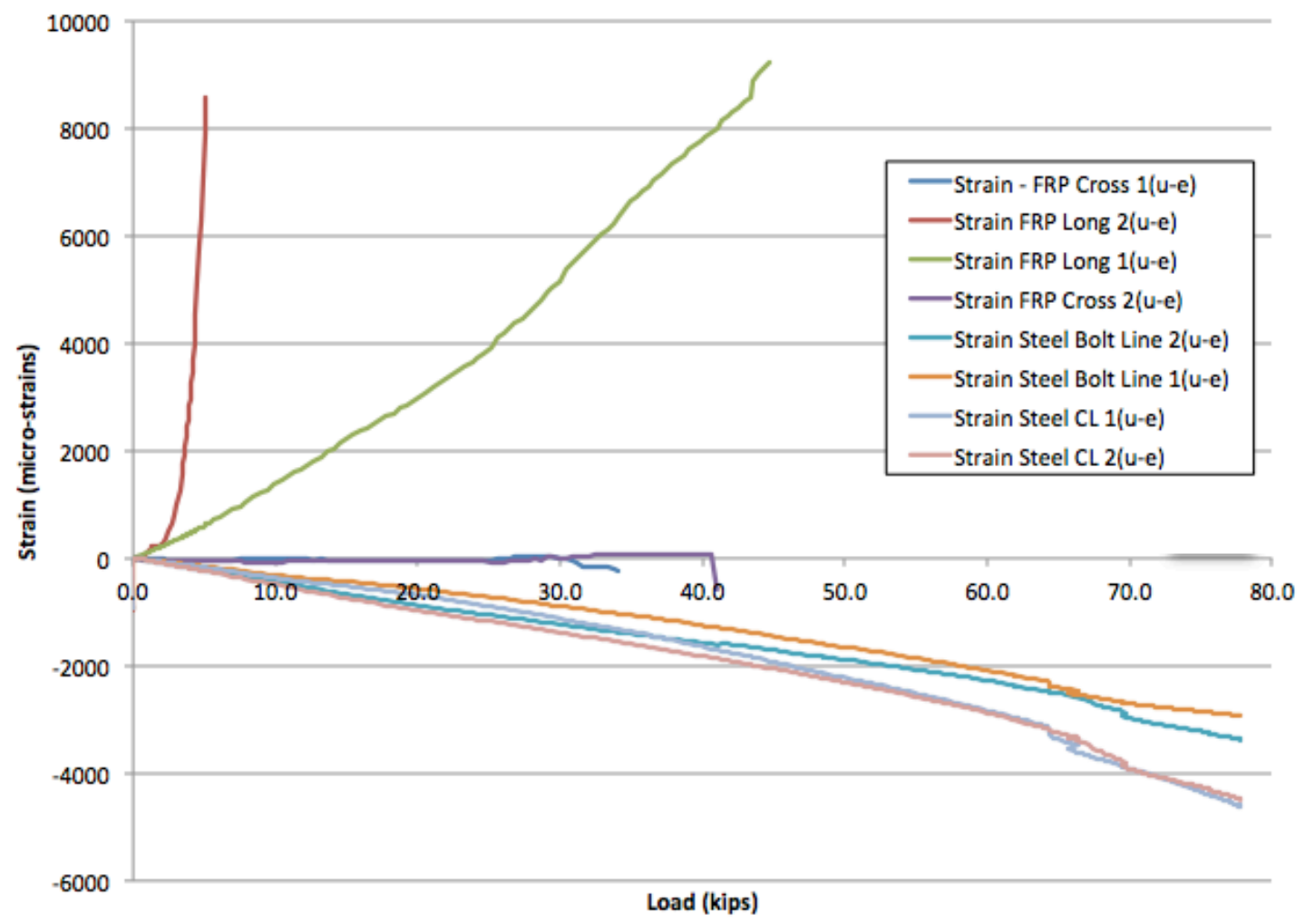

Figure 5-2 - Plot of recorded strains vs. load. Termination of FRP strain readings occurred when violent fiber fracture severed data acquisition leads or at $\sim 9000$ microstrains, the upper measurement limit of the strain gauges.

The measured maximum load capacity of the specimen, 77.8 kips, agrees well with an idealization of the steel plate and FRP layers as a simple moment couple. However, the deflection of the specimen greatly exceeded expectations, Figure 5-3. This may be due to slipping of the CFRP, of which there is extensive evidence. This slipping would have manifested in the shedding of substantial strains before finally accumulating the design load. As can be seen in Figure 5-4, much of the CFRP split down the long axis of the specimen at the hole locations. This permitted portions of the CFRP to slip relative to the concrete and other FRP fibers. Slipping on the order of 1 in was observed at the ends of the slab after the test, Figure 5-5. 


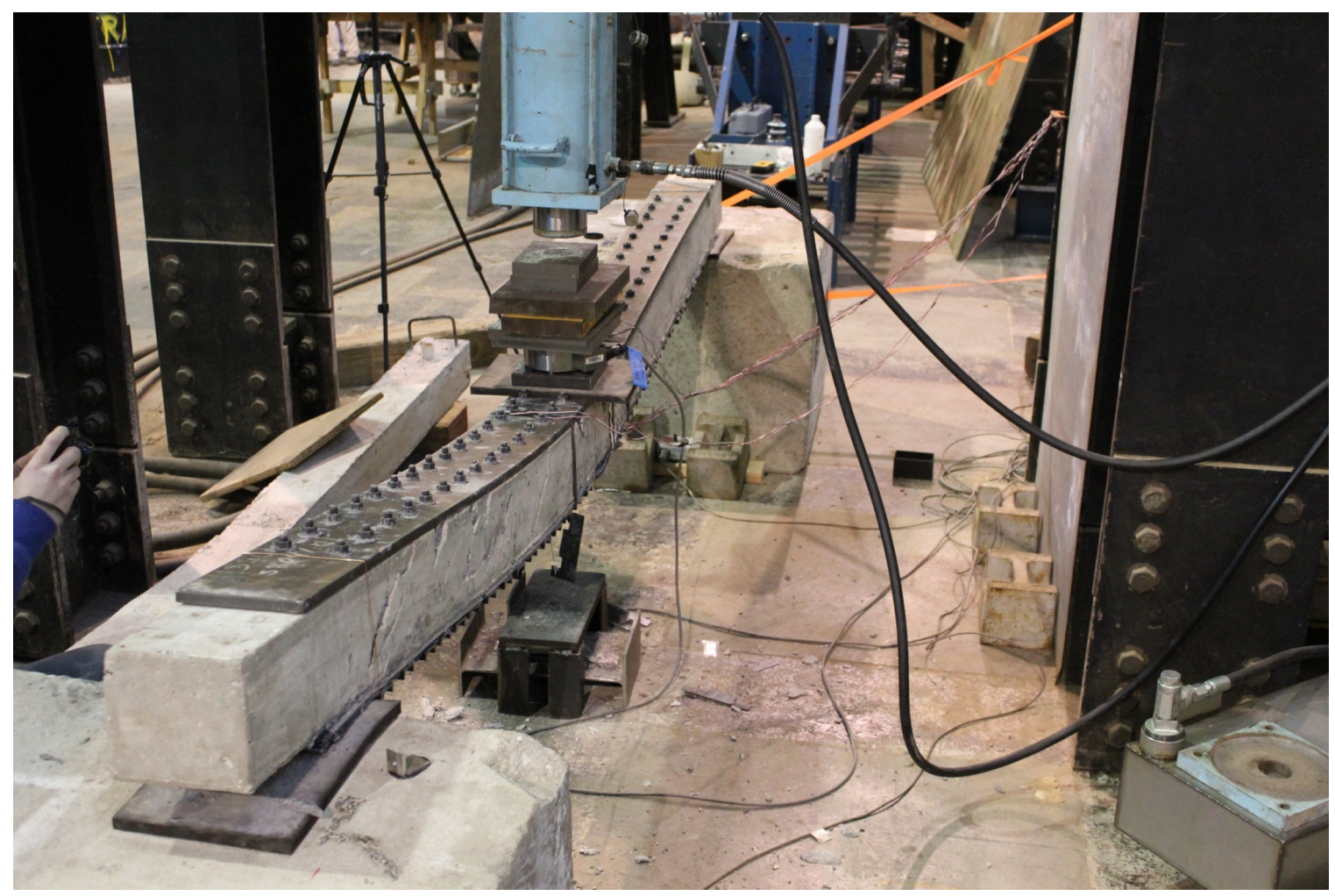

Figure 5-3 - The slab exhibited very large deflections, much of it permanent as seen here after unloading at the conclusion of the test. 


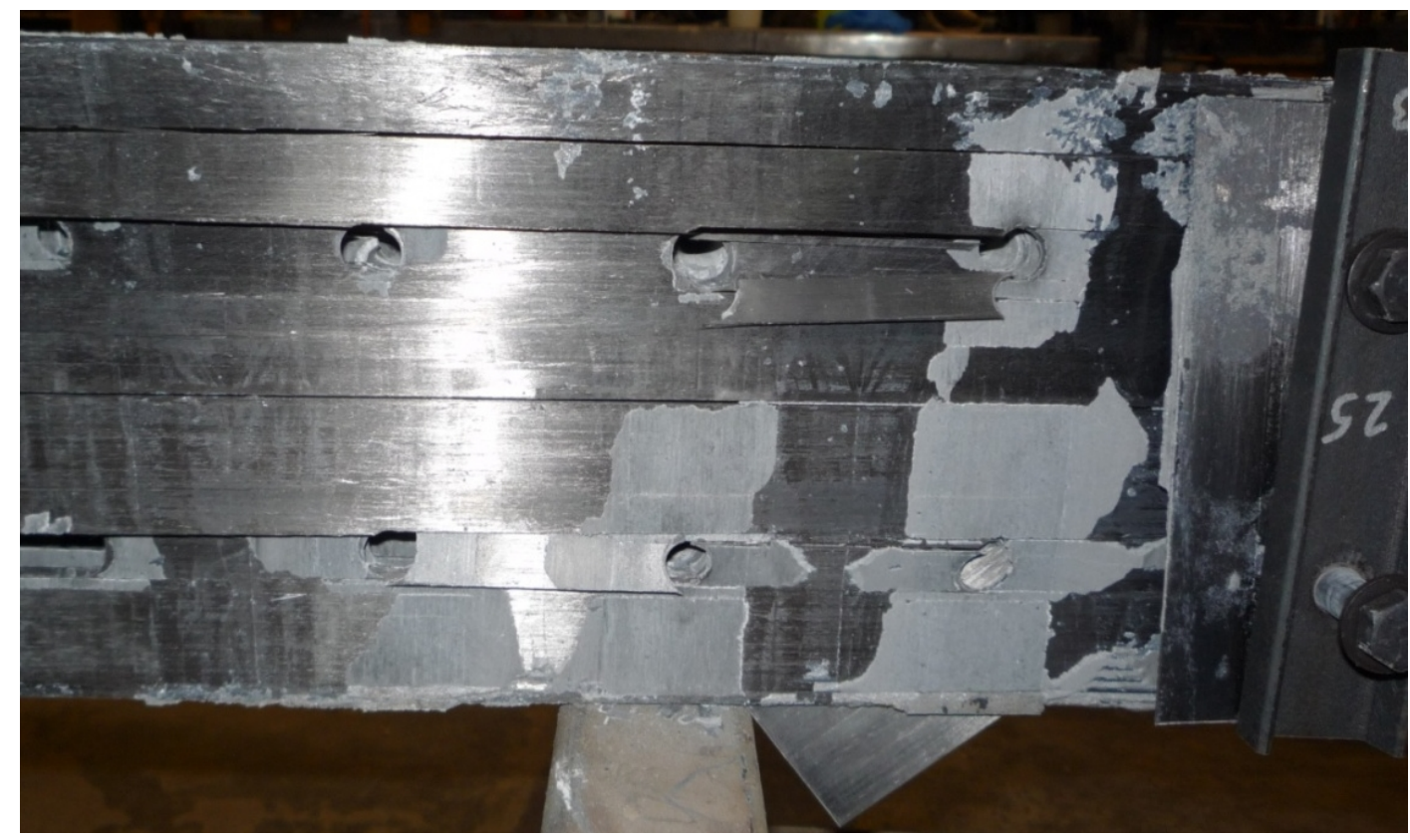

Figure 5-4 - The longitudinal CFRP sheets split next to many of the bolt holes. This may have contributed to extensive slipping of the CFRP sheets.

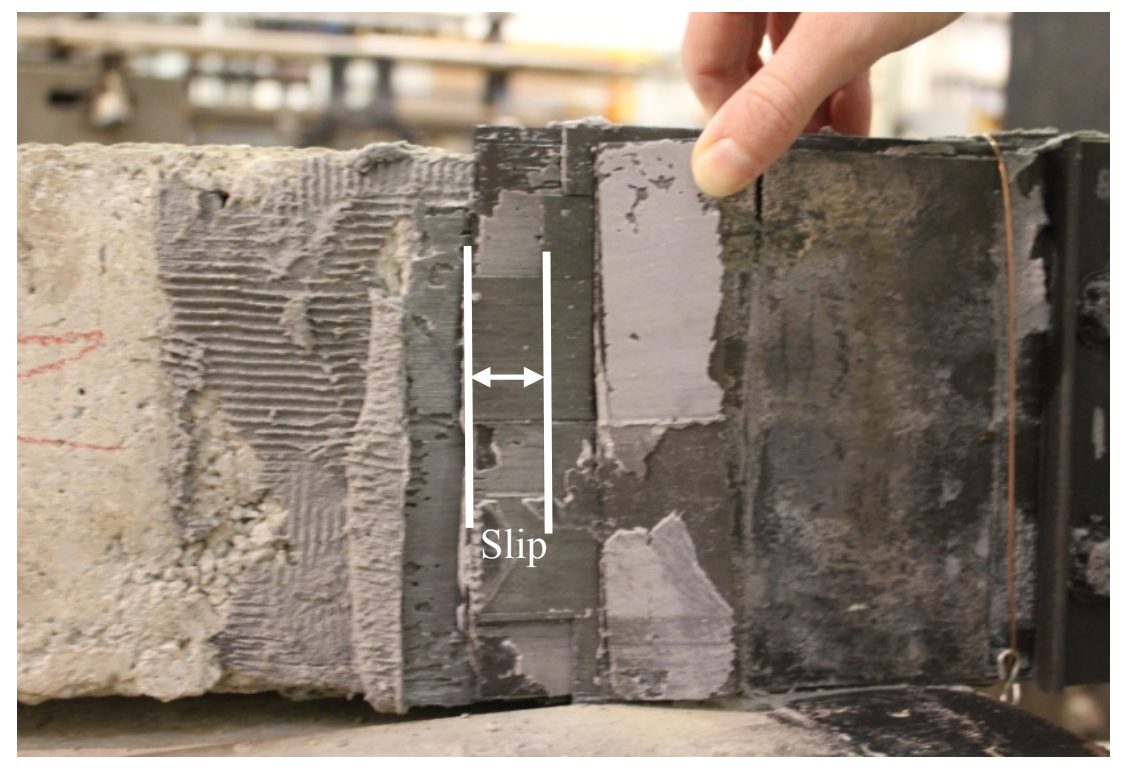

Figure 5-5 - End view of the slab showing significant displacement and splitting in the FRP sheets. The edges of the FRP sheets were initially aligned.

Despite the slipping, the specimen was able to develop the full strength of the CFRP and fracture approximately $60 \%$ of the CFRP, as seen in Figure $5-6.72 \%$ of the outer 
longitudinal layer, $58 \%$ of the middle longitudinal layer, and $50 \%$ of the inner longitudinal layer was fractured.

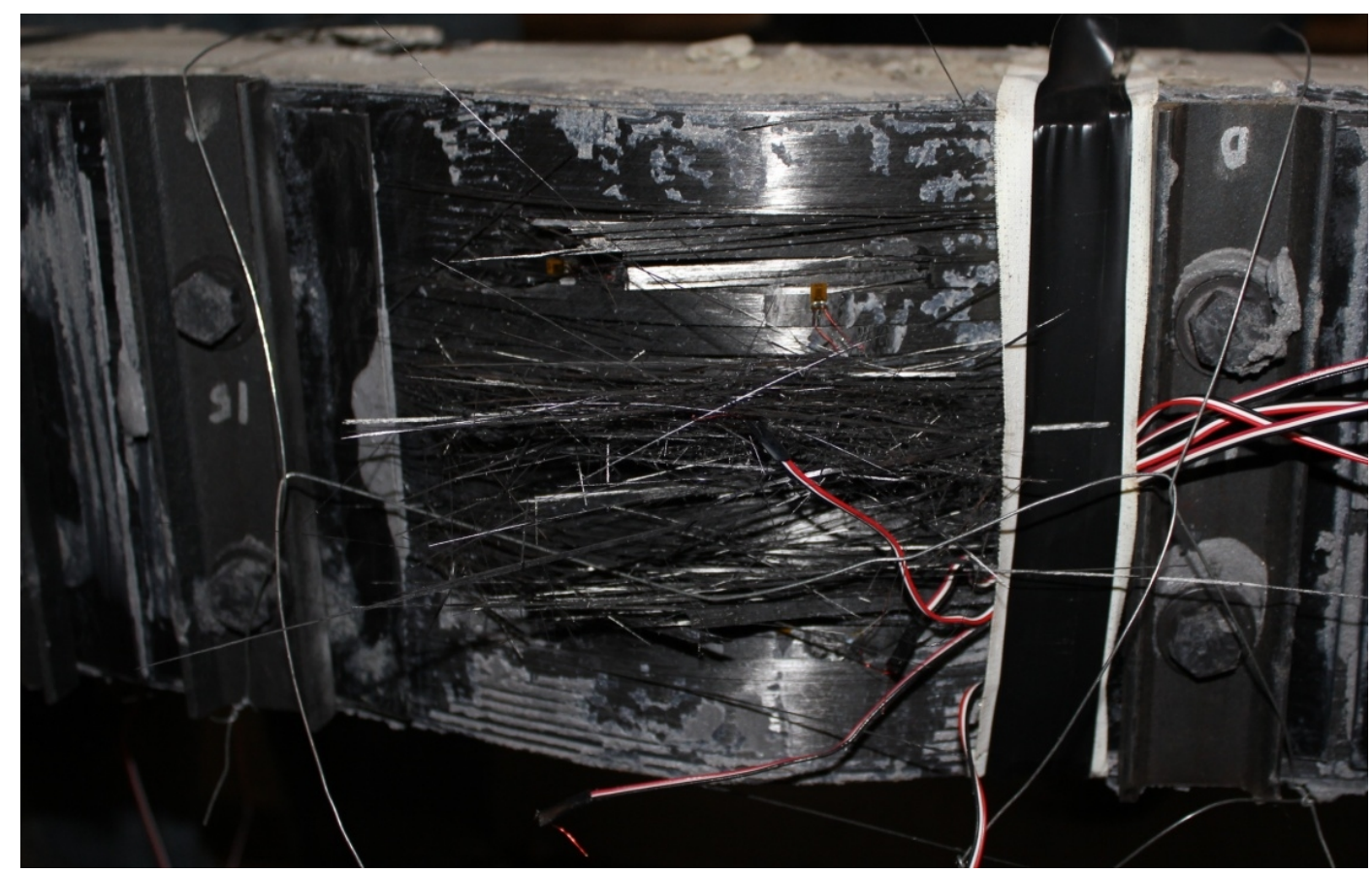

Figure 5-6 - Much of the longitudinal FRP at midspan was fractured, despite slipping and splitting.

Post-test disassembly revealed that the concrete had sustained severe shear cracking, Figure 5-7, and had failed much of the concrete cover. The failure of the concrete indicates that compressive stresses at the top of the beam exceeded the capacity of the concrete. The majority of the compressive force in the moment couple came from the steel plate. On the tension side it was evident that the CFRP had completely delaminated, staying attached to the specimen only via the anchoring system, Figure 5-8. 


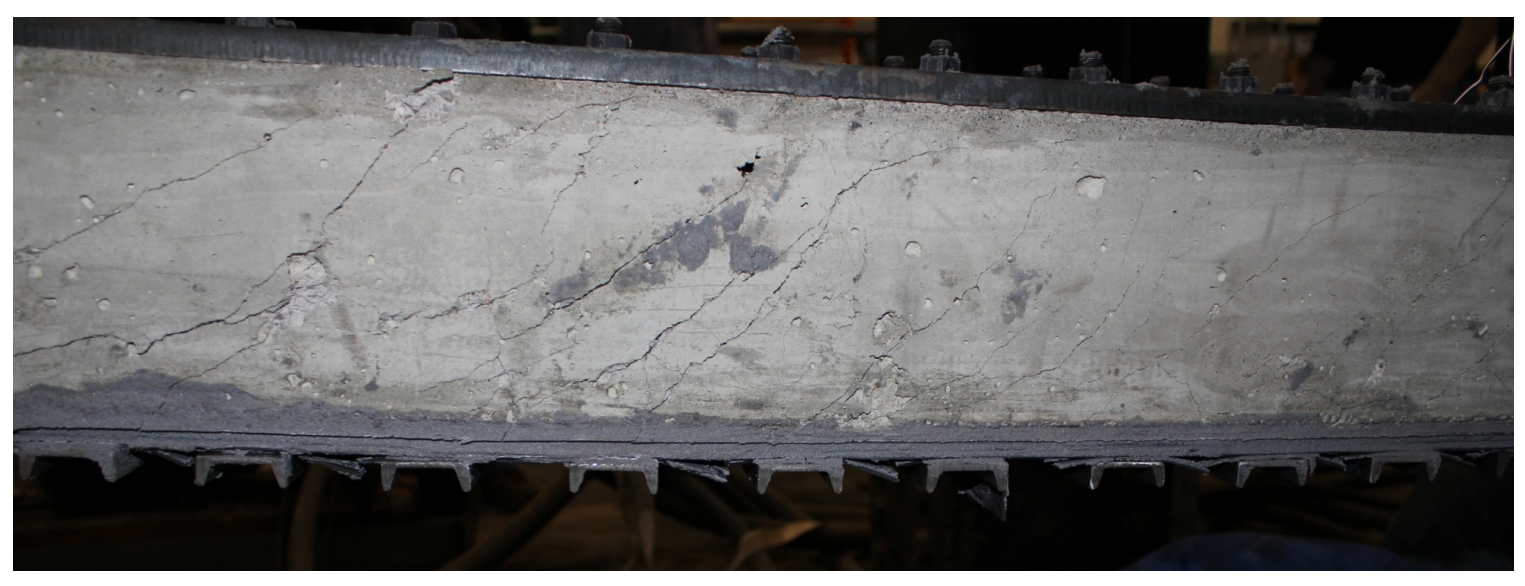

Figure 5-7 - Extensive shear cracking was observed.

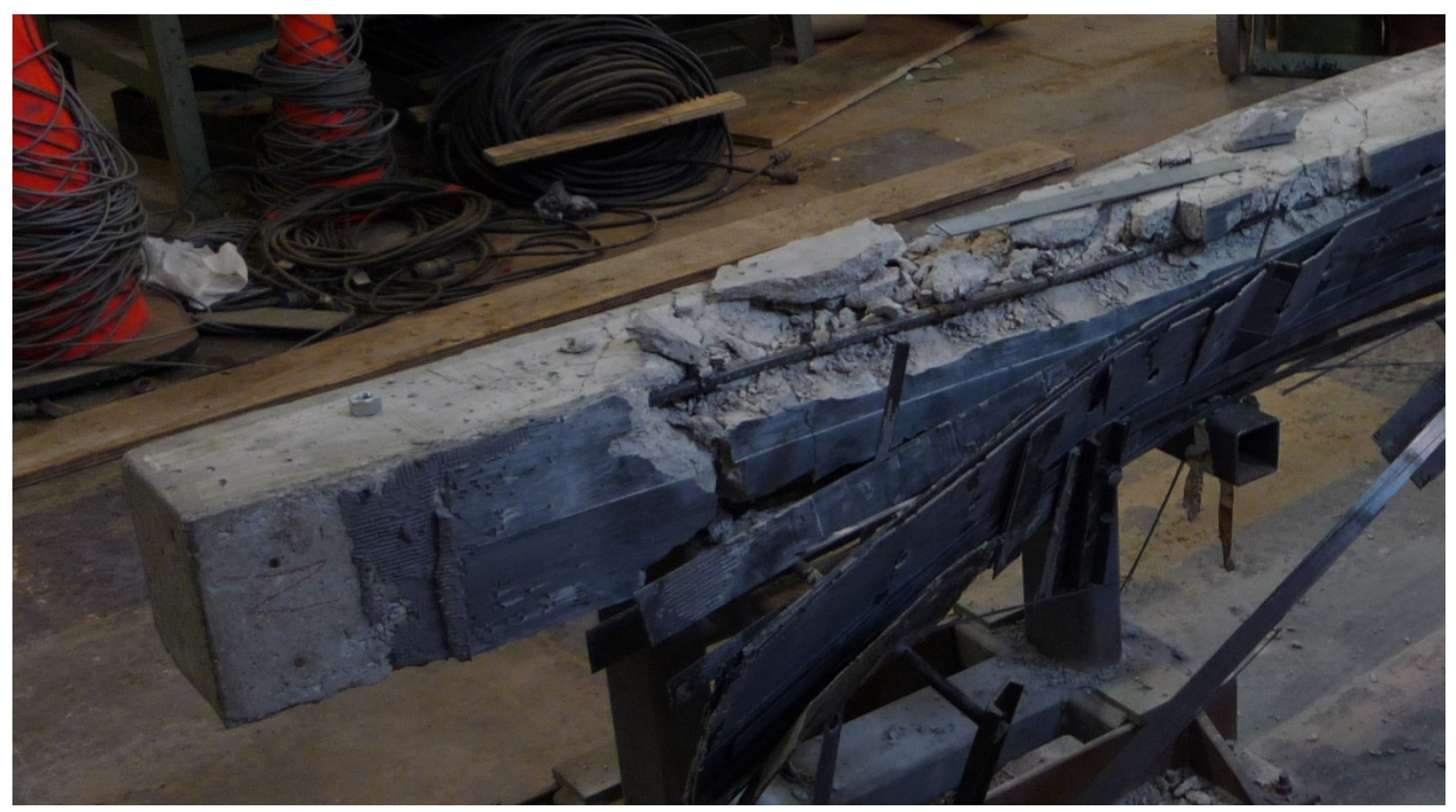

Figure 5-8 - Most of the concrete cover was sloughed off, and the CFRP completely delaminated. 


\section{THEORETICAL ANALYSIS}

A static resistance function (SRF) can be used to determine the dynamic response of the strengthened specimen. The SRF is defined as the load-deflection curve of a system under static load (Genelin et al. 2009). This section describes the theoretical basis for determination of the SRF and validates it with the test data.

\subsection{Static Analysis}

In order to perform the static analysis, nonlinear bending theory was used to calculate the load-deflection curve following the method outlined in Hsu and Mo (2010) and recommended by ACI 440 (1996). For the simplified case of a linear doubly reinforced rectangular section at ultimate using Whitney's stress block, one can develop an internal force diagram, Figure 6-1.

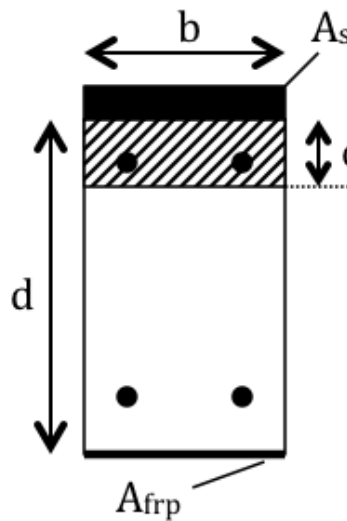

Reinforced Concrete Section
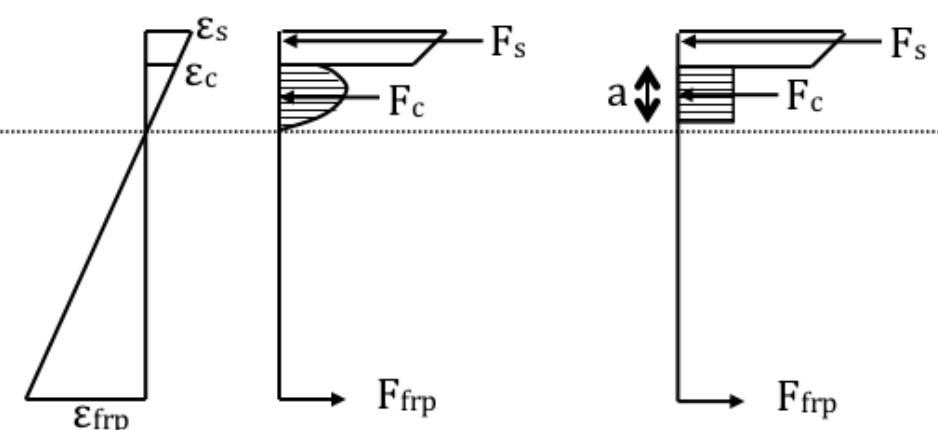

Force Equilibrium (Nonlinear Concrete Stress Distribution)
Force Equilibrium (Equivalent Concrete Stress Distribution)

Figure 6-1 - Internal strain and stress distribution for a rectangular section under flexure at ultimate limit state. 
Given the small strength of the reinforcing bars relative to the large $100 \mathrm{ksi}$ steel plate and corresponding FRP, it is ignored in these equations. Taking the moment equilibrium about the FRP tensile force $\mathrm{F}_{\text {frp }}$ yields:

$$
M=F_{c}\left(d-\frac{a}{2}\right)+A_{s}^{\prime} f_{s}^{\prime}\left(d-d^{\prime}\right)
$$

Where;

$F_{c}:$ Concrete compression force

$\mathrm{d}$ : Depth of tension reinforcement

a : Depth of Whitney stress block

$A_{S}^{\prime}:$ Area of compression reinforcement

$f_{s}^{\prime}$ : Yield strength of compression reinforcement

$d^{\prime}$ : Depth of compression reinforcement

In order to consider the nonlinear behavior of the concrete, begin by expressing the magnitude of the compression resultant $C$ of the concrete as:

$$
C=b \int_{0}^{c} \sigma d x=b \frac{c}{\varepsilon_{u}} \int_{0}^{\varepsilon_{u}} \sigma d \varepsilon
$$

Where;

$c:$ Depth of the neutral axis

$\sigma:$ Compressive stress of concrete as a function of strain 
$\varepsilon_{u}$ : Maximum compressive strain of concrete at the compression surface

Define the coefficient $k_{1}$ as:

$$
k_{1}=\frac{c}{f_{c}^{\prime} b c}
$$

Substituting Equation 6-3 into Equation 6-2, yields an expression for $k_{1}$ :

$$
k_{1}=\frac{1}{f_{c}^{\prime} \varepsilon_{u}} \int_{0}^{\varepsilon_{u}} \sigma d \varepsilon
$$

If one defines the location of the resultant $\mathrm{C}$ as $k_{2} c$, measured from the top surface of the cross section, and takes the moment about the neutral axis, one obtains:

$$
C\left(c-k_{2} c\right)=b \int_{0}^{c} \sigma x d x=b\left(\frac{c}{\varepsilon_{u}}\right)^{2} \int_{0}^{\varepsilon_{u}} \sigma \varepsilon d \varepsilon
$$

Substituting Equation 6-2 into Equation 6-5 yields:

$$
k_{2}=1-\frac{1}{\varepsilon_{u}} \frac{\int_{0}^{\varepsilon_{u}} \sigma \varepsilon d \varepsilon}{\int_{0}^{\varepsilon_{u}} \sigma d \varepsilon}
$$

Substituting Equations 6-4 and 6-6 into Equation 6-1 yields:

$$
M=f_{c}^{\prime \prime} k_{1} b c\left(d-k_{2} c\right)+A_{s}^{\prime} f_{s}^{\prime}\left(d-d^{\prime}\right)
$$

Where;

$f_{c}^{\prime \prime}$ : Maximum concrete stress in the compression zone

The nonlinear behavior of the concrete is described by the Hognestad (1955) stress strain curve in Equation 6-8: 


$$
\sigma=f_{c}^{\prime}\left[2\left(\frac{\varepsilon}{\varepsilon_{0}}\right)-\left(\frac{\varepsilon}{\varepsilon_{o}}\right)^{2}\right]
$$

Where;

$\varepsilon_{0}$ : Strain at maximum stress $f_{c}^{\prime}$, normally taken as 0.002 .

However, in Kent and Park (1971), the authors found that that equation tends to underestimate the concrete stress for large strains in confined concrete. As the steel plate and CFRP fabric in this test contributed substantially to confinement of the concrete the improved equation developed by Kent and Park (1971) was utilized. This equation is

plotted in Figure 6-2.

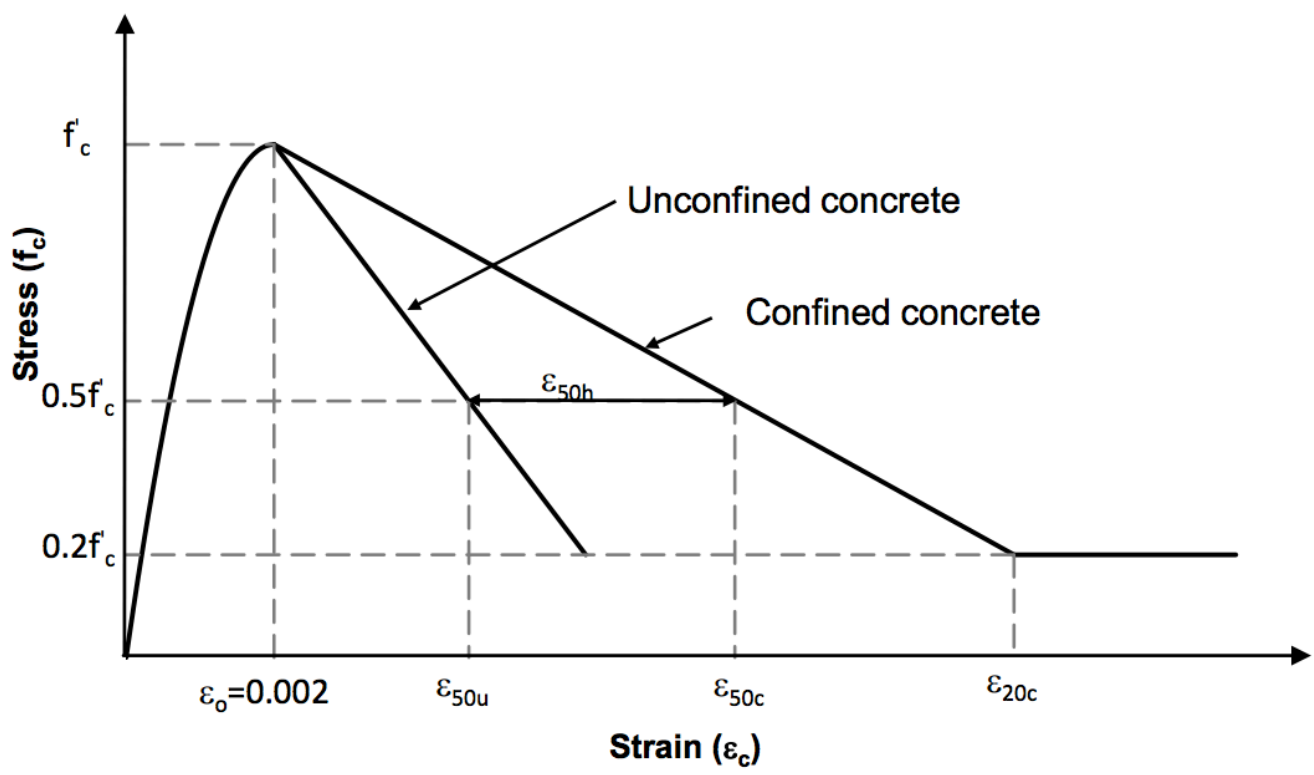

Figure 6-2 - Stress-strain behavior of confined concrete (Kent and Park 1971). 
In the Kent-Park equation in the region $0<\varepsilon_{c}<\varepsilon_{0}$, Equation 6-8 governs. For the region $\varepsilon_{c}>\varepsilon_{o}$, a straight line is plotted through $\left(\varepsilon_{50 c}, 0.5 f^{\prime} c\right)$, with $\varepsilon_{50 c}$ given by:

$$
\varepsilon_{50 c}=\frac{3+0.002 f_{c}^{\prime}}{f^{\prime} c-1000}+\frac{3}{4} \rho_{s} \sqrt{b^{\prime \prime} / s_{h}}
$$

Where;

$\rho_{s}$ : Ratio of the volume of transverse reinforcement to the volume of the confined core

$b^{\prime \prime}:$ Width of the confined core

$s_{h}:$ Reinforcing tie spacing

Additionally, the confined concrete is assumed to maintain a minimum strength of $0.2 f_{c}^{\prime}$ at very large strains.

A solution for the moment capacity for a given concrete strain can be obtained with Equation 6-7 through either trial-and-error by iteratively assuming values for $c$ and checking against force equilibrium equations, or by development and solution of a system of quadratic equations. Regardless, once a value for $c$ had been obtained, the curvature of the specimen can be calculated as:

$$
\phi=\frac{\varepsilon_{u}}{c}
$$

A Microsoft Excel spreadsheet was developed to automate these calculations. The system of linear equations described in Hsu and Mo (2010) were solved with a macro-driven guess-and-check routine. The integrals in Kent and Park (1971) were calculated by use of 
the trapezoidal approximation rule. A set of sample calculations can be seen in Appendix A.

\subsubsection{Theoretical Behavior}

This section examines the theoretical behavior of the beam if it was assumed that there was perfect strain compatibility between all layers in the specimen, i.e. that no debonding or slipping occurred between the CFRP layers or at the interface between the CFRP and the concrete member surface. This was the intent of the anchoring systems that had been installed.

A summary of the material properties used can be found in Table 6-1. The CFRP properties are reported by the material manufacturer (Sika 2005) and the steel properties are assumed based on the known properties for ASTM 514 steel. Of note is the high tensile strength of the FRP, but slightly lower elastic modulus relative to the steel.

Table 6-1- Material Properties

Steel Sika Carbodur

\begin{tabular}{ccc}
\hline Young's Modulus (E)(ksi) & 29000 & 23900 \\
Steel yield strength $\left(\mathrm{f}_{\mathrm{y}}\right)(\mathrm{ksi})$ & 100 & 406 \\
Strain $(\varepsilon)$ at rupture & $0.34 \%$ & $1.70 \%$ \\
\hline
\end{tabular}

The load-deflection relationship that was calculated can be seen in Figure 6-3. The load at which the FRP was calculated to reach its rupture strain is indicated with an X. There is an indication of yielding in the slab as seen by the change in slope of the relationships 
at around 2.5 in deflection. At this point the steel plate yields in compression. The behavior of the CFRP is elastic - no yielding of the material is experienced.

The nominal moment at the predicted CFRP rupture strain is $3660 \mathrm{kip}$-in per foot width. Using the conditions from the laboratory testing of a 6 in wide specimen, in 3-point bending load on an $8 \mathrm{ft}$ span, this corresponds to load of $76.3 \mathrm{kip}$ and midspan deflection at the predicted CFRP rupture strain is $4.4 \mathrm{in}$.

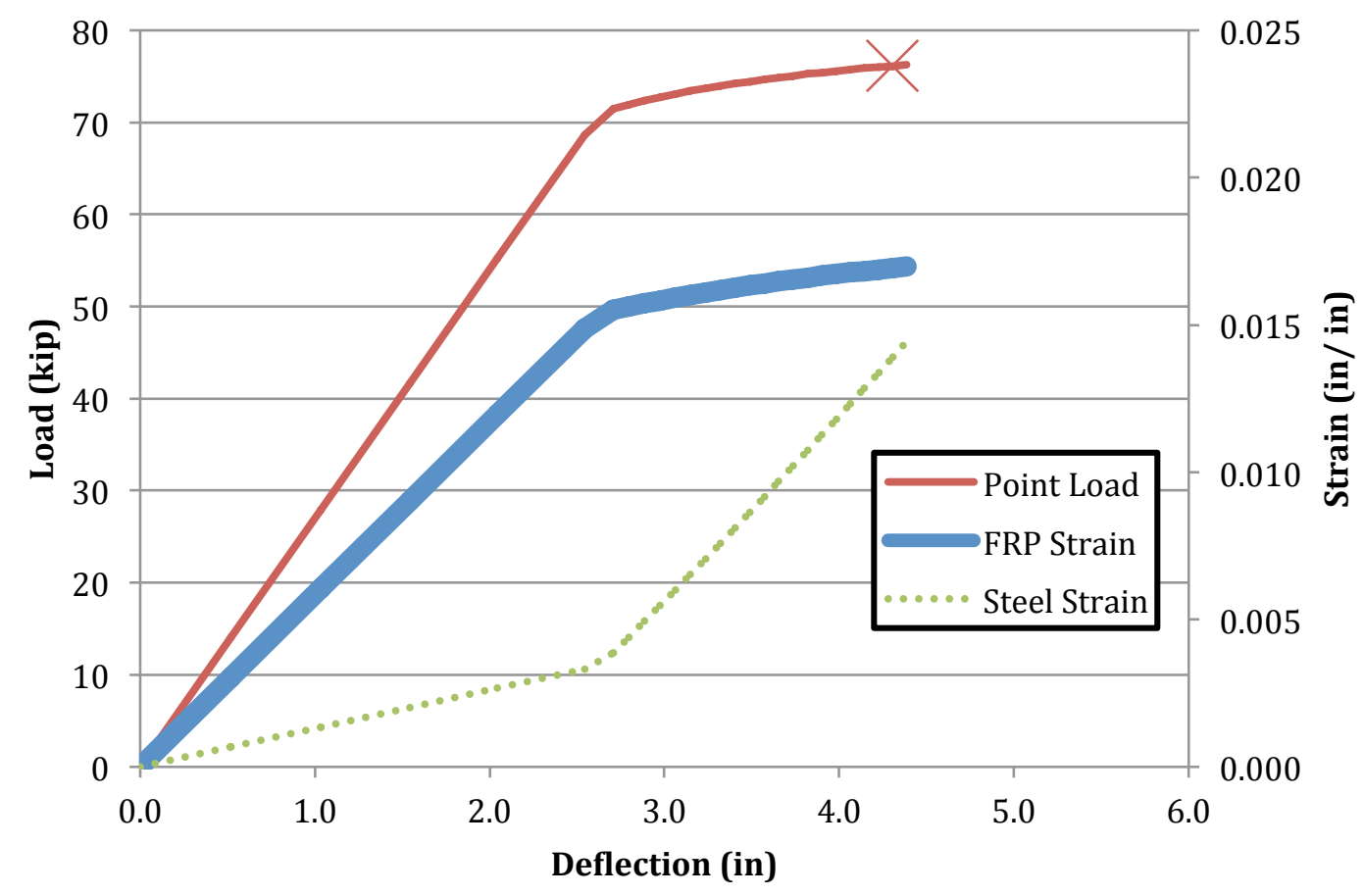

Figure 6-3 - Load Deflection and Strain Deflection Relationships. Load at which FRP reaches rupture strain indicated with an $\mathrm{X}$. 


\subsubsection{Actual Behavior}

Slipping of the CFRP layers was observed during the laboratory test. Methods for more sophisticated modeling of interlayer slip exist, but interlayer slip is a complex phenomenon and substantial testing would be required to obtain the appropriate parameters for analysis. Therefore a comparison of the theoretical and actual behavior of the beam is presented next.

The theoretical load-deflection relationship compared to the actual can be seen in Figure 6-4. Initially it is evident that the slope of the actual and theatrical load deflection curves is the same. This indicates that the theatrical analysis is initially accurate. However, at about 0.5 in of displacement the slope of the actual load deflection curve decreases. This is the beginning of slipping of the CFRP. The slipping of the CFRP was also heard in the video of the test at this displacement level. The reduction in stiffness of the beam is about $85 \%$. At approximately 70 kips of load the theoretical analysis predicts yielding in the steel compression plate. Data from the strain gages indicates that this occurred earlier in the test at only 50 kips of load. Again, the slipping of the CFRP resulted in higher strains in the steel and therefore an earlier yield load. At approximately 64 kips of load there was fracture of a portion of the CFRP. The lack of load shedding indicates that the force in the fractured CFRP fibers was effectively transferred to other fibers. The theoretical analysis was not able to account for the difference in slipping between sections of CFRP, therefore, fracture was assumed to occur all at once at 76 kips of load and 4.25 in of deflection.

The theoretical load capacity of the specimen was $76.3 \mathrm{kip}$. This result agrees well with the measured peak capacity of $77.8 \mathrm{kip}$, an error of just $2 \%$. The specimen midspan 
deflection at the predicted CFRP rupture strain is 4.4 in, representing an error of $14 \%$ from the measured midspan deflection at CFRP rupture of 5.1 in The major reason for the difference in the deflection prediction is the slipping of the CFRP. Table 6-2 summarizes the key results from each static analysis case and the laboratory test results.

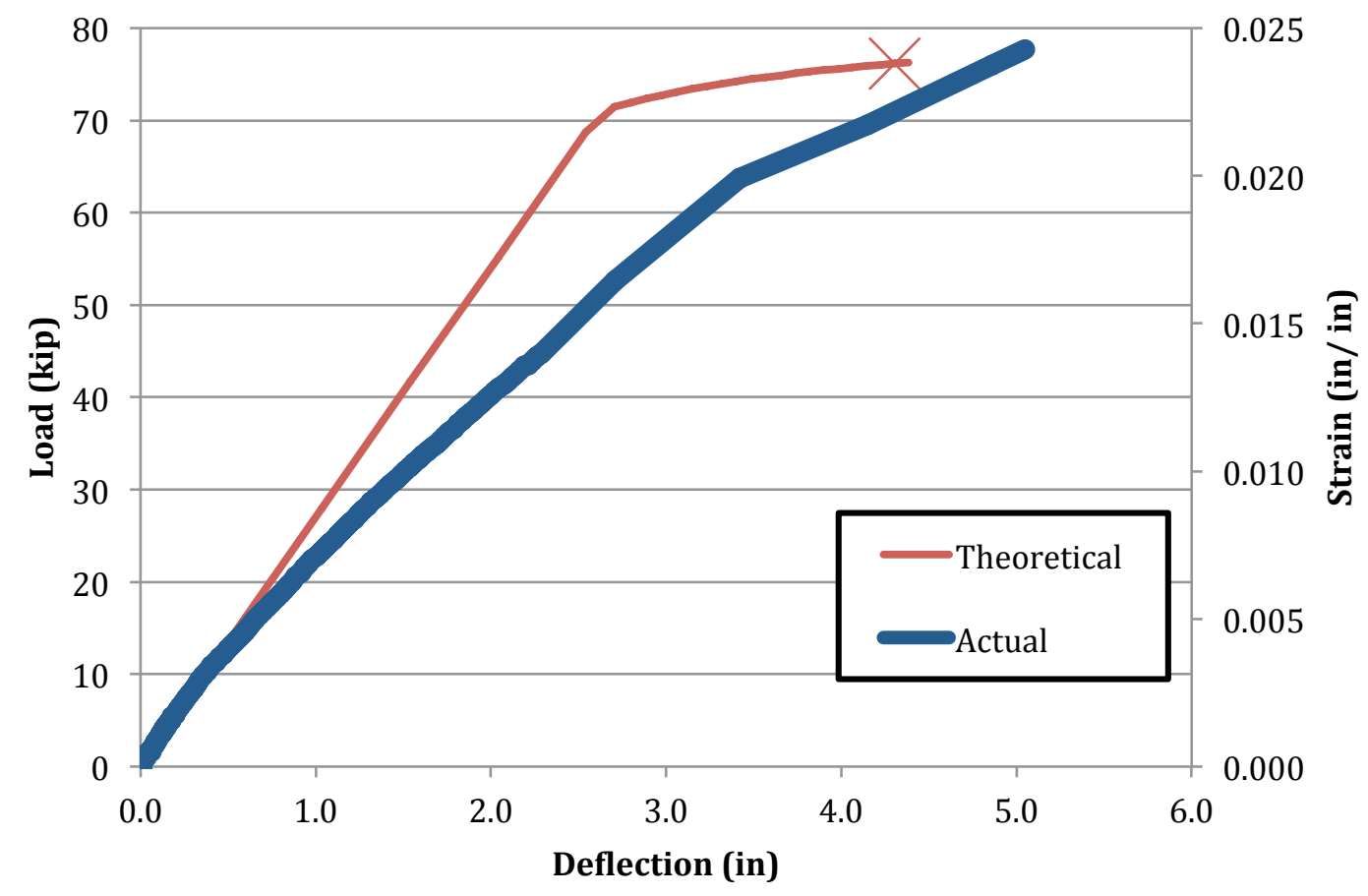

Figure 6-4 - Theoretical and actual load deflection relationships . Load at which FRP reaches rupture strain indicated with an $\mathrm{X}$.

Table 6-2 - Key static analysis results

\begin{tabular}{lcccccc}
\multicolumn{1}{c}{ Test } & \multicolumn{2}{c}{ Load } & \multicolumn{2}{c}{ Moment } & \multicolumn{2}{c}{ Deflection } \\
& kip & Error & kip-in & Error & in & Error \\
\hline $\begin{array}{l}\text { Experimental Result } \\
\text { Analysis }\end{array}$ & 77.8 & - & 1867 & - & 5.1 & - \\
& 76.3 & $2 \%$ & 1830 & $2 \%$ & 4.4 & $14 \%$ \\
\hline
\end{tabular}


Though the analysis underestimated the deflection, a greater deflection during the laboratory test should not necessarily be regarded as a determent. During a dynamic loading, increased deflection represents increased ductility and energy absorption. This is discussed further in Section 6.2.

\subsection{Dynamic Analysis}

With the Static Resistance Function (SRF) established, an assessment of the dynamic response of the load resisting system needs to be performed. Several methods for doing this exist, including empirical procedures (UFC 2008), finite element analysis (Williams 2002), strain energy approximation, and the Single Degree of Freedom (SDOF) analysis (Biggs 1964). While empirical procedures promise ease of use, most have been developed for far-field blasts and are not entirely valid at very close scaled ranges. Finite element analysis can produce more accurate results, but are highly labor intensive. Fortunately, for close-in blasts an SDOF analysis can produce good results with much less computation, and a strain energy approximation can offer meaningful results with just a few simple calculations.

\subsubsection{Blast Load}

The first step in dynamic analysis is determining the loading on the slab from the blast pressures. A finite-element hydro-code analysis was previously performed in CTH to determine the pressures and impulses for an assumed cylindrical charge with $\mathrm{L} / \mathrm{D}=1$ and scaled range $1.0 \mathrm{lb} / \mathrm{ft}^{1 / 3}$ (Orton et al. 2013). Pressure and impulse data from this analysis was reused. 
As can be seen in the Figure 6-5, the peak pressure is very high directly under the blast at the center of the slab. The pressure decreases significantly as you move away from the center of the slab. The CTH simulation determined the time-pressure history for every location on the slab in a $5 \mathrm{~cm}$ by $5 \mathrm{~cm}$ grid. As the entire slab is moving in unison, the total pressure on the slab can be determined at each time interval and used as the external load. Figure 6-6 shows this total pressure for the scaled range considered in this research.

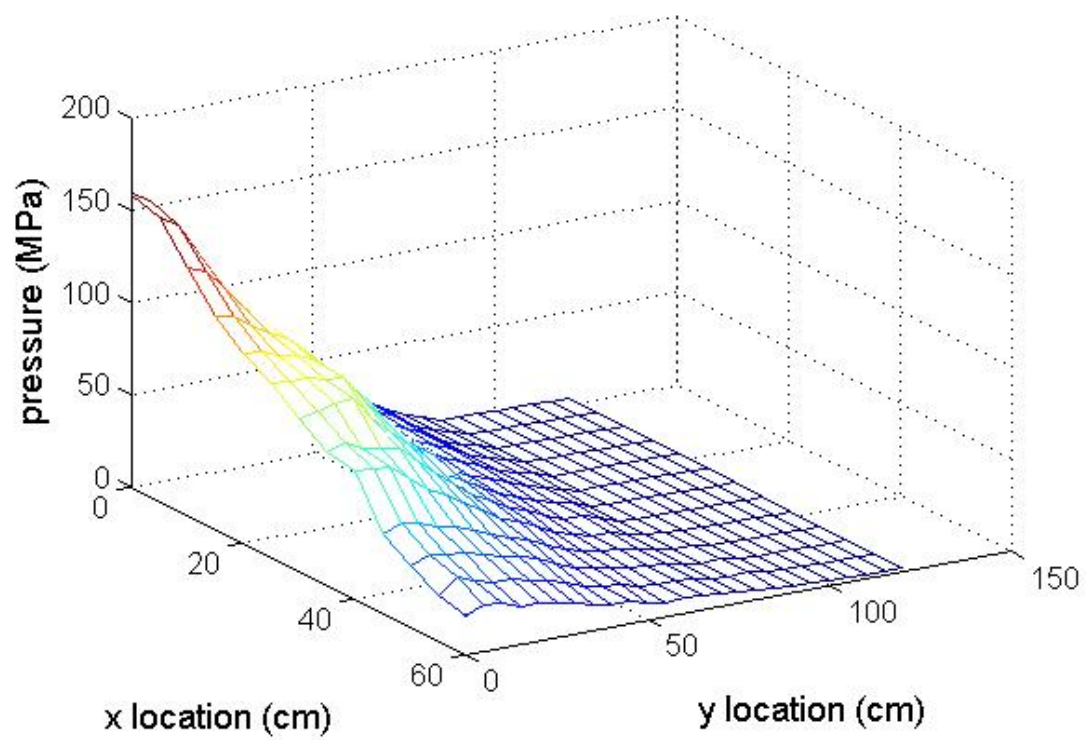

Figure 6-5 - Peak pressures from hydro-code analysis as scaled range $1.0 \mathrm{lb} / \mathrm{ft}^{1 / 3}$ 


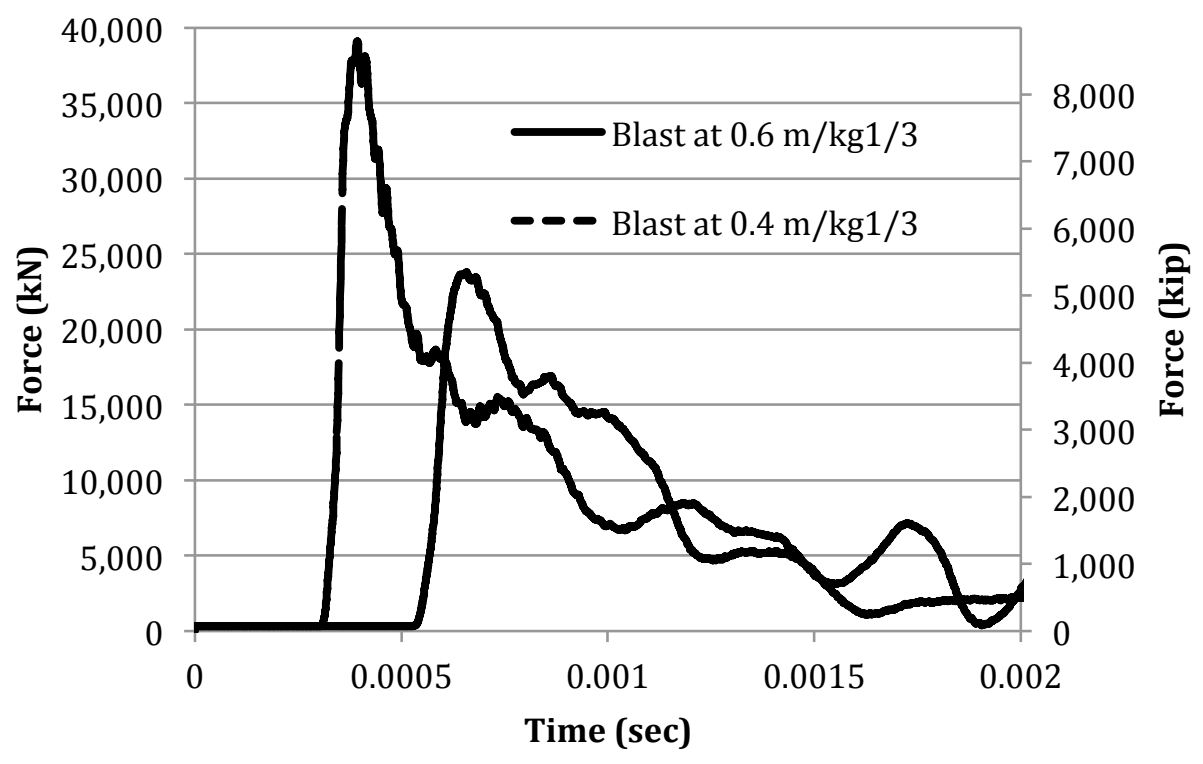

Figure 6-6 - External load (total pressure) for SDOF analysis.

\subsubsection{Slab Strength - Yield Line Analysis}

The static testing and analysis of the retrofit system has determined the flexural response of the system, and data from these analysis can be used to formulate a load-deflection relationship to be used in a dynamic analysis. However, the effects of the non-uniform pressure distribution must be considered.

One simple way of handling this for a slab section is through the use of yield line analysis, Figure 6-7. Typical yield line analyses considers a uniform load, but in the case of a close-in blast this is not conservative, as the center of the slab experiences a dramatically higher pressure than the portions closer to the supports. However, as long as a plausible yield line pattern is chosen, a yield line analysis can still be conducted for a non-uniform load, generating a reasonably accurate value for a peak resistance. 
A yield line analysis is based upon equilibrium of work, and the equation of internal and external work. Internal work is created by the slab rotating at the moment strength about the yield lines. For a rectangular slab with constant moment resistance $m$ in two perpendicular directions, internal work becomes

$$
W_{I}=2 m\left(\frac{b}{x}+\frac{2 a}{b}\right)
$$

Where;

$a$ : Length of the longer side of the slab

$b:$ Length of the shorter side of the slab

$x$ : Distance to the crossing of the yield lines, taken as $\mathrm{b} / 2$ for 45 degree yield lines

External work is given by the summing the product of the external force (pressure) and displacement across the area of the slab.

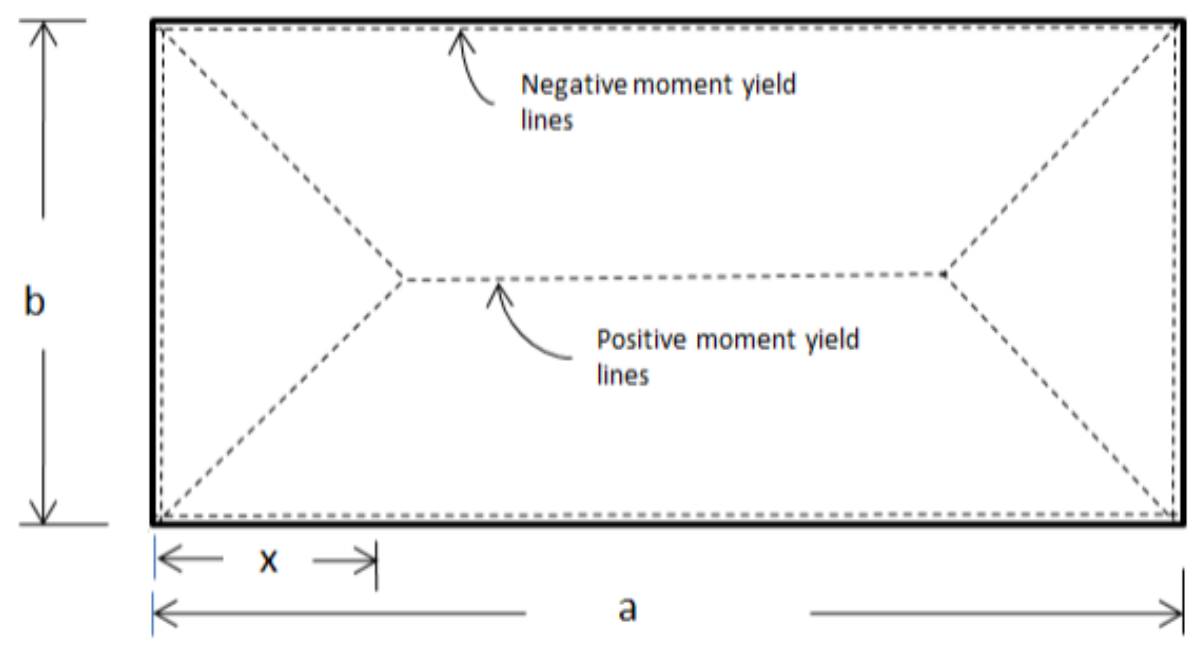

Figure 6-7 - Yield Line Analysis 


\subsubsection{Strain Energy Approximation}

For close-in blasts, a full dynamic analysis may not be required, as a simple approximation based upon strain energy can yield good results (Biggs 1964). Close-in blast loads are very impulsive, with a duration $t_{d}$ much less than the natural period $t_{n}$ of the system. If $t_{d} / t_{n}<0.1$ the loading can be considered as a pure impulse (ASCE 1997). For these systems an analysis can be as simple as equating the kinetic energy of the blast load to the strain energy in the deflecting slab. For the slab to survive the blast, the available strain energy must exceed the kinetic energy of the blast. An impulse $i$ gives a system with mass $M$ an initial velocity:

$$
\dot{y}=i / M
$$

Therefore the kinetic energy $K E$ of the blast is:

$$
K E=\frac{1}{2} M \dot{y}^{2}=\frac{i^{2}}{2 M}
$$

The strain energy $S E$ in the slab is the area under the load deflection curve $\mathrm{f}(\mathrm{x})$ for the slab:

$$
S E=\int_{0}^{a} f(x) d x
$$

Where;

$x$ : Deflection of the slab

$a$ : Peak deflection of the slab

$f(x)$ : Load deflection function. 


\subsubsection{Single Degree Of Freedom Analysis}

A Single Degree Of Freedom (SDOF) analysis involves representing the structural system in question as a mass-spring system, as show in Figure 6-8. The spring represents the resistance of the slab to load, and can be modeled using the Static Resistance Function (SRF) derived from static testing and analysis. The mass of the slab is modified by a load mass factor $\mathrm{K}_{\mathrm{LM}}$ to relate the equivalent mass and resistance of the SDOF model to that of the actual slab (Biggs 1964). It is important to note that load mass factor and the resistance function are both very dependent on how the slab responds under the blast load; this response can vary based on the intensity of the blast.
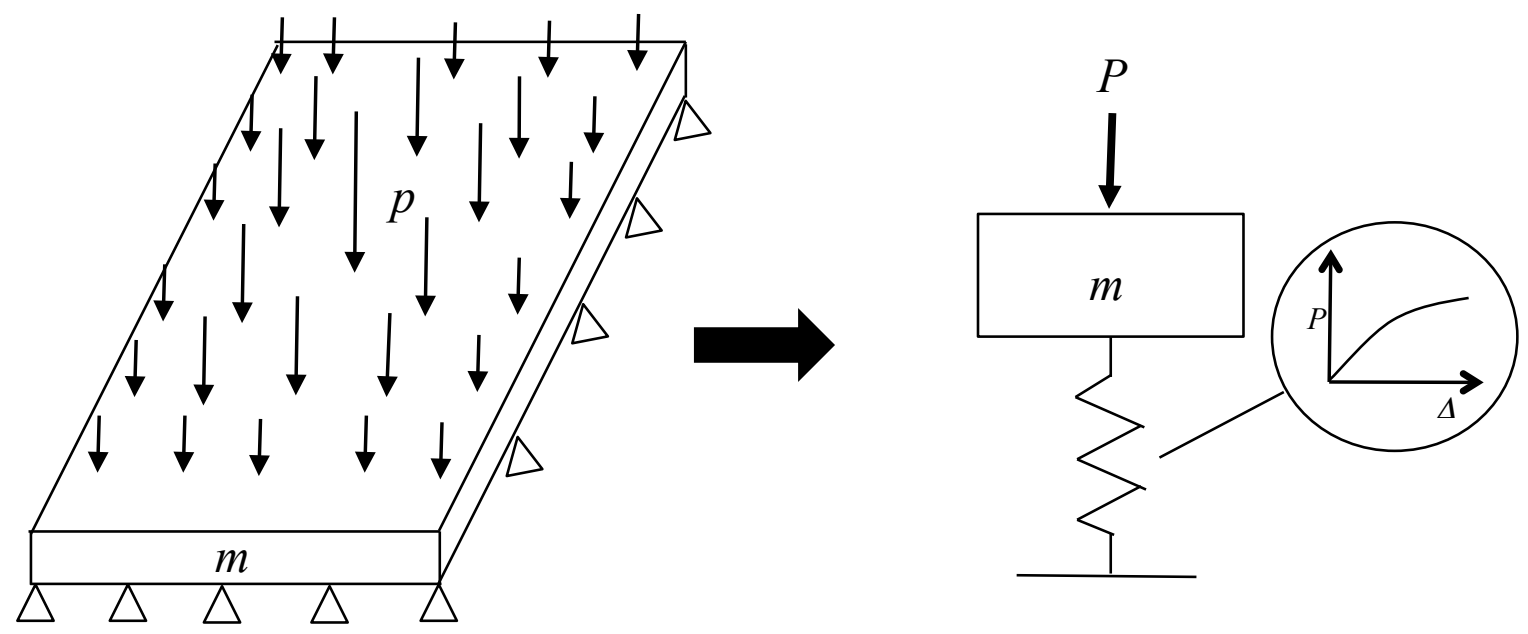

Figure 6-8 - Representation of a slab by a spring-mass system. 
The equation of motion of the SDOF system, Equation 6-15, was solved using a finite difference approximation of the first and second time derivatives of the displacement, known as the central difference method. The resistance function used in the calculations was derived from the static test results and static analysis discussed earlier.

$$
m \ddot{u}(t)+c \dot{u}(t)+f_{s}(u(t))=P(t)
$$

Where;

$\mathrm{u}(t)$ : Displacement of the system at time $t$.

$\dot{u}(t)$ : Velocity, the first derivative of displacement with respect to time.

$\ddot{u}(t)$ : Acceleration, the second derivative of displacement with respect to time.

$P(t)$ : Load acting on the system at time $t$.

$f_{s}(u(t))$ : Resistance of the system for the displacement at time $t$.

$m$ : Mass of the system.

$c$ : Damping coefficient of the system.

The central different approximation is given by Equations 6-16 and 6-17:

$$
\begin{aligned}
& \dot{u}\left(t_{i}\right)=\frac{u\left(t_{i+1}\right)-u\left(t_{i-1}\right)}{2 \Delta t} \\
& \ddot{u}\left(t_{i}\right)=\frac{u\left(t_{i+1}\right)-2 u\left(t_{i}\right)+u\left(t_{i-1}\right)}{(\Delta t)^{2}}
\end{aligned}
$$

Where:

$\Delta t$ : Time interval between calculation steps.

Substituting Equation 6-16 and 6-17 into Equation 6-15:

$$
m \frac{u\left(t_{i+1}\right)-2 u\left(t_{i}\right)+u\left(t_{i-1}\right)}{(\Delta t)^{2}}+c \frac{u\left(t_{i+1}\right)-u\left(t_{i-1}\right)}{2 \Delta t}+f_{s}\left(u\left(t_{i}\right)\right)=P\left(t_{i}\right)
$$

Rearranging for $u\left(t_{i+1}\right)$ :

$$
u\left(t_{i+1}\right)=\frac{1}{\left(\frac{m}{(\Delta t)^{2}}-\frac{c}{2 \Delta t}\right)}\left[\left(\frac{2 m}{(\Delta t)^{2}}\right) u\left(t_{i}\right)-\left(\frac{m}{(\Delta t)^{2}}-\frac{c}{2 \Delta t}\right) u\left(t_{i-1}\right)-f\left(u\left(t_{i}\right)\right)+P\left(t_{i}\right)\right]
$$


(Equation 6-19)

Defining some convenient constants:

$$
\begin{aligned}
& a=\frac{m}{(\Delta t)^{2}}-\frac{c}{2 \Delta t} \\
& b=\frac{2 m}{(\Delta t)^{2}}
\end{aligned}
$$

Equation 6-19 can be written as:

$$
u\left(t_{i+1}\right)=\frac{1}{a}\left[b u\left(t_{i}\right)-a u\left(t_{i-1}\right)-f\left(u\left(t_{i}\right)\right)+P\left(t_{i}\right)\right] \quad \text { (Equation 6-22) }
$$

The first step in the calculations is a special case, namely:

$$
\begin{aligned}
& u\left(t_{i-1}\right)=u\left(t_{0}\right)-\Delta t \dot{u}\left(t_{0}\right)+\frac{(\Delta t)^{2}}{2} \ddot{u}\left(t_{0}\right) \\
& \ddot{u}\left(t_{0}\right)=\frac{P\left(t_{0}\right)-c \dot{u}\left(t_{0}\right)+f_{s}\left(u\left(t_{0}\right)\right)}{m}
\end{aligned}
$$

Where:

$\mathrm{u}\left(t_{0}\right):$ Displacement at time $\mathrm{t}=0$

$\dot{u}\left(t_{0}\right)$ : Velocity at time $\mathrm{t}=0$.

$\ddot{u}\left(t_{0}\right)$ : Acceleration at time $\mathrm{t}=0$.

$P\left(t_{0}\right)$ : Load acting on the system at time $\mathrm{t}=0$.

The critical damping coefficient, $c_{r}$, is given by:

$$
c_{r}=2 \sqrt{k m}
$$

Where $k$ is the stiffness of the system.

The damping coefficient, $c$, is then given by:

$$
c=\xi c_{r}
$$

Where $\xi$ is the damping ratio of the system. $\xi$ is assumed equal to $5 \%$ for most structures unless there is a particular reason to expect a higher damping ratio (Chopra 2007). 
Utilization of the central difference method with a nonlinear resistance function often results in significant error caused by the attempt to force a negative stiffness during the retrograde phases of the oscillation. In the implementation used for this research, this problem was addressed by assuming a stiffness equal to the initial linear region of the resistance function whenever the sign of the velocity is negative.

When using the central difference method, special attention must be paid to setting the time step short enough to avoid computation instability. As described in Chopra (2007), any time step selected must satisfy

$$
\frac{\Delta t}{T_{n}}<\frac{1}{\pi}
$$

Where $T_{n}$ is the natural period of the system under analysis.

However, a time step that satisfies this requirement may still be too large to obtain an accurate result. $\Delta t / T_{n} \leq 0.1$ is normally required for the central different method, and for structural dynamics applications $\Delta \mathrm{t} / \mathrm{T}_{\mathrm{n}}$ on the order of 0.01 is more common (Chopra 2007). Here, due to the extremely short time interval of the load, a time step of $1 \times 10^{-6}$ seconds is used, the same as the time domain resolution of the load data.

\subsubsection{Dynamic Analysis Results}

In both dynamic analyses that were performed the same case was considered. Analyzed was the case of an $8 \mathrm{ft}$ by $4 \mathrm{ft}$ reinforced concrete slab 5.5 in deep, strengthened with the system designed for this research, and moment connected on all sided. This case is representative of a structural slab in a building floor or structural concrete wall. 


\section{Strain Energy Approximation Results}

The following input parameters were used for the kinetic energy calculations for these conditions.

$$
\begin{aligned}
& i_{1.0}=3.233 \mathrm{kip}-\mathrm{sec} \\
& i_{1.5}=4.669 \mathrm{kip}-\mathrm{sec} \\
& K_{l m}=0.489 \\
& M=0.00348 \mathrm{kip}-\mathrm{sec}^{2} / \mathrm{in}
\end{aligned}
$$

Using Equation 6-13, a kinetic energy of 6404 kip-in was found for the $1.0 \mathrm{ft} / \mathrm{lb}^{1 / 3}$ scaled range blast, and $3052 \mathrm{kip}$-in for the $1.5 \mathrm{ft} / \mathrm{lb}^{1 / 3}$ scaled range blast. The strain energy capacity of the retrofitted system was determined to be 17,100 kip-in using equation 614, implemented with a yield line analysis in Microsoft Excel, whereas the un-retrofitted reinforced concrete slab was found to have a strain energy capacity of just 1460 kip-in Since the strain energy capacity of the reinforced system is greater than the kinetic energy of the blast, this analysis predicts that with the retrofit the structural system will be able absorb the blast energy via deflection, without rupture. The un-retrofitted slab is predicted to fail completely.

\section{Single Degree of Freedom Results}

The slab strength data developed from the static tests and processed with a yield line analysis was combined with the external blast load data in a Microsoft Excel spreadsheet implementation of the central difference method discussed in Section 6.2.4. Key numerical inputs can be seen in Table 6-3. A plot of the static resistance function used can be seen in Figure 6-9. The time history result of the analysis is shown in Figure 6-10. Of particular note is the maximum deflection, $1.4 \mathrm{in}$. This is significantly less than the 
deflection associated with failure during the static tests, indicating that the system should be able to withstand the analyzed load.

Table 6-3 - SDOF input parameters

\begin{tabular}{ccc} 
Parameter & Value & Units \\
\hline $\mathrm{m}$ & 0.003481824 & $\mathrm{kip}^{*} \mathrm{sec} 2 / \mathrm{in}$ \\
$\mathrm{c}$ & 0.187167965 & $\mathrm{kip}^{*} \mathrm{sec} / \mathrm{in}$ \\
$\mathrm{T}_{\mathrm{n}}$ & 0.006367712 & $\mathrm{sec}$ \\
$\mathrm{K}_{\mathrm{lm}}$ & 0.489 & \\
$\Delta \mathrm{t}$ & 0.000001 & $\mathrm{sec}$ \\
$\mathrm{k}$ & 3390 & $\mathrm{k} / \mathrm{in}$ \\
$\mathrm{c}_{\mathrm{r}}$ & 6.871210312 & \\
$\xi$ & 0.05 & \\
$\mathrm{c}$ & 0.343560516 & \\
\hline
\end{tabular}

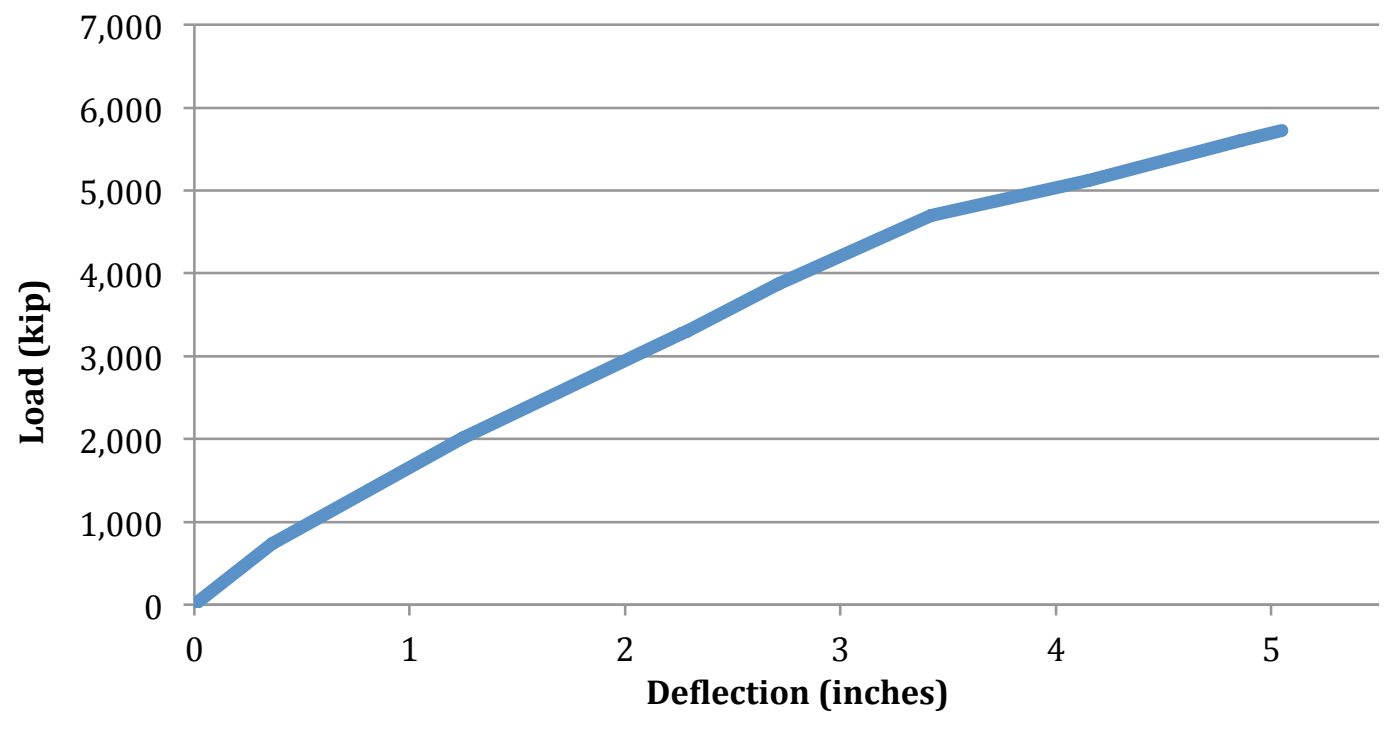

Figure 6-9 - Load deflection relationship used in SDOF analysis. 


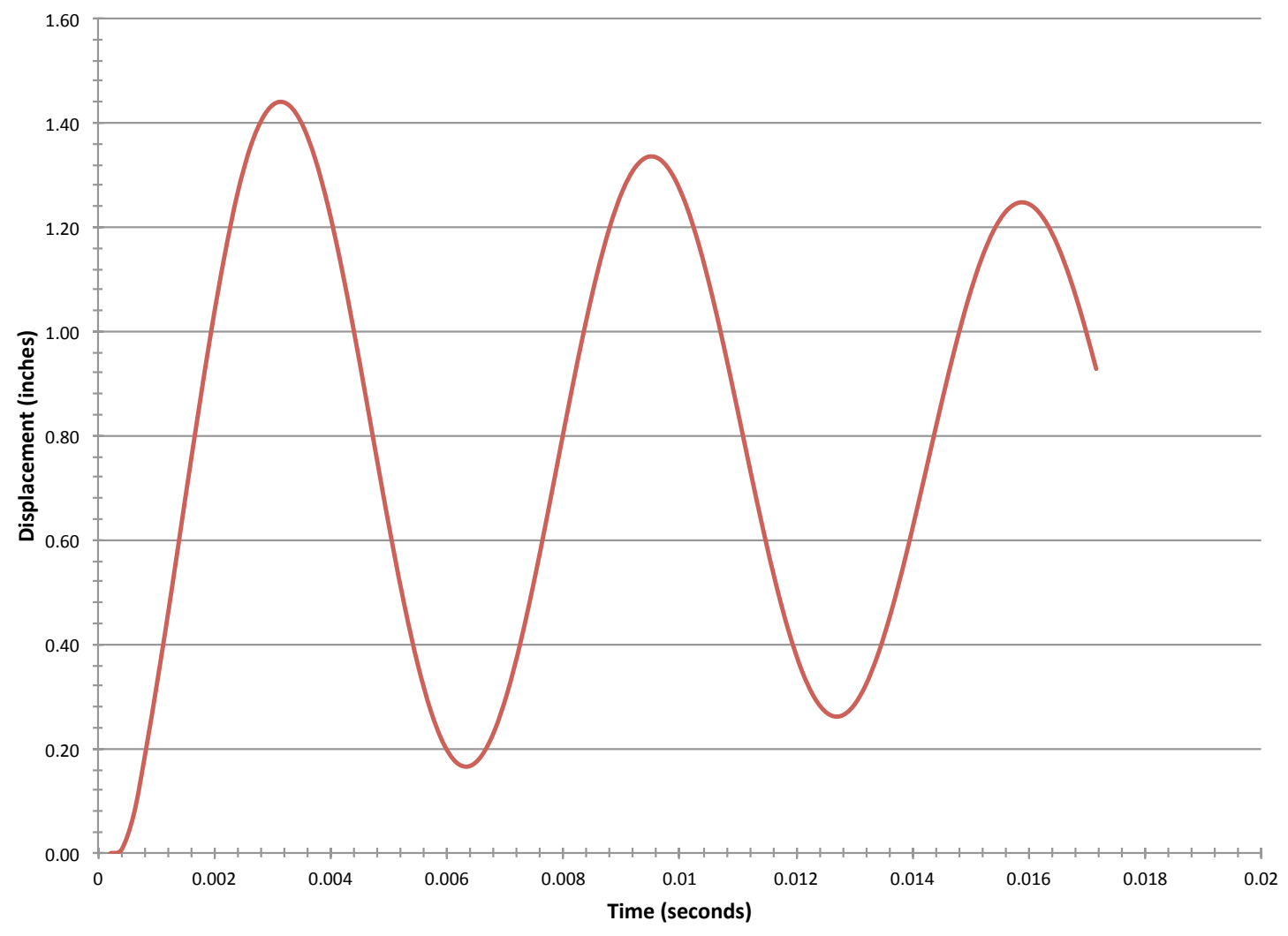

Figure 6-10 - Response time history from SDOF analysis. Peak deflection of approximately 1.5 in is much less than the deflection associated with failure during the static tests. 


\section{SUMMARY AND CONCLUSIONS}

A CFRP-based strengthening design was created for a reinforced concrete slab that could be subjected to a close-in blast threat. The design consisted of a $1 / 2$ in thick $100 \mathrm{ksi}$ steel plate on the front face and 6 layers of pultruded CFRP on the back face in two orthogonal directions. In addition, mechanical anchors (bolts) were installed through the thickness of the slab to anchor the CFRP and to provide additional confinement to the concrete.

To evaluate the potential of the CFRP mitigation design, a static beam test was conducted. The beam test consisted of a 6 in wide section of the slab loaded in 3 point bending. The test showed a significant amount of strength (77.6 kips) available that agreed with theoretical calculations based on full CFRP tensile capacity. $60 \%$ of the individual CFRP fibers were fractured at the midspan. However, the test also showed significant slipping and splitting of the CFRP layers. The specimen demonstrated greater than expected ductility, which could prove to be an asset in absorbing blast energy. The mechanical anchors used in the test also performed well and allowed $60 \%$ of the CFRP to reach fracture strength. Such anchorage systems could be employed in future research.

Dynamic single degree of freedom (SDOF) analysis indicates that under a design 1.0 $\mathrm{ft} / \mathrm{b}^{1 / 3}$ scale range blast, an $8 \mathrm{ft}$ by $4 \mathrm{ft}$ by 5.5 in two way slab retrofitted with this system would survive the blast with less than 1.5 in peak deflection, well inside the over 5 in of deflection required to fail the specimin during static testing.

Conclusions drawn from this test include: 
- The steel plate and CFRP mitigation system shows indications of the ability to withstand close-in blast loads. Static testing of a CFRP and steel plate mitigated 6 in wide slice of a typical RC slab showed a strength increase by a factor of 22 and a deflection increase of $93 \%$ over an unmitigated specimen. The increase in strength and deflection leads to an 11 fold increase in the strain energy capacity of the system. This would allow the mitigated system to withstand significantly higher blast loads. A dynamic analysis of the system indicated that a blast load of $1.0 \mathrm{ft} / \mathrm{lb}^{1 / 3}$ could be resisted by the system.

- Reasonable quantities of CFRP are able to match the strength of A514 steel armoring. This could permit the installation of retrofit systems in confined or difficult access locations, or on those structure where the substantial increase in dead load from steel plating may not be tenable.

- Mechanical anchoring systems can allow very high strength CFRP to develop its full strength. However, testing showed significant slipping of the CFRP which reduced the overall stiffness of the beam.

The test results suggest the following items should be researched in the future:

- Dynamic blast tests. Though these static results are promising, they cannot replace a blast test. Previous studies have shown that strain rate effects are not to be taken lightly (Marchand et al. 1994). Not only do material properties change, but entire failure modes have been found that are not likely to be discovered with static testing. These failure modes have been found to be strongly influenced by the peak pressure and duration of a blast wave pulse (Toutlemonde et al. 1993). 
- Full two way bending on a slab to study the interaction of the layers of unidirectional CFRP

- Use of wet layup CFRP and fiber anchors. This may help to prevent the splitting that was observed by avoiding the creation of stress concentrations by drilling pultruded CFRP. This would also ease installation.

- Test of a slab with fixed connections. The test in this research was in 3 point bending, but many use cases will have the ends of the slab cast into moment connections. This could have an impact on the failure mode, particularly when combined with dynamic effects. 


\section{REFERENCES}

440, A. (1996). "State of the art report on fiber reinforced plastic reinforcement for concrete structures." American Concrete Institute

ASCE, A. S. o. C. E. (1997). Design of Blast Resistant Buildings in Petrochemical Facilities.

Baseheart, T. M. (1983). "Reinforced Concrete Response To Near Field Explosions." Air Force Office of Scientific Research.

Biggs, J. M. (1964). Introduction to Structural Dynamics, McGraw-Hill.

Bonacci, J. F., and Maalej, M. (2001). "Behavioral trends of RC beams strengthened with externally bonded FRP." Journal of Composites for Construction, 5(2), 102-103.

Chopra, A. K. (2007). Dynamics of Structures, Pearson Upper Saddle River, New Jersey.

Correia, J. R., Branco, F., Gonilha, J., Silva, N., and Camotim, D. (2010). "Glass Fibre Reinforced Polymer Pultruded Flexural Members: Assessment of Existing Design Methods." Structural Engineering International 4, 8.

Drotleff, J. E., Laboratory, U. S. A. R., and Division, F. C. G. S. (1996). Research in Close-in Blast Loading from High Explosives, Army Research Laboratory.

Fitzer, E. (1985). "Technical Status and Future Prospects of Carbon Fibres and their Application in Composites with Polymer Matrix (CFRPs)." Carbon Fibres and Their Composites, E. Fitzer, ed., Springer Berlin Heidelberg, 3-45.

Fyfe (2012). "Commercial, Municipal \& Residential Building Applications." $<$ http://www.fyfeco.com/applications/\%3E. (July 4, 2012).

Genelin, C. L., Dinan, R. J., Hoemann, J. M., and Salim, H. A. (2009). "Evaluation of Blast Resistance Rigid Walled Expeditionary Structures." Air Force Research Laboratory, Tyndall Air Force Base, FL, 19.

Hsu, T. T. C., and Mo, Y.-L. (2010). Unified theory of concrete structures, John Wiley \& Sons, Ltd, West Sussex, United Kingdom.

India, P. T. o. (2007 ). "'93 blasts: 3 more get death sentence." The Times of India, Bennett, Coleman \& Co. Ltd, Mumbai.

Khalifa, A., Alkhrdaji, T., Nanni, A., and Lansburg, S. (1999). "Anchorage of Surface Mounted FRP Reinforcement." Concrete International: Design and Construction, 21(10), 49-54. 
Kim, I. (2008). "Use of CFRP to Provide Continuity in Existing Reinforced Concrete Members Subjected to Extreme Loads." Dissertation. University of Texas at Austin, Texas, USA.

Kim, J. H. J., Yi, N. H., Kim, S. B., Choi, J. K., and Park, J. C. (2009). "Experiment Study On Blast Loading Response Of

Frp-Retrofitted Rc Slab Structures." The Second Official International Conference of the International Institute for FRP in Construction for Asia-Pacific RegionSeoul, Korea.

Lamanna, A. J. (2002). "Flexural strengthening of reinforced concrete beams with mechanically fastened fiber reinforced polymer strips." Doctor of Philosophy Dissertation, The University of Wisconsin at Madison.

Luo, K.-M., Lin, S.-H., Chang, J.-G., and Huang, T.-H. (2002). "Evaluations of kinetic parameters and critical runaway conditions in the reaction system of hexaminenitric acid to produce RDX in a non-isothermal batch reactor." Journal of Loss Prevention in the Process Industries, 15(2), 119-127.

Marchand, K. A., Woodson, S., and Knight, T. (1994). "Revisiting Concrete Spall and Breach Prediction Curves: Strain Rate (Scale Effect) and Impulse (Pulse Length and Charge Shape) Considerations." Report to Army Engineer Waterways Experiment Station, 26.

Mosalam, K. M., and Mosallam, A. S. (2001). "Nonlinear transient analysis of reinforced concrete slabs subjected to blast loading and retrofitted with CFRP composites." Composites Part B: Engineering, 32(8), 623-636.

Nam, J. W., Kim, H. J., Kim, S. B., Yi, N. H., and Kim, J. H. J. (2010). "Numerical evaluation of the retrofit effectiveness for GFRP retrofitted concrete slab subjected to blast pressure." Composite Structures, 92(5), 1212-1222.

Orton, S. (2013). "Simplified Analysis of CFRP Strengthened Reinforced Concrete Slabs Under Close-in Blasts." International Journal of Protective Structures Prepublication, 23.

Orton, S., Brune, M., Kirby, J., and Wheeler, M. (2011). "Use of Carbon Fiber Anchors to Improve Performance of CFRP Strengthened Concrete Structures Subjected to Blast and Impact Loads." ACI Special Publication, 281, 1-20.

Orton, S. L., Chiarito, V. P., Minor, J. K., and Coleman, T. G. (2013). "Experimental Testing of CFRP Strengthened Reinforced Concrete Wall Elements Loaded by Close-in Blast." Journal of Structural Engineering Feb 2013, 13.

Orton, S. L., Jirsa, J. O., and Bayrak, O. (2008). "Design considerations of carbon fiber anchors." Journal of Composites for Construction, 12(6), 608-616. 
Ray, J. C., Walker, B. E., Chiarito, V. P., Minor, J. K., Guynes, D. C., and Walker, L. (2011). "Analysis of Reinforced Concrete Bridge Tower Walls Subjected to Blast Loadings: Series II Data Report." Limited Distribution Technical Report, US Army Engineer Research and Development Center, Vicksburg, MS.

Razaqpur, G. A., Tolba, A., and Contestabile, E. (2007). "Blast loading response of reinforced concrete panels reinforced with externally bonded GFRP laminates." Composites Part B: Engineering, 38(5-6), 535-546.

Sika (2005). "Sika Carbodur - Carbon fiber laminate for structural strengthening." Sika, ed.

Strongwell (2006). "SAFSTRIP Introduced." Strongwell News, $<$ http://www.strongwell.com/news/2006/safstrip-introduced/\%3E. (July 4, 2012).

Toutlemonde, F., Boulay, C., and Gourraud, C. (1993). "Shock-tube tests of concrete slabs." Materials and Structures, 26(1), 38-42.

UFC (2008). "Unified Facilities Criteria." United States Department of Defense.

Williams, K. (2002). "Validation of a Loading Model for Simulating Blast Mine Effects on Armored Vehicles." 7th International LS-DYNA Users Conference, Penetration/Explosive Section 6, Livermore Software Technology Corporation, $35-44$.

Zoltek (2011). "How is Carbon Fiber Made?", <http://www.zoltek.com/carbonfiber/howis-it-made $/ \% 3 \mathrm{E}$. (June 16, 2012). 


\section{APPENDIX A - NONLINEAR BENDING ANALYSIS}

Sample calculations for static nonlinear analysis of specimen behavior.

Given:

Geometric Properties

FRP Material Properties

$\mathrm{d}=5.25$ in

$\mathrm{f}_{\mathrm{y}, \text { frp }}=406 k s i$

$\mathrm{d}^{\prime}=-0.25$ in

$\mathrm{E}_{\mathrm{s}, \text { frp }}=23,900 k s i$

$\mathrm{b}=6$ in

$\mathrm{A}_{\mathrm{s}}^{\prime}=3 \mathrm{in}^{2}$

$\mathrm{e}_{\mathrm{y}, \text { frp }}=0.01699$

$\mathrm{A}_{\text {frp }}=0.846 \mathrm{in}^{2}$

Nonlinear Properties

Concrete Material Properties

$\varepsilon_{0}=0.002$

$\mathrm{k}_{3}=0.85$

$f_{c}^{\prime}=4000 p s i$

$\mathrm{b}^{\prime \prime}=6$ in

$\mathrm{s}_{\mathrm{h}}=3$ in

Steel Material Properties

$\mathrm{f}_{\mathrm{y} \text {, steel }}=100 \mathrm{ksi}$

$\mathrm{E}_{\mathrm{S} \text {, steel }}=29,000 \mathrm{ksi}$

$\mathrm{e}_{\mathrm{y}, \mathrm{s}}=0.00345$

Find moment at $\varepsilon_{\mathrm{c}}=0.0030$

1) Develop Kent-Park equations. Referring to Figure 6-2:

$$
\begin{aligned}
& \varepsilon_{50 \mathrm{u}}=\frac{3 p s i+0.002 f_{c}^{\prime}}{f_{c}^{\prime}-1000 p s i}=\frac{3 p s i+0.002 * 4000 p s i}{4000 p s i-1000 p s i}=0.003 \overline{6} \mathrm{in} / \mathrm{in} \\
& V_{\text {trans }}=V_{s}+V_{\text {frp }}+V_{\text {bolts }}=9 \mathrm{in}^{2}+2.54 \mathrm{in}^{2}+n_{b} A_{b} d=11.54 \mathrm{in}^{2}+2\left(0.3125 \mathrm{in}^{2}\left(\frac{\pi}{4}\right)(5.25 \mathrm{in})=12.34 \mathrm{in}^{3}\right. \\
& V_{\text {confined }}=b^{\prime \prime} s_{h} d=(6 \mathrm{in})(3 \mathrm{in})(5.25 \mathrm{in})=94.5 \mathrm{in}^{3} \\
& \rho_{\mathrm{s}}=\frac{V_{\text {trans }}}{V_{\text {confined }}}=\frac{12.34 \mathrm{in}^{3}}{94.5 \mathrm{in}^{3}}=0.1306
\end{aligned}
$$


$\varepsilon_{50 \mathrm{~h}}=\frac{3}{4} \rho_{\mathrm{s}} \sqrt{b^{\prime \prime} / s_{h}}=\frac{3}{4}(0.1306) \sqrt{\frac{6 \text { in }}{3 \text { in }}}=0.1385 \mathrm{in} / \mathrm{in}$

$\varepsilon_{50 \mathrm{c}}=\varepsilon_{50 \mathrm{u}}+\varepsilon_{50 \mathrm{~h}}=0.003 \overline{\mathrm{b}} \frac{\mathrm{in}}{\mathrm{in}}+0.1385 \frac{\mathrm{in}}{\mathrm{in}}=0.1422 \mathrm{in} / \mathrm{in}$

For the region $\varepsilon_{\mathrm{c}}<\varepsilon_{\mathrm{o}}$

$\sigma=f_{c}^{\prime}\left[2\left(\frac{\varepsilon}{\varepsilon_{0}}\right)-\left(\frac{\varepsilon}{\varepsilon_{o}}\right)^{2}\right]=4000$ psi $*\left[2\left(\frac{\varepsilon}{.002 \text { in } / \text { in }}\right)-\left(\frac{\varepsilon}{.002 \text { in } / \text { in }}\right)^{2}\right]$

For the region $\varepsilon_{\mathrm{c}}>\varepsilon_{\mathrm{o}}, \sigma$ is given by the greater of

$f_{c}^{\prime}-\frac{f_{c}^{\prime}\left(\varepsilon_{c}-\varepsilon_{0}\right)}{2\left(\varepsilon_{50 c}-\varepsilon_{0}\right)}$ or $0.2 f_{c}^{\prime}$

$4000 p s i-\frac{4000 p s i\left(\varepsilon_{\mathfrak{c}}-0.002 \text { in } / \text { in }\right)}{0.2804 \text { in } / \text { in }}$ or $800 p s i$

2) With an equation for $\sigma\left(\varepsilon_{c}\right)$ developed, obtain $k_{1}, k_{2}$, and $f_{c}^{\prime \prime}$ values.

Utilize trapezoidal approximation to determine values for definite integrals:

$$
\begin{aligned}
& \int_{0}^{0.003} \sigma d \varepsilon=9.3229 p s i \\
& \int_{0}^{0.003} \sigma \varepsilon d \varepsilon=0.0167 p s i
\end{aligned}
$$




$$
\begin{aligned}
& k_{1}=\frac{1}{f_{c}^{\prime} \varepsilon_{u}} \int_{0}^{\varepsilon_{u}} \sigma d \varepsilon=\frac{1}{4000 p s i * 0.003 \mathrm{in} / \mathrm{in}} * 9.3299 \mathrm{psi}=\mathbf{0 . 7 7 7 5} \\
& k_{2}=1-\frac{1}{\varepsilon_{u}} \frac{\int_{0}^{\varepsilon_{u}} \sigma \varepsilon d \varepsilon}{\int_{0}^{\varepsilon_{u}} \sigma d \varepsilon}=1-\frac{1}{0.003}\left(\frac{0.0167 \mathrm{psi}}{9.3229 \mathrm{psi}}\right)=\mathbf{0 . 4 0 2 9} \\
& f_{c}^{\prime \prime}=k_{3} f_{c}^{\prime}=0.85 * 4000 \mathrm{psi}=\mathbf{3 4 0 0} \mathbf{p s i}
\end{aligned}
$$

3) Determine $c$ by guess-and-check.

Guess a value of $c=0.8511$ in

$\varepsilon_{\text {frp }}=\frac{d-c}{c} * \varepsilon_{c}=\frac{5.25 \mathrm{in}-0.8511 \mathrm{in}}{0.8511 \mathrm{in}} 0.003 \frac{\mathrm{in}}{\mathrm{in}}=0.0155 \mathrm{in} / \mathrm{in}$

$F_{f r p}=\varepsilon_{f r p} E_{s, f r p}=\left(0.015 \frac{i n}{i n}\right)(23,900 k s i)=370.7 k s i$

$370.689 k s i<\mathrm{f}_{\mathrm{y}, \text { frp }}=406 k s i=>$ Use $370.7 k s i$

$\varepsilon_{s}^{\prime}=\frac{c-d^{\prime}}{c} * \varepsilon_{c}=\frac{0.8511 \mathrm{in}+0.25 \mathrm{in}}{0.8511 \mathrm{in}} 0.003 \frac{\mathrm{in}}{\mathrm{in}}=0.00388 \frac{\mathrm{in}}{\mathrm{in}}$

$F_{s}^{\prime}=\varepsilon_{s}^{\prime} E_{s, \text { steel }}=\left(0.00388 \frac{\mathrm{in}}{\mathrm{in}}\right)(29,000 \mathrm{ksi})=112.6 \mathrm{ksi}$

$112.6 k s i>\mathrm{f}_{\mathrm{y}, \text { steel }}=100 k s i=>$ Use $100 k s i$

Calculate a value of $\mathrm{c}$ :

$c=\frac{A_{f r p} F_{f r p}-A_{S}^{\prime} F_{S}{ }^{\prime}}{f_{c}^{\prime \prime} k_{1} b}=\frac{\left(0.846 \mathrm{in}^{2}\right)(370.7 \mathrm{ksi})-\left(3 \mathrm{in}^{2}\right)(100 \mathrm{ksi})}{(3400 \mathrm{psi})(0.7775)(6 \mathrm{in})}=0.8571 \mathrm{in}$

$0.8571 \mathrm{in} 0.8511 \mathrm{in}$, so $c$ is correct.

4) Calculate the moment. 


$$
\begin{aligned}
M= & f_{c}^{\prime \prime} k_{1} b c\left(d-k_{2} c\right)+A_{s}^{\prime} f_{s}^{\prime}\left(d-d^{\prime}\right) \\
M= & (3400 \mathrm{psi})(0.7775)(6 \mathrm{in})(0.8511 \mathrm{in})(5.25 \mathrm{in}-0.4029(0.8511 \mathrm{in})) \\
& +(3 \mathrm{in})(100 \mathrm{ksi})(5.25 \mathrm{in}+0.25 \mathrm{in}) \\
M= & 1716.2 \mathrm{ksi}
\end{aligned}
$$

Comparing this value of $M$ to the value found in the Microsoft Excel routine, $1716.2 \mathrm{ksi}$, demonstrates that the hand calculations match those of the automated analysis. 